\title{
Non-invasive positive pressure ventilation (CPAP or bilevel NPPV) for cardiogenic pulmonary oedema
}

\section{Review information}

Review type: Intervention

Review number: 0416

\section{Authors}

Nicolas Berbenetz ${ }^{1}$, Yongjun Wang ${ }^{2}$, James Brown ${ }^{3}$, Charlotte Godfrey ${ }^{4}$, Mahmood Ahmad ${ }^{5}$, Flávia MR Vital ${ }^{6}$, Pier Lambiase $^{7}$, Amitava Banerjee ${ }^{8}$, Ameet Bakhai ${ }^{9}$, Matthew Chong ${ }^{10}$

${ }^{1}$ Queen's University, Kingston, Canada

${ }^{2}$ Schulich School of Medicine \& Dentistry, Western University, London, Canada

${ }^{3}$ Cardiology, Royal Free Hospital, London, UK

${ }^{4}$ St Helier Hospital, London, UK

${ }^{5}$ Cardiology Department, Royal Free Hospital, London, UK

${ }^{6}$ Cochrane Brazil Minas Gerais, Muriaé, Brazil

${ }^{7}$ Centre for Cardiology in the Young, The Heart Hospital, University College London Hospitals, London, UK

8Institute of Health Informatics Research, University College London, London, UK

${ }^{9}$ Barnet General Hospital Cardiology Department, Barnet \& Chase Farm NHS Trust, Barnet, UK

10Western University, London, Canada

Citation example: Berbenetz N, Wang Y, Brown J, Godfrey C, Ahmad M, Vital FMR, Lambiase P, Banerjee A, Bakhai A, Chong M. Non-invasive positive pressure ventilation (CPAP or bilevel NPPV) for cardiogenic pulmonary oedema.

Cochrane Database of Systematic Reviews 2013 , Issue 5 . Art. No.: CD005351. DOI:

10.1002/14651858.CD005351.pub3 .

\section{Contact person}

\section{Nicolas Berbenetz}

Queen's University

Kingston

Canada

E-mail: nberbenetz@gmail.com

\section{Dates}

Assessed as Up-to-date: 20 September 2018

Date of Search: 20 September 2018

Next Stage Expected: 20 September 2020

Protocol First Published:Issue 3, 2005

Review First Published: Issue 3, 2008

Last Citation Issue: Issue 5, 2013

\section{What's new}

\begin{tabular}{|l|l|l|}
\hline Date & Event & Description \\
\hline 10 December 2018 & New citation: conclusions changed & $\begin{array}{l}\text { We include seven new studies in our review update. We } \\
\text { have excluded } 15 \text { previously-included studies from the } \\
\text { update. Our conclusions now include strength-of-evidence } \\
\text { recommendations and have been updated. }\end{array}$ \\
\hline 30 October 2018 & Updated & $\begin{array}{l}\text { A new review team has updated this review and meta- } \\
\text { analysis. We compared non-invasive positive pressure } \\
\text { ventilation to standard medical care for acute cardiogenic } \\
\text { pulmonary oedema. Our inclusion criteria have been } \\
\text { updated and we include RCTs only. We performed our } \\
\text { updated literature search from database inception to } 20 \\
\text { September } 2018 . \text { We identified new articles for inclusion } \\
\text { and have fully revised this systematic review. }\end{array}$ \\
& &
\end{tabular}

History 
0416 Non-invasive positive pressure ventilation (CPAP or bilevel NPPV) for cardiogenic pulmonary oedema

\begin{tabular}{|c|c|c|}
\hline Date & Event & Description \\
\hline 12 November 2012 & Updated & New search in April 2011 found 11 new studies \\
\hline 1 December 2011 & Updated & $\begin{array}{l}\text { Eleven new studies have been included in this review } \\
\text { update. } \\
\text { Background section has been updated. } \\
\text { No changes have been made to the methodology. The } \\
\text { search strategies have been modified in MEDLINE and } \\
\text { EMBASE, and the dates over which the databases were } \\
\text { searched were updated. } \\
\text { The conclusions have been amended slightly. The use of } \\
\text { CPAP produces fewer adverse events compared to the } \\
\text { standard treatment or compared the Bilevel NPPV, but the } \\
\text { main thrust of the review has not changed. }\end{array}$ \\
\hline 17 April 2008 & Amended & Converted to new review format. \\
\hline
\end{tabular}

\section{Abstract}

\section{Background}

Non-invasive positive pressure ventilation (NPPV) has been used to treat respiratory distress due to acute cardiogenic pulmonary oedema (ACPE). We performed a systematic review and meta-analysis update on NPPV for adults presenting with ACPE.

\section{Objectives}

To evaluate the safety and effectiveness of NPPV compared to standard medical care (SMC) for adults with ACPE. The primary outcome was hospital mortality. Important secondary outcomes were endotracheal intubation, treatment intolerance, hospital and intensive care unit length of stay, rates of acute myocardial infarction, and adverse event rates.

\section{Search methods}

We searched CENTRAL (CRS Web, 20 September 2018), MEDLINE (Ovid, 1946 to 19 September 2018), Embase (Ovid, 1974 to 19 September 2018), CINAHL Plus (EBSCO, 1937 to 19 September 2018), LILACS, WHO ICTRP, and clinicaltrials.gov. We also reviewed reference lists of included studies. We applied no language restrictions.

\section{Selection criteria}

We included blinded or unblinded randomised controlled trials in adults with ACPE. Participants had to be randomised to NPPV (continuous positive airway pressure (CPAP) or bilevel NPPV) plus standard medical care (SMC) compared with SMC alone.

\section{Data collection and analysis}

Two review authors independently screened and selected articles for inclusion. We extracted data with a standardised data collection form. We evaluated the risks of bias of each study using the Cochrane 'Risk of bias' tool. We assessed evidence quality for each outcome using the GRADE recommendations.

\section{Main results}

We included 24 studies (2664 participants) of adult participants (older than 18 years of age) with respiratory distress due to ACPE, not requiring immediate mechanical ventilation. People with ACPE presented either to an Emergency Department or were inpatients. ACPE treatment was provided in an intensive care or Emergency Department setting. There was a median follow-up of 13 days for hospital mortality, one day for endotracheal intubation, and three days for acute myocardial infarction. Compared with SMC, NPPV may reduce hospital mortality (risk ratio (RR) $0.65,95 \%$ confidence interval (Cl) 0.51 to 0.82 ; participants $=2484$; studies $=21 ; \mathrm{I}^{2}=6 \%$; low quality of evidence) with a number needed to treat for an additional beneficial outcome (NNTB) of 17 (NNTB 12 to 32). NPPV probably reduces endotracheal intubation rates (RR $0.49,95 \% \mathrm{Cl}$ 0.38 to 0.62 ; participants $=2449$; studies $=20 ; 1^{2}=0 \%$; moderate quality of evidence) with a NNTB of 13 (NNTB 11 to 18 ). There is probably little or no difference in acute myocardial infarction (AMI) incidence with NPPV compared to SMC for ACPE (RR 1.03, $95 \% \mathrm{Cl} 0.91$ to 1.16 ; participants $=1313$; studies $=5 ; \mathrm{I}^{2}=0 \%$; moderate quality of evidence). We are uncertain as to whether NPPV increases hospital length of stay (mean difference (MD) ?0.31 days, $95 \% \mathrm{Cl}$ ? 1.23 to 0.61 ; participants $=1714$; studies $=11 ;\left.\right|^{2}=55 \%$; very low quality of evidence). Adverse events were generally similar between NPPV and SMC groups, but evidence was of low quality.

\section{Authors' conclusions}

Our review provides support for continued clinical application of NPPV for ACPE, to improve outcomes such as hospital mortality and intubation rates. NPPV is a safe intervention with similar adverse event rates to SMC alone. Additional 
0416 Non-invasive positive pressure ventilation (CPAP or bilevel NPPV) for cardiogenic pulmonary oedema

research is needed to determine if specific subgroups of people with ACPE have greater benefit of NPPV compared to SMC. Future research should explore the benefit of NPPV for ACPE patients with hypercapnia.

\section{Plain language summary}

\section{A breathing intervention for shortness of breath due to heart failure Background}

Heart failure is one of the leading causes of hospital admission in the world. People with heart failure often experience shortness of breath and leg swelling. These symptoms may develop over hours to weeks, or rapidly over a few hours. Such rapid deterioration is called acute cardiogenic pulmonary oedema.

Providing air under pressure through a face or nose mask can treat shortness of breath. This treatment is called non-invasive ventilation and its use in heart failure is controversial.

\section{Study characteristics}

Randomised controlled studies compare treatments to find out if they are truly effective. We searched for randomised studies comparing non-invasive ventilation to routine care for adults with acute cardiogenic pulmonary oedema. We compared studies treating people with non-invasive ventilation versus medical care. Medical care includes therapies such as providing extra oxygen and water pills to patients. The evidence upon which this review is based is current to September 2018.

\section{Review question}

We sought to address if non-invasive ventilation in adults with acute cardiogenic pulmonary oedema reduces rates of deaths, the need for a breathing tube, and heart attacks.

\section{Key results and quality of evidence}

We found 24 studies with 2664 participants comparing non-invasive ventilation to medical care alone. Non-invasive ventilation may decrease the chances of dying in hospital. The quality of results for studies reporting death in hospital was low. Studies were poorly conducted, and results were not similar across studies. In addition, non-invasive ventilation probably reduces the chances of needing a breathing tube. The quality of results for studies reporting breathing tube rates was moderate. Studies evaluating breathing tube rates were poorly conducted. Non-invasive ventilation probably has little or no effect on getting a heart attack. The quality of results for studies reporting heart attack rates was moderate, and studies had inconsistent results for this outcome. We are unsure if the length of hospital stay is improved with non-invasive ventilation. The quality of results for studies reporting hospital length of stay was very low, which was due to poor study conduct and inconsistent results. Finally, non-invasive ventilation may make little or no difference to adverse events (complications), compared to medical care. The quality of results for studies reporting adverse events was low. Studies evaluating adverse events were poorly conducted and had inconsistent results.

\section{Background}

\section{Description of the condition}

Abnormal heart function in heart failure (HF) can produce signs and symptoms of reduced cardiac output (Ezekowitz 2017 ). A rapid deterioration in HF symptoms is called congestive heart failure (CHF) or acute cardiogenic pulmonary oedema (ACPE). Symptoms of ACPE can include dyspnoea, orthopnoea, peripheral oedema, cough, fatigue, and weight gain (Wang 2005). Signs of ACPE can include the presence of a third heart sound, jugular venous distension, rales, lower extremity oedema, wheezing, and ascites (Wang 2005). Approximately one million people a year are discharged from hospitals in the United States with HF (Benjamin 2017). ACPE severity is variable, but the presence of hypoxia, respiratory failure, and hypotension can indicate a higher risk presentation (Ponikowski 2016 ). Many conditions can trigger ACPE, such as acute coronary syndrome (ACS), tachyarrhythmia, valvular heart disease, and hypertension (Ponikowski 2016). Importantly, ACPE is also associated with an in-hospital mortality of approximately $10 \%$ and one-year mortality of $30 \%$ (Rudiger 2005).

ACPE can be conceptualised as left ventricular failure with elevated left ventricular filling pressures. Elevated filling pressures produce higher pulmonary capillary pressures and fluid extravasation into alveoli due to overwhelmed lymphatic vessel absorption capacity (Allison 1991; Packer 1993). Pulmonary oedema fluid can dilute surfactant and neutralise its lubricating properties, causing a reduction in lung compliance and increased work of breathing (Allison 1991; Park 2001). In the upright position, oedema accumulates at the lung bases, causing a ventilation-perfusion (V-Q) mismatch, which can cause hypoxia (Allison 1991).

\section{Description of the intervention}

ACPE treatment guidelines have been prepared in several countries, including Canada (Ezekowitz 2017) and Europe (Ponikowski 2016). Treatment options include: loop diuretics (e.g. furosemide), vasodilators (e.g. nitroglycerin), supplemental oxygen, non-invasive positive pressure ventilation (NPPV), and endotracheal intubation (Ezekowitz 2017; Ponikowski 2016). Treating the underlying cause of ACPE is also necessary (e.g. antihypertensives for hypertension, coronary angiography for ST elevation myocardial infarction) (Ezekowitz 2017; Ponikowski 2016; Yancy 2013).

Endotracheal intubation raises the risk for adverse events, such as nosocomial infections (e.g. pneumonia), tracheal injury, and prolonged hospital length of stay (Gay 2009). In contrast to the invasiveness of endotracheal intubation, NPPV can be provided in the form of continuous positive airwav pressure (CPAP) and bilevel NPPV (BiPAP® - 
Respironics, Inc, Murrysville, PA) using face or nasal masks. CPAP maintains a constant positive airway pressure throughout the respiratory cycle. In contrast, bilevel NPPV provides additional inspiratory positive airway pressure and positive end-expiratory pressure (Nava 2009).

\section{How the intervention might work}

The cardiovascular and pulmonary systems work together to maintain homeostasis. During normal inhalation contraction of the diaphragm and intercostal muscles produces a more negative pleural pressure compared to the lungs at rest (Alviar 2018). This negative pleural pressure reduces left ventricular pressure relative to systemic arterial pressure (Alviar 2018). In contrast, during positive pressure ventilation, inhalation involves a positive pleural pressure which raises left ventricular pressure relative to systemic arterial pressure and reduces left ventricular afterload due to a baroreceptor reflex (Alviar 2018; Buda 1979). Intrapleural pressure influences right ventricular inflow and left ventricular outflow. The difference between airway pressure and intrapleural pressure (transpulmonary pressure gradient) affects pulmonary vasculature, which in turn influences left ventricular inflow and right ventricular outflow (Alviar 2018). NPPV reduces pulmonary workload, improves cardiac output, and enhances lung compliance (Baratz 1992; Lenique 1997). During ACPE interstitial and alveolar oedema reduce lung compliance. Application of positive pressure at end expiration can force fluid out of alveoli, improving pulmonary vascular resistance and enhancing gas exchange (Alviar 2018 ). In addition, positive pressure ventilation could prevent alveolar collapse and enhance alveolar expansion with inspiration improving airway compliance (Alviar 2018). This mechanism could explain how NPPV applied during ACPE can lead to improved oxygenation (Räsänen 1985). During respiratory distress without NPPV the intrapleural pressure becomes more negative and left ventricular afterload is increased, because left ventricular systolic pressure is more negative compared to the systemic circulation (Alviar 2018; Magder 1983). In terms of left ventricular function, NPPV reduces preload, afterload, myocardial oxygen demand, and enhances hydrostatic displacement of alveolar oedema (Alviar 2018). In left ventricular failure, NPPV can improve cardiac output by reducing left ventricular afterload. In contrast, in right ventricular failure, NPPV reduces right ventricular preload and can reduce right ventricular cardiac output (Alviar 2018). The net benefit of NPPV in heart failure will depend on the relative left and right ventricular functions, and afterload (Alviar 2018). Furthermore, NPPV use in ACPE may prevent endotracheal intubation without significant adverse events (Nava 2009). Mechanical ventilation can be life-saving for people with respiratory failure needing airway protection and with severe hypoxia associated with failed NPPV therapy (Alviar 2018). However, mechanical ventilation is associated with additional adverse events, such as endotracheal tube complications (Tobin 1994 ), ventilator-associated lung injury (Slutsky 2013), ventilator-associated pneumonia (Spalding 2017), barotrauma (e.g. pneumothorax) (Anzueto 2004), and ventilator-induced diaphragmatic dysfunction (Levine 2008).

\section{Why it is important to do this review}

Since the increased clinical use of NPPV in the 1980s, many studies have evaluated NPPV's effectiveness for ACPE, and have reported mixed results (Nava 2009). Furthermore, current heart failure guidelines differ in their NPPV recommendations. Canadian guidelines recommend against routine use of NPPV, and suggest that NPPV could be used for ACPE with persistent hypoxia despite standard medical care (Ezekowitz 2017). In addition, Canadian guidelines warn of the clinical risks of NPPV, including worsening right heart failure, worsening hypercapnia, aspiration, and pneumothorax (Ezekowitz 2017). In contrast, European guidelines (Ponikowski 2016) suggest NPPV be considered and started quickly in people with ACPE who present with tachypnoea (respiratory rate greater than 25 breaths a minute) and hypoxia $\left(\mathrm{SpO}_{2}\right.$ less than $\left.90 \%\right)$. Furthermore, they are of the opinion that NPPV can reduce respiratory distress and endotracheal intubation. The main risk of NPPV emphasised by the European guidelines is hypotension (Ponikowski 2016). American guidelines do not provide treatment guidance for ACPE (Yancy 2013). Given the differences in opinion between these two major heart failure guidelines on the use of NPPV for ACPE, we have updated our systematic review and meta-analysis.

\section{Objectives}

To evaluate the safety and effectiveness of NPPV compared to standard medical care (SMC) for adults with ACPE. The primary outcome was hospital mortality. Important secondary outcomes were endotracheal intubation, treatment intolerance, hospital and intensive care unit length of stay, rates of acute myocardial infarction, and adverse event rates.

\section{Methods}

\section{Criteria for considering studies for this review}

\section{Types of studies}

For inclusion, studies had to be randomised controlled trials (RCTs). We excluded studies that were cluster-randomised or used a cross-over design. We ruled out cluster-randomised studies to avoid heterogeneity in study design, heterogeneity from the unit of randomisation (e.g. intensive care unit (ICU) versus emergency room (ER)), and variation in eligibility criteria at the individual level compared to a cluster level. We ruled out cross-over studies because we did not consider them an appropriate design for acute cardiogenic pulmonary oedema (ACPE). In a cross-over study, a carry-over effect from the initial therapy (e.g. medical therapy or NPPV) could influence the second intervention (e.g. medical therapy or NPPV), such that participants entering the second intervention differ from those during the first intervention. To avoid publication bias, we included studies irrespective of final publication status. We also included studies reported as full text, abstract only, and unpublished data. 
0416 Non-invasive positive pressure ventilation (CPAP or bilevel NPPV) for cardiogenic pulmonary oedema

We included trials reporting on adults (18 years and older) with ACPE. A diagnosis of ACPE can have symptoms and clinical signs of hypoperfusion or congestion, or both, such as dyspnoea, pulmonary congestion, jugular venous distension, congestive hepatomegaly, peripheral oedema, confusion, oliguria, and cool extremities (Wang 2005; Yancy 2013). The clinical diagnosis could be supported by a chest radiograph, electrocardiograms, serum biomarkers (e.g. troponin for acute myocardial infarction or Brain natriuretic peptide / N-terminal-pro hormone Brain natriuretic peptide for HF), or echocardiography. We excluded trials investigating NPPV for people with a primary diagnosis of pneumonia, alternative aetiologies of respiratory failure (e.g. endocarditis, cardiac surgery patients, unknown cause), or its use as a weaning strategy.

\section{Types of interventions}

For inclusion, the intervention group had to have received nasal or face mask NPPV (CPAP, or bilevel NPPV, or both) with standard medical care (SMC). In contrast, the control group had to have received the same SMC alone (Ponikowski 2016; Y Yancy 2013).

\section{Types of outcome measures}

\section{Primary outcomes}

- Hospital mortality

\section{Secondary outcomes}

- Endotracheal intubation

- Incidence of acute myocardial infarction (AMI) during hospitalisation, after starting treatment, (e.g. cardiac biomarker elevation creatinine kinase (CK) or troponin) with or without electrocardiographic (ECG) changes or symptoms of myocardial ischaemia

- Intolerance to allocated treatment (e.g. early treatment discontinuation in people not meeting criteria for endotracheal intubation)

- Treatment failure (the combination of mortality, intubation, and intolerance to the allocated treatment)

- Hospital length of stay (from hospital admission to hospital discharge or death)

- ICU length of stay (from ICU admission to ICU discharge or death)

- Vital signs: blood pressure one hour post-intervention, respiratory rate

- Arterial blood gases $\left(\mathrm{PaO}_{2}\right)$ one hour post-intervention

- Adverse events

For inclusion, studies had to report one or more of the clinical outcomes of interest. We sought additional information from principal investigators as required, including for outcomes that were measured but not reported in the final publication.

\section{Search methods for identification of studies}

\section{Electronic searches}

We identified trials through systematic searches of the following databases:

- Cochrane Central Register of Controlled Trials (CENTRAL) (CRS Web, 20 September 2018).

- Database of Abstracts of Reviews Effectiveness (DARE) in the Cochrane Library (Issue 2 of 4, 2015).

- MEDLINE (Ovid, 1946 to 19 September 2018).

- Embase (Ovid, 1974 to 19 September 2018).

- Cumulative Index to Nursing and Allied Health Literature (CINAHL) Plus (EBSCO, 1937 to 20 September 2018).

- LILACS (1982 to 20 September 2018).

- WHO International Clinical Trials Registry Platform (ICTRP; apps.who.int/trialsearch/) (searched 20 September 2018).

- Clinicaltrials.gov (searched 20 September 2018)

The RCT filter for MEDLINE is the Cochrane sensitivity-maximising RCT filter and, for Embase search terms as recommended in the Cochrane Handbook for Systematic Reviews of Interventions were applied. (Lefebvre 2011). We searched all databases from their inception to the present, without language restriction or consideration of final publication status. We present the search strategies for each database in Appendix 1. Finally, we also considered studies that were ongoing or awaiting classification at the time of the last version of this review.

\section{Searching other resources}

We checked the bibliographies of retrieved articles to identify related published and unpublished studies.

\section{Data collection and analysis}

We followed the recommendations outlined in the Cochrane Handbook for Systematic Reviews of Interventions in preparing this review (Higgins 2011; Higgins 2017).

\section{Selection of studies}

In our updated search, two review authors (NB, MC) independently screened citations and selected trials that met the inclusion criteria. We resolved disagreements by consensus with a third review author (YW). In the previous version of this review, two review authors ( $F V$ and $M L$ ) independently screened citations and selected trials meeting the inclusion criteria with disagreements resolved by a third review author (AA) (Vital 2013). 
0416 Non-invasive positive pressure ventilation (CPAP or bilevel NPPV) for cardiogenic pulmonary oedema

We used a standardised and piloted data collection form to record data on study characteristics, risks of bias, and outcomes. Two review authors (NB, YW) independently extracted:

- characteristics of the study (design, methods of randomisation, withdrawals and dropouts, intention-to-treat analysis (ITT), informed consent, place and multicentre study, funding, conflicts of interest, study dates);

- participants (age, gender, number, diagnostic criteria, inclusion and exclusion criteria);

- interventions (type of NPPV, timing and duration of therapy, co-interventions, SMC (intervention and dose); and

- outcomes reported.

We requested unpublished data from primary authors to supplement outcomes where needed. Two review authors (NB, YW) performed data extraction for all selected study reports independently, with partial extraction by an additional two review authors (CG and MA). We resolved disagreements by consensus with a third senior review author (MC).

\section{Assessment of risk of bias in included studies}

Two review authors (NB, YW) independently assessed risks of bias for each study, using the criteria outlined in the Cochrane Handbook for Systematic Reviews of Interventions (Higgins 2011). We resolved any disagreements by consensus with a third review author (MC). We assessed risks of bias according to the following domains, using the Cochrane 'Risk of bias' tool:

- Random sequence generation.

- Allocation concealment.

- Blinding of participants and personnel.

- Blinding of outcome assessment.

- Completeness of outcome data.

- Selective reporting bias.

- Other bias (any other sources of potential bias, e.g. trial prematurely stopped)

We graded each potential source of bias as high, low, or unclear and provide a justification for our judgement in the 'Risk of bias' table. We summarise the 'Risk of bias' judgements across different studies for each of the domains listed. If unpublished data were used in the 'Risk of bias' assessment, we noted this in the 'Risk of bias' table. When we considered treatment effects, we took into account the risks of bias for studies that contributed to that outcome.

\section{Assessment of bias in conducting the systematic review}

We conducted the review according to our published protocol and report any deviations from it in the Differences between protocol and review section of the review.

\section{Measures of treatment effect}

We analysed dichotomous data as risk ratios (RRs) with $95 \%$ confidence intervals (Cls), and continuous data as mean difference (MDs) with 95\% Cls.

\section{Unit of analysis issues}

We included RCTs with a parallel design. If the same outcome was measured at repeated time points, we selected the longest time point for inclusion in the review, to avoid double counting. In trials with multiple intervention arms, we included the control group with SMC and combined the treatment groups if they had a similar intervention (NPPV: CPAP or BiPAP). For subgroup analysis in studies comparing CPAP, bilevel NPPV, and SMC we divided the control group evenly between groups, as suggested in the Cochrane Handbook for Systematic Reviews of Interventions (Higgins 2011).

\section{Dealing with missing data}

We contacted investigators or study sponsors to obtain missing numerical outcome data where required (e.g. when a study was reported as an abstract only). Where this was not possible and the missing data were thought to introduce serious bias, we explored the impact of study inclusion in the overall assessment of results by performing a sensitivity analysis.

\section{Assessment of heterogeneity}

We quantified the impact of statistical heterogeneity using the $\mathrm{I}^{2}$ statistic (Higgins 2011). An $\mathrm{I}^{2}$ of 0 to $40 \%$ may represent low heterogeneity, $30 \%$ to $60 \%$ may represent moderate heterogeneity, $50 \%$ to $90 \%$ may represent substantial heterogeneity, and $75 \%$ to $100 \%$ may represent considerable heterogeneity. In interpreting the heterogeneity values, we also considered the magnitude and direction of effects and strength of evidence for heterogeneity (e.g. P value from the Chi ${ }^{2}$ test or a confidence interval for $\mathrm{I}^{2}$ ). In addition, we inspected forest plots for signs of heterogeneity. If substantial heterogeneity was present, we reported it and conducted exploratory analyses to identify sources of heterogeneity (e.g. participants, treatments and study quality). We hypothesised that age, gender, and co-morbidities may represent potential sources of heterogeneity among participants. Furthermore, heterogeneity may be related to the initial treatment(s) used, the levels of pressure applied with NPPV, or treatment duration.

\section{Assessment of reporting biases}

Funnel plots allowed us to examine and explore small-study biases and publication bias (Egger 1997). We generated funnel plots for each outcome with at least 10 studies.

\section{Data synthesis}

We undertook meta-analysis only where studies were sufficiently similar for results to be clinically meaningful and if we identified more than two trials reporting data for that outcome. For these studies, we pooled dichotomous and 
0416 Non-invasive positive pressure ventilation (CPAP or bilevel NPPV) for cardiogenic pulmonary oedema

continuous variables using a random-effects model. We chose a random-effects model, as we anticipated heterogeneity in study participants, interventions, and outcomes of included studies. We presented the number needed to treat for an additional beneficial outcome (NNTB) when an effect was indicated by meta-analysis. We report summary estimates of treatment effect with their associated $95 \%$ Cls. We conducted all analyses using Cochrane statistical software (Review Manager 2014).

\section{'Summary of findings' table}

We created a 'Summary of findings' table for the main outcomes of the review: hospital mortality, endotracheal intubation $(\mathrm{ETI})$, acute myocardial infarction (AMI), intolerance to allocated treatment, hospital length of stay, ICU length of stay and adverse events. We generated these tables using GRADEpro software (gradepro.org/) and imported them into Review Manager 5.

\section{GRADE}

We used the five GRADE domains (study limitations, consistency of effect, imprecision, indirectness, and publication bias) to assess the quality of a body of evidence as it relates to the studies. For this process, we used methods and recommendations described in Section 8.5 and Chapter 12 of the Cochrane Handbook for Systematic Reviews of Interventions (Higgins 2011; Higgins 2017). We justified all decisions to downgrade the quality of evidence using footnotes provided in the 'Summary of findings' table (Guyatt 2008;

Two review authors (NB, YW) working independently, made judgements about evidence quality, with disagreements resolved by consensus with a third senior review author (MC).

\section{Subgroup analysis and investigation of heterogeneity}

We performed subgroup analyses for the following outcomes: hospital mortality, ETI, AMI, intolerance to allocated treatment, and hospital length of stay. Subgroups of interest included: type of NPPV (CPAP or bilevel NPPV), location of therapy (ER versus ICU), baseline hypercapnia status. In addition, for AMI we planned a subgroup analysis by time of event relative to treatment (AMI before or after initiation of treatment). Unfortunately, our planned AMI subgroup analysis was not possible, due to inconsistent definitions of AMI between studies. Please see Differences between protocol and review for further details. For mean, systolic, and diastolic blood pressure after one hour of therapy we performed a subgroup analysis by NPPV type (CPAP or bilevel NPPV). We used the test for subgroup differences to detect whether the effect estimate differed between groups of studies. We used a $P$ value of less than 0.05 for this test, as suggesting a true difference between subgroups, but acknowledge that this test has limited power when there are few studies.

\section{Sensitivity analysis}

We decided a priori to perform sensitivity analyses on hospital mortality, ETI, and adverse events. These sensitivity analyses covered:

- including studies with only low risk of bias.

- including studies without missing data.

- including only studies with a final diagnosis of cardiogenic pulmonary oedema being present in $50 \%$ or more of included participants.

For mortality, we considered a trial to be at low risk of bias if it met the criteria for low risk of bias in the following domains: random sequence generation and incomplete outcome data. For ETI and adverse events, we rated trials at low risk of bias if they met the low-risk-of-bias criteria for the following domains: random sequence generation and allocation concealment.

\section{Reaching conclusions}

We base our conclusions only on findings from the quantitative or narrative synthesis of studies included in this review. In addition, we outline the gaps in the evidence for NPPV in ACPE, and suggest future directions for research.

\section{Results}

\section{Description of studies}

\section{Results of the search}

Our updated search identified 3791 references (CENTRAL 905, DARE 12, MEDLINE 1266, Embase 878, LILACS 67, CINAHL Plus 397, WHO ICTRP 168, and clinicaltrials.gov 98). After de-duplication and reviewing reference lists from included articles, we screened 2807 references for inclusion. After screening, we obtained full-text articles for 94 references. Ultimately, we have included in this review update 24 studies (37 references) with a total of 2664 participants treated with NPPV versus SMC for ACPE. We excluded 43 studies (57 references). Our review update includes seven new studies since May 2013 (Austin 2013; Ducros 2011; El-Refay 2016; Hao 2002; Li 2005; Moritz 2003; Zokaei 2016) and excludes 15 previously included studies (Bautin 2005; Bellone 2004; Bellone 2005; Bersten 1991; Delclaux 2000; Ferrer 2003; Ferrari 2007; Ferrari 2010; Fontanella 2010; Liesching 2014; Martin-Bermudez 2002; Mehta 1997; Moritz 2007; Sharon 2000; Weitz 2007). Our PRISMA flowchart summarises the study selection process (Figure 1). We provide additional information on included and excluded studies in the following sections: Characteristics of included studies; Characteristics of excluded studies.

\section{Included studies}

Study design 
0416 Non-invasive positive pressure ventilation (CPAP or bilevel NPPV) for cardiogenic pulmonary oedema

We included 24 parallel-design RCTs in this review update (Agmy 2008; Austin 2013; Crane 2004; Ducros 2011; El-Refay 2016; Frontin 2011; Gray 2008; Hao 2002; Kelly 2002; L'Her 2004; Levitt 2001; Li 2005; Lin 1991; Lin 1995; Masip 2000; Moritz 2003; Nava 2003; Park 2001; Park 2004; Räsänen 1985; Takeda 1997; Takeda 1998; Thys 2002; Zokaei 2016). The funding sources for seven studies was public (Agmy 2008; Austin 2013; Ducros 2011; Frontin 2011; Gray 2008; Masip 2000; Thys 2002). One study reported receiving funds from a nonprofit organisation (Kelly 2002). Two studies were funded by device manufacturers (Crane 2004; L'Her 2004) and 14 studies provided no details on funding sources (El-Refay 2016; Hao 2002; Levitt 2001; Li 2005; Lin 1991; Lin 1995; Moritz 2003; Nava 2003; Park 2001; Park 2004; Räsänen 1985; Takeda 1997; Takeda 1998; Zokaei 2016). We summarise each study in our Characteristics of included studies tables.

Population

The mean participant age in our review was $73.3 \pm 9.0$ years. Our review includes studies from 14 countries: Australia, Belgium, Brazil, China, Egypt, Finland, France, Iran, Italy, Japan, Spain, Taiwan, the UK, and the USA. Furthermore, five studies were multicentre (Crane 2004; Ducros 2011; Gray 2008; L'Her 2004; Nava 2003). Studies varied in size from eight to 1069 participants, with a median and mean study size of 55 and 114 participants respectively. Ten studies were conducted in an emergency department (ED or ER) setting (Crane 2004; El-Refay 2016; Gray 2008; Kelly 2002; Levitt 2001; L'Her 2004; Moritz 2003; Nava 2003; Park 2004; Thys 2002), eight studies were conducted in an ICU setting (Agmy 2008; Lin 1991; Lin 1995; Masip 2000; Räsänen 1985; Takeda 1997; Takeda 1998; Zokaei 2016), and three studies did not reference a specific study location ( $\mathrm{HaO} 2002$; Li 2005; Park 2001). Three studies were started in the pre-hospital setting with further care in the ER and the ICU if required (Austin 2013; Ducros 2011; Frontin 2011).

\section{Intervention}

Six studies compared all three interventions: CPAP, bilevel NPPV, and SMC (Agmy 2008; Crane 2004; El-Refay 2016; Gray 2008; Park 2001; Park 2004). Twelve studies compared CPAP against SMC ( 2002; Kelly 2002; L'Her 2004; Lin 1991; Lin 1995; Moritz 2003; Räsänen 1985; Takeda 1997; Takeda 1998). Six studies compared bilevel NPPV against SMC (Levitt 2001; Li 2005; Masip 2000; Nava 2003; Thys 2002; Zokaei 2016). We summarise the NPPV settings including mask type, inspiratory positive airway pressure (IPAP), expiratory positive airway pressure (EPAP), positive end-expiratory pressure (PEEP), and duration of NPPV in Table 1. The NPPV patientventilator interface varied between exclusive use of nasal masks (Takeda 1997; Takeda 1998), a choice between a nasal or face mask (Levitt 2001; Park 2001; Zokaei 2016), and exclusive use of face masks. We have summarised the SMC provided in each trial in Table 2. SMC included supplemental oxygen and pharmacologic treatments. SMC pharmacologic treatments included loop diuretics (furosemide), nitrates (e.g. nitroglycerin, isosorbide dinitrate), opioids (e.g. morphine), and ionotropes if required.

\section{Outcomes}

Commonly-reported outcomes included hospital mortality, endotracheal intubation (ETI), acute myocardial infarction (AMI), hospital length of stay, ICU length of stay, change in systolic blood pressure (SBP) and respiratory rate (RR) during treatment, and change in arterial blood glasses $\left(\mathrm{PaO}_{2}\right)$. In reviewing the methodology for each study, we found that only three studies (Austin 2013; Ducros 2011; Gray 2008) provided a power calculation to detect a mortality difference. In addition, hospital mortality was reported at variable time periods. We summarise the time point at which hospital mortality was measured in Table 3. The median length of follow-up for hospital mortality was 13 days. AMI during the study period was reported by five studies (Crane 2004; Gray 2008; Levitt 2001; Nava 2003; Park 2001). AMI definitions were inconsistent, varying between new ST segment elevation on ECG, to myocardial enzyme elevation (e.g. CK, troponin) with ECG changes, and myocardial enzyme elevation alone. Treatment intolerance or early treatment discontinuation was reported by Agmy 2008. Explicit definitions for treatment failure as an indicator for potential endotracheal intubation are summarised in Table 4.

Several outcomes, including systolic blood pressure, mean blood pressure, diastolic blood pressure, $\mathrm{PaO}_{2}$, and respiratory rate, are reported as continuous outcomes. For these outcomes, we used the reported mean and standard deviations. Certain data were only available in graphical format and we extracted them by measuring the graph: $\mathrm{PaO}_{2}(\underline{\mathrm{Lin}} 1995)$. We converted arterial blood gas data from kilopascals $(\mathrm{kPa})$ to millimetres of mercury $(\mathrm{mmHg})$ for three studies $(\underline{\mathrm{Crane}} 2004$; Gray 2008; Kelly 2002), using the conversion of $1 \mathrm{kPA}$ to $7.50 \mathrm{mmHg}$ (Zumdahl 2002).

\section{Excluded studies}

We excluded citations if they were duplicates of the same study $(N=27)$, an ineligible intervention $(N=14)$, an ineligible population $(\mathrm{N}=5)$, a quasi-randomised controlled trial $(\mathrm{N}=4)$, an ineligible study type $(\mathrm{N}=17)$, and if the study was withdrawn after study registration $(\mathrm{N}=3)$. We have excluded 15 studies included in the previous version of this review. Of these, we excluded three studies conducted on an inappropriate population (Bautin 2005; Delclaux 2000; Ferrer 2003). We excluded four quasi-randomised controlled trials (Bersten 1991; Moritz 2007; Sharon 2000; Weitz 2007 ). Finally, we excluded eight studies which compared bilevel NPPV against CPAP, without an additional comparison against SMC (Bellone 2004; Bellone 2005; Ferrari 2007; Ferrari 2010; Fontanella 2010; Liesching 2014; Martin-Bermudez 2002; Mehta 1997). We provide additional details explaining each excluded study in Characteristics of excluded studies tables.

\section{Risk of bias in included studies}

We present our 'Risk of bias' assessments in Characteristics of included studies tables. We provide a graphic 
0416 Non-invasive positive pressure ventilation (CPAP or bilevel NPPV) for cardiogenic pulmonary oedema summary of our assessments (Figure 2; Figure 3).

\section{Allocation (selection bias)}

All included studies had randomly-allocated treatments. Randomisation sequence generation was at low risk of bias in eight studies (Austin 2013; Crane 2004; Frontin 2011; Gray 2008; L'Her 2004; Levitt 2001; Masip 2000; Nava 2003) and at unclear risk of bias in 16 studies (Agmy 2008; Ducros 2011; El-Refay 2016; Hao 2002; Kelly 2002; Li 2005; Lin 1991; Lin 1995; Moritz 2003; Park 2001; Park 2004; Räsänen 1985; Takeda 1997; Takeda 1998; Thys 2002; Zokaei 2016).

Allocation concealment was at low risk of bias in seven studies (Austin 2013; Crane 2004; Frontin 2011; Gray 2008; L'Her 2004; Nava 2003; Thys 2002), at unclear risk of bias in 16 studies (Agmy 2008; Ducros 2011; El-Refay 2016; Hao 2002; Kelly 2002; Levitt 2001; Li 2005; Lin 1991; Lin 1995; Moritz 2003; Park 2001; Park 2004; Räsänen 1985; Takeda 1997; Takeda 1998; Zokaei 2016), and at high risk of bias in one study (Masip 2000).

\section{Blinding (performance bias and detection bias)}

Blinding of participants and personnel was not possible for most studies, given the nature of the intervention. Twelve studies were at unclear risk of bias, as they did not state whether or not they had blinded participants and personnel (Hao 2002; Kelly 2002; Levitt 2001; Li 2005; Moritz 2003; Nava 2003; Park 2001; Park 2004; Räsänen 1985; Takeda 1997; Takeda 1998; Zokaei 2016). Twelve studies did not blind participants and personnel (Agmy 2008; Austin 2013; Crane 2004; Ducros 2011; El-Refay 2016; Frontin 2011; Gray 2008; L'Her 2004; Lin 1991; Lin 1995; Masip 2000; Thys 2002).

Blinding of outcome assessments was not explicitly stated for most studies. Three studies were at low risk of bias for outcome assessment blinding (Austin 2013; Ducros 2011; El-Refay 2016), 19 studies were at unclear risk of bias (Agmy 2008; Crane 2004; Frontin 2011; Hao 2002; Kelly 2002; Levitt 2001; Li 2005; Lin 1991; Lin 1995; Masip 2000; Moritz 2003; Nava 2003; Park 2001; Park 2004; Räsänen 1985; Takeda 1997; Takeda 1998; Thys 2002; Zokaei 2016), and two studies were at high risk of bias (Gray 2008; L'Her 2004).

\section{Incomplete outcome data (attrition bias)}

Three studies had high risk of bias due to incomplete outcome data (El-Refay 2016; Lin 1991; Park 2004). These studies excluded a significant number of participants after randomisation. Seven studies did not present enough information to judge the completeness of outcome data and were rated at unclear risk (Hao 2002; Levitt 2001; Li 2005; Moritz 2003; Park 2001; Takeda 1997; Zokaei 2016). Fourteen studies presented complete outcome data and were at low risk of bias (Agmy 2008; Austin 2013; Crane 2004; Ducros 2011; Frontin 2011; Gray 2008; Kelly 2002; L'Her 2004; Lin 1995; Masip 2000; Nava 2003; Räsänen 1985; Takeda 1998; Thys 2002).

\section{Selective reporting (reporting bias)}

Most studies did not provide enough information to judge whether they included all planned outcomes. Three studies (Austin 2013; Frontin 2011; Gray 2008) were at low risk of bias for selective reporting, given that the authors performed prospective trial registration and reported all their prespecified outcomes. Eighteen studies did not present enough information to determine if the outcomes presented were prespecified, and were at unclear risk of bias (Crane 2004; 트Refay 2016; Hao 2002; Kelly 2002; L'Her 2004; Levitt 2001; Li 2005; Lin 1991; Lin 1995; Masip 2000; Moritz 2003; Nava 2003; Park 2001; Park 2004; Räsänen 1985; Takeda 1997; Takeda 1998; Thys 2002). Three studies were at high risk of bias, as they failed to report prespecified outcomes or the outcomes reported were not in an extractable format (Agmy 2008; Ducros 2011; Zokaei 2016).

\section{Other potential sources of bias}

Two studies were reported in abstract form only (Agmy 2008; Austin 2013). Seven studies had high risk of other potential sources of bias (Agmy 2008; Ducros 2011; El-Refay 2016; Hao 2002; L'Her 2004; Levitt 2001; Li 2005). Agmy 2008 was reported as a personal communication in addition to abstracts which did not have quantitative data. There is a discrepancy between counts reported on clinicaltrials.gov and the personal communication data. We have used the personal communication data in our analysis. Other potential sources of bias included study termination due to poor recruitment, low likelihood of significant findings, or presenting data without a measure of variance (e.g. standard deviation). Our funnel plot of hospital mortality for NPPV versus SMC demonstrates some asymmetry for studies of intermediate sample size, which may indicate the presence of publication bias (see Figure 4).

\section{Effects of interventions}

\section{Hospital mortality}

NPPV may reduce hospital mortality compared to SMC alone (RR $0.65,95 \% \mathrm{Cl} 0.51$ to 0.82 ; participants $=2484$; studies = $21 ; I^{2}=6 \%$; Analysis 1.1 ; low quality of evidence), with a number needed to treat for an additional beneficial outcome (NNTB) of 17 (NNTB 12 to NNTB 32). We summarise our findings in Summary of findings table 1. We downgraded the evidence for hospital mortality by one level due to serious risk of bias (unclear or high risk of bias for randomisation sequence, allocation concealment, and other significant bias), and by one level due to imprecision (most trials had few participants and events, with a wide confidence interval).

We performed subgroup analysis by NPPV type (CPAP or bilevel), and found no significant difference between CPAP or bilevel NPPV (Analysis 1.2), based on the test for differences between subgroups $(P=0.64)$. Park 2001 reported no deaths in the bilevel NPPV arm and the SMC arm. El-Refay 2016 reported no deaths in the CPAP or bilevel NPPV arms. CPAP may reduce hospital mortality (RR $0.65,95 \% \mathrm{Cl} 0.48$ to 0.88 ; participants $=1454$; studies $=16 ; I^{2}=9 \%$ ) and bilevel 
0416 Non-invasive positive pressure ventilation (CPAP or bilevel NPPV) for cardiogenic pulmonary oedema

NPPV may reduce hospital mortality (RR $0.72,95 \% \mathrm{Cl} 0.53$ to 0.98 ; participants = 1030; studies $=11 ; I^{2}=0 \%$ ).

Our treatment location subgroup analysis (Analysis 1.3) revealed no significant difference between participants treated with NPPV in the ER compared to the ICU, based on the test for differences between subgroups $(P=0.51)$. People treated with NPPV in the ICU may have reduced hospital mortality compared to SMC (RR $0.52,95 \% \mathrm{CI} 0.35$ to 0.77 ; participants = 862; studies $\left.=10 ; 1^{2}=0 \%\right)$. Similarly, people treated with NPPV in the ER may have reduced hospital mortality compared to SMC (RR 0.66, 95\% Cl 0.47 to 0.93; participants = 1596; studies = 10; $\mathrm{I}^{2}=18 \%$ ). Baseline $\mathrm{PaCO}_{2}$ subgroup

analysis (Analysis 1.4) revealed a significant subgroup difference between studies with baseline eucapnia or hypercapnia (test for differences between subgroups $\mathrm{P}=0.005)$. People with eucapnia treated with NPPV compared to SMC may have reduced hospital mortality $\left(\mathrm{RR} 0.41,95 \% \mathrm{Cl} 0.27\right.$ to 0.63 ; participants $=581$; studies $=10 ; \mathrm{I}^{2}=0 \%$ ). In contrast, hypercapnic people may not benefit from NPPV compared to SMC (RR 0.82, 95\% Cl 0.65 to 1.03; participants = 1903; studies $=11 ;\left.\right|^{2}=0 \%$ ).

Low-risk-of-bias sensitivity analysis eliminated the observed reduction in hospital mortality with NPPV compared to SMC (RR $0.81,95 \% \mathrm{Cl} 0.61$ to 1.06 ; participants = 1505; studies = 7; Analysis $1.5 ;\left.\right|^{2}=6 \%$ ). A sensitivity analysis that excluded studies with missing data (RR $0.68,95 \% \mathrm{Cl} 0.54$ to 0.86 ; participants = 2283 ; studies = 18 ; Analysis 1.6 ; $\left.\right|^{2}=5 \%$ ) indicates that NPPV may reduce hospital mortality. Finally, changing our statistical model from random-effects to fixed-effect also indicates that NPPV may reduce hospital mortality compared to SMC alone $(\mathrm{RR} 0.67,95 \% \mathrm{Cl} 0.55$ to 0.81 ; participants $=$ 2484 ; studies = 21; Analysis $1.7 ;\left.\right|^{2}=6 \%$ ).

\section{Endotracheal intubation (ETI)}

NPPV compared to SMC probably reduces ETI (RR 0.49, 95\% Cl 0.38 to 0.62; participants = 2449; studies = 20; Analysis $\underline{1.8} ; 1^{2}=0 \%$; moderate quality of evidence) with a NNTB of 13 (NNTB 11 to NNTB 18). Two studies contributed data from only one of their three study arms: Kelly 2002 reported no ETI events for CPAP or SMC arms, and El-Refay 2016 reported no ETI events for CPAP or bilevel NPPV.

Our subgroup analysis by NPPV type indicates no significant difference between CPAP or bilevel NPPV compared to SMC (test for differences between subgroups $\mathrm{P}=0.75$ ). Both CPAP compared to SMC (RR 0.46, 95\% Cl 0.34 to 0.62 ; participants = 1413; studies =15; $I^{2}=0 \%$ ) and bilevel NPPV compared to SMC (RR 0.50,95\% CI 0.31 to 0.81 ; participants $=1036$; studies $=11 ;\left.\right|^{2}=23 \%$ ) probably reduce ETI (Analysis 1.9). Treatment location subgroup analysis (ER or ICU, Analysis 1.10) revealed no significant difference between participants treated in the ER or ICU with NPPV compared to SMC (test for differences between subgroups $P=0.40)$. NPPV use in the ER setting probably reduces ETI (RR $0.60,95 \%$ CI 0.37 to 0.96 ; participants $=1561$; studies $=9 ;\left.\right|^{2}=21 \%$ ). Participants treated with NPPV in the ICU setting probably have reduced ETI (RR 0.40, 95\% Cl 0.29 to 0.56; participants = 862; studies = 10; $1^{2}=0 \%$ ). Our $\mathrm{PaCO}_{2}$ subgroup

analysis (Analysis 1.11) revealed a significant difference between baseline eucapnic and hypercapnic studies (test for differences between subgroups $\mathrm{P}=0.03$ ). Both eucapnic participants treated with NPPV (RR $0.37,95 \% \mathrm{Cl} 0.26$ to 0.52 ; participants $=523$; studies $=9 ; 1^{2}=0 \%$ ) and hypercapnic participants treated with NPPV (RR $0.64,95 \% \mathrm{Cl} 0.46$ to 0.91 ; participants $=1926$; studies $=11 ; I^{2}=0 \%$ ) probably have reduced ETI rates compared to SMC, but the effect was larger in those with $\mathrm{PaCO}_{2}$ ? $45 \mathrm{mmHg}$.

Low-risk-of-bias sensitivity analysis indicates there was probably no ETI rate reduction with NPPV compared to SMC (RR $0.85,95 \% \mathrm{Cl} 0.55$ to 1.32 ; participants = 1491 ; studies = 6 ; Analysis $1.12 ;\left.\right|^{2}=0 \%$ ). In contrast, sensitivity analysis that excluded studies with missing data (Analysis 1.13) indicates that NPPV probably reduces ETI rates compared to SMC (RR $0.52,95 \% \mathrm{Cl} 0.40$ to 0.69 ; participants $=2248$; studies $=17 ; \mathrm{I}^{2}=0 \%$ ). We performed additional post hoc analysis exploring the effect of exclusive use of face masks to deliver NPPV compared to studies with permissive use of nasal or face masks (Analysis 1.14). We found no significant subgroup differences. Exclusive face mask use (RR $0.52,95 \% \mathrm{Cl} 0.40$ to 0.69 ; participants $=2213$; studies $=15 ;\left.\right|^{2}=0 \%$ ) or permissive use of nasal masks (RR $0.35,95 \% \mathrm{Cl}$ 0.20 to 0.62 ; participants $=236$; studies $=5 ; 1^{2}=0 \%$ ) probably reduced $\mathrm{ETI}$.

\section{Incidence of acute myocardial infarction (AMI)}

There is probably little or no difference in AMI incidence with NPPV compared to SMC for ACPE (RR $1.03,95 \%$ CI 0.91 to 1.16; participants = 1313; studies = 5; Analysis $1.15 ;\left.\right|^{2}=0 \%$; moderate quality of evidence). The median length of follow-up for AMI was three days. Subgroup analysis by NPPV type revealed no significant differences between CPAP or bilevel NPPV (Analysis 1.16; test for differences between subgroups $\mathrm{P}=0.30$ ). Both CPAP (RR 0.96, 95\% Cl 0.80 to 1.14 ; participants = 569; studies = $\left.;\left.\right|^{2}=0 \%\right)$ and bilevel NPPV (RR 1.09, 95\% CI 0.92 to 1.29 ; participants = 744; studies = $5 ; I^{2}=0 \%$ ) probably have little or no difference in AMI incidence compared to SMC. Several trials reported no AMl events in either treatment arm: CPAP versus bilevel versus SMC (Park 2004), and bilevel NPPV versus SMC (Park 2001; Thys 2002). Study location subgroup analysis was not possible, as only one study (Park 2001) was conducted in an unknown location while the remaining studies were conducted in the $\mathrm{ER}$. Baseline $\mathrm{PaCO}_{2}$ subgroup analysis was not possible, as only one study (Park 2001) had baseline eucapnia while the remaining studies had baseline hypercapnia. Our planned subgroup analysis comparing AMI rates before and after NPPV intervention was not possible, due to inconsistent AMI definitions (e.g. STEMI, NSTEMI, angina).

\section{Intolerance to allocated treatment}

We were interested in obtaining information on treatment intolerance of NPPV compared to SMC. Unfortunately, this outcome was inconsistently defined. Potential outcomes providing similar information included:

- Treatment failure. This outcome was more commonly reported. Treatment failure could indicate the need for endotracheal intubation. This outcome was inconsistently defined and was often a clinical diagnosis. Criteria for endotracheal intubation 
0416 Non-invasive positive pressure ventilation (CPAP or bilevel NPPV) for cardiogenic pulmonary oedema

are summarised in Table 4.

- Crane 2004 reported on treatment failure, which was defined as worsening respiratory function or reduced level of consciousness. Treatment failure occurred in one SMC participant, four CPAP participants, and one bilevel NPPV participant. Only one CPAP participant and one bilevel NPPV participant were intubated.

- Ducros 2011 reported on the presence of intubation criteria, which they defined as medically refractory hypoxaemia, loss of consciousness, psychomotor agitation, or haemodynamic instability. They reported 13 SMC participants and four CPAP participants meeting intubation criteria. Only six SMC participants and three CPAP participants were intubated.

- Kelly 2002 reported no treatment failures in the CPAP group and two treatment failures in the SMC group.

- L'Her 2004 reported no treatment failures or changes to the assigned treated after one hour of therapy. After 12 hours of treatment there were 11 SMC participants with coma and one CPAP participant with coma.

- Lin 1991 reported treatment failure in five CPAP participants and 10 SMC participants during the first three hours of treatment, leading to endotracheal intubation.

- Lin 1995 reported nine CPAP participants and 17 SMC participants meeting treatment failure criteria. Only six CPAP participants and 12 SMC participants were ultimately intubated, as the final decision was based on clinical judgement.

- Räsänen 1985 reported on treatment failure after three hours of therapy in 13 SMC participants and seven CPAP participants.

- Thys 2002 defined treatment failure based on clinical deterioration assessed by the clinician. Thys 2002 reported that all five participants assigned to SMC had treatment failure with placebo NPPV, and were switched over to active NPPV therapy.

- Treatment intolerance was inconsistently defined.

- Agmy 2008 reported one event in each treatment group (CPAP, bilevel NPPV, and SMC) of NPPV intolerance leading to ETI.

- Gray 2008 reported rates of participants changing to a new treatment, i.e. 65 of 363 SMC participants, 55 of 340 CPAP participants, and 85 of 352 participants for bilevel NPPV.

Given the heterogeneity in clinical definitions of treatment failure and our desired outcome being intolerance to allocated treatment, we are unable to draw any conclusions on the effect of NPPV compared to SMC for ACPE.

\section{Hospital and ICU length of stay}

We are uncertain whether NPPV reduces hospital length of stay compared to SMC for ACPE (MD ?0.31 days, 95\% CI ?1.23 to 0.61 ; participants $=1714$; studies $=11$; Analysis $1.17 ;\left.\right|^{2}=55 \%$; very low quality of evidence). The mean hospital length of stay was 9.65 days. Subgroup analysis by NPPV type found no significant subgroup differences $(P=0.22)$ between participants treated with CPAP (MD ? 0.52 days, $95 \% \mathrm{Cl}$ ? 1.77 to 0.72 ; participants = 943; studies = 7; $\left.\right|^{2}=59 \%$ ) or with bilevel NPPV (MD 0.39 days, $95 \% \mathrm{Cl} ? 0.35$ to 1.13 ; participants $=771$; studies $=6 ;\left.\right|^{2}=0 \%$ ) compared to SMC for hospital length of stay (Analysis 1.18). Treatment location subgroup analysis identified no significant difference $(P=0.84)$ between ACPE participants treated with NPPV in the ER (MD ?0.38 days, 95\% Cl ?1.70 to 0.93; participants = 1455; studies = $8 ;\left.\right|^{2}=68 \%$ ) compared to the ICU (MD ?0.21 days, 95\% CI ?1.30 to 0.89; participants = 259; studies = 3; Analysis $1.19 ;\left.\right|^{2}=0 \%$ ). Subgroup analysis by baseline $\mathrm{PaCO}_{2}$ ( (Analysis 1.20$)$ found a significant difference $(P=0.01)$ in hospital length of stay between eucapnic ACPE participants (MD ?1.18 days, 95\% Cl ?2.33 to ?0.04; participants = 397; studies = $5 ; I^{2}=44 \%$ ) and hypercapnic ACPE participants (MD 0.60 days, $95 \% \mathrm{Cl} ? 0.15$ to 1.34 ; participants = $1317 ;$ studies = $6 ; I^{2}=$ $7 \%$ ). However, the evidence quality was very low, and we are uncertain whether eucapnic or hypercapnic ACPE participants had reduced hospital lengths of stay.

We are uncertain whether NPPV reduces ICU length of stay compared to SMC for ACPE. We found significant heterogeneity with ICU length-of-stay data which were reported by six studies (Ducros 2011; Frontin 2011; Lin 1995; Takeda 1997; Thys 2002; Zokaei 2016). In addition, the quality of evidence was very low. We did not pool ICU length-of-stay data, due to significant heterogeneity (Analysis 1.21). We downgraded the quality of evidence for ICU length of stay by one level due to serious risk of bias. Most information was from studies at low or unclear risk of bias. Furthermore, lack of blinding was likely to lower confidence in our ICU length-of-stay findings. We also downgraded the evidence quality by one level due to data inconsistency. ICU length-of stay-data were heterogeneous with an $\mathrm{I}^{2}$ of $99 \%$ and visually-evident heterogeneity. Finally, we downgraded by one level for imprecision, because most of the trials had few participants, with the confidence interval crossing a mean difference of 0 .

\section{Vital signs one hour after intervention}

\section{Systolic blood pressure (SBP)}

There is probably little or no difference in SBP after one hour in people with ACPE treated with NPPV compared to SMC (MD ? $1.72 \mathrm{mmHg}, 95 \% \mathrm{Cl}$ ? 5.03 to 1.58; participants = 1408; studies = 7; Analysis $1.22 ; \mathrm{I}^{2}=0 \%$; moderate quality of evidence). The mean SBP was $128.4 \mathrm{mmHg}$ in the SMC group. We downgraded the quality of evidence for SBP by one level for imprecision, as the included studies had few participants and wide confidence intervals. Subgroup analysis by NPPV type (Analysis 1.23) found no significant subgroup difference $(P=0.95)$ between SBP in people with ACPE treated with CPAP (MD ? $1.65 \mathrm{mmHg}, 95 \% \mathrm{Cl}$ ? 5.58 to 2.28 ; participants = 866; studies = 7; $\left.\right|^{2}=0 \%$ ) or bilevel NPPV (MD ? $1.89 \mathrm{mmHg}, 95 \% \mathrm{Cl}$ ? 8.01 to 4.23 ; participants = 542; studies = 3; $\left.\right|^{2}=0 \%$ ) compared to SMC.

\section{Diastolic blood pressure (DBP)}

People with ACPE treated with NPPV compared to SMC probably have little or no difference in DBP after one hour of 
treatment $(\mathrm{MD} 1.46 \mathrm{mmHg}, 95 \% \mathrm{Cl}$ ? 1.86 to 4.78 ; participants = 1361; studies = 6; Analysis $1.24 ; \mathrm{I}=42 \%$; moderate quality of evidence). The mean DBP was $71.9 \mathrm{mmHg}$ in the SMC group. We downgraded DBP quality of evidence by one level for imprecision, because the included studies had few participants and wide confidence intervals. Subgroup analysis by NPPV type (Analysis 1.25) demonstrated no significant subgroup difference $(P=0.96)$ between DBP in people with ACPE treated with CPAP (MD $0.92 \mathrm{mmHg}, 95 \% \mathrm{Cl}$ ?3.92 to 5.75 ; participants = 823; studies = $6 ; 1^{2}=64 \%$ ) or bilevel NPPV (MD $1.08,95 \% \mathrm{Cl}$ ?2.88 to 5.04; participants $=538$; studies $=3 ; \mathrm{I}^{2}=0 \%$ ) compared to SMC.

\section{Mean blood pressure (MBP)}

There is probably little or no difference in MBP after one hour for people with ACPE treated with NPPV compared to SMC (MD $-2.50 \mathrm{mmHg}, 95 \% \mathrm{Cl}-8.29$ to 3.30 ; participants = 251; studies $=3 ; \mathrm{I}^{2}=20 \%$; Analysis 1.26 ; moderate quality of evidence). The mean MBP was $101 \mathrm{mmHg}$. We downgraded MBP quality of evidence by one level for imprecision, because the included studies had few participants and wide confidence intervals. We did not perform subgroup analysis by NPPV type, due to the small number of studies.

\section{Respiratory rate $(\mathrm{RR})$}

NPPV for ACPE probably reduces the RR after one hour of treatment compared to SMC (MD ?1.87 breaths a minute, 95\% $\mathrm{Cl}$ ?2.70 to ? 1.03; participants $=1636$; studies $=10$; Analysis $1.27 ; \mathrm{I}^{2}=17 \%$; moderate quality of evidence). The mean RR after one hour of therapy was 27.4 breaths a minute in the SMC group. We downgraded RR quality of evidence by one level for imprecision, because the included studies had few participants and wide confidence intervals. Subgroup analysis by NPPV type (Analysis 1.28) demonstrated no significant subgroup differences $(P=0.70)$ in RR after one hour between CPAP compared to SMC (MD ? 1.64 breaths a minute, $95 \% \mathrm{Cl}$ ?2.41 to ?0.87; participants = 1107 ; studies $\left.=10 ;\left.\right|^{2}=0 \%\right)$ and bilevel NPPV compared to SMC (MD ?2.17 breaths a minute, $95 \% \mathrm{Cl}$ ? 4.69 to 0.35 ; participants $=529 ;$ studies $=3 ; 1^{2}=38 \%$ ).

\section{Arterial oxygen concentration $\left(\mathrm{PaO}_{2}\right)$ after one hour of intervention}

NPPV compared to SMC for ACPE may improve $\mathrm{PaO}_{2}$ after one hour of therapy (MD $16.19 \mathrm{mmHg}, 95 \% \mathrm{Cl} 3.54$ to 28.84 ; participants = 1428; studies $=10$; Analysis $1.29 ; 1^{2}=91 \%$; low quality of evidence). The mean $\mathrm{PaO}_{2}$ after one hour of therapy was $133.9 \mathrm{mmHg}$ in the $\mathrm{SMC}$ group. We downgraded $\mathrm{PaO}_{2}$ quality of evidence by one level due to imprecision. Most trials had few participants and the confidence interval crossed the line of no effect. We downgraded by an additional level for inconsistency, because the $\mathrm{PaO}_{2}$ data were visually heterogeneous, with an $\mathrm{I}^{2}$ of $91 \%$. Our subgroup analysis by NPPV type (Analysis 1.30) demonstrated no significant subgroup differences $(\mathrm{P}=0.42)$ in $\mathrm{PaO}_{2}$ after one hour between CPAP compared to SMC (MD $9.55 \mathrm{mmHg}, 95 \% \mathrm{Cl}$ ? 9.10 to 28.19 ; participants $=761$; studies $=8 ; \mathrm{I}^{2}=88 \%$ ) and bilevel NPPV compared to SMC (MD $19.50 \mathrm{mmHg}, 95 \% \mathrm{Cl} 4.29$ to 34.71 ; participants =667; studies =6; $2^{2}=86 \%$ ). We did not pool $\mathrm{PaCO}_{2}$ and $\mathrm{pH}$ after one hour of treatment, as these outcomes require assessment compared to baseline values. In addition, we were unable to pool the treatment failure outcome, as this composite outcome of mortality, ETI rate, and treatment intolerance was not reported.

\section{Adverse events}

Eleven trials (Agmy 2008; Crane 2004; Ducros 2011; Frontin 2011; Gray 2008; L'Her 2004; Lin 1995; Masip 2000; Nava 2003; Park 2004; Räsänen 1985) compared NPPV against SMC for ACPE and reported adverse events (Analysis 1.31). There were 228 adverse events reported in 1230 NPPV participants compared to 116 adverse events for 808 SMC participants. Adverse events included skin damage, pneumonia, gastrointestinal bleeding, gastric distention, vomiting, pneumothorax, sinusitis, mask discomfort, hypotension, arrhythmia, cardiorespiratory arrest, gastric aspiration, stroke, seizures, claustrophobia, and hypercapnia.

Three trials (Gray 2008; Masip 2000; Nava 2003) reported that participants treated with NPPV probably have increased mask discomfort compared to SMC (RR $12.59,95 \% \mathrm{Cl} 2.39$ to 66.28 ; participants $=1100$; studies $=3 ;\left.\right|^{2}=0 \%$; moderate quality of evidence). We downgraded the evidence for mask discomfort by one level for imprecision, because there were few events and wide confidence intervals.

Three trials (Agmy 2008; Nava 2003; Räsänen 1985) reported worsening hypercapnia with treatment. Participants treated with NPPV or SMC for ACPE probably have little or no difference in rates of worsening hypercapnia. We downgraded the evidence quality for hypercapnia by one level for imprecision, due to few events and wide confidence intervals.

Park $2004(n=83)$ reported a higher incidence of gastric distention in the NPPV group (13/56 in NPPV group, 0/27 in SMC group; RR 13.26, $95 \% \mathrm{Cl} 0.82$ to 215.12), but the number of events was low and the confidence interval wide. There was some weak evidence of a lower incidence of cardiorespiratory arrest in the NPPV group (24/836 (NPPV) versus 26/516 (SMC); RR 0.60, 95\% Cl 0.34 to 1.05). There was no evidence of a difference between groups for the other adverse events.

Overall, we assessed the evidence for adverse events to be of low quality. We downgraded the evidence by one level for serious risk of bias (unclear or high risk of bias in at least one domain), and by one additional level for imprecision (the included studies had few participants and wide confidence intervals).

\section{Discussion}

\section{Summary of main results}

Our updated systematic review and meta-analysis includes 24 RCTs with 2664 participants. Compared to standard medical care (SMC), the use of non-invasive positive pressure ventilation (NPPV) for acute cardiogenic pulmonary oedema (ACPE) 
may reduce hospital mortality and probably reduces endotracheal intubation (ETI) rates. In addition, there was probably little or no difference between NPPV and SMC for rates of acute myocardial infarction (AMI), systolic blood pressure (SBP), diastolic blood pressure (DBP), or mean blood pressure (MBP) after one hour of therapy. We are uncertain if NPPV reduces hospital length of stay. However, NPPV (compared to SMC) probably improves respiratory rate after one hour of treatment, may slightly improve $\mathrm{PaO}_{2}$ after one hour of therapy, and probably increases mask discomfort.

NPPV use for ACPE may reduce hospital mortality compared to SMC alone, with a number needed to treat for an additional beneficial outcome (NNTB) of 17 (NNTB 12 to NNTB 32) (Summary of findings table 1). Our subgroup analysis by NPPV type identified no significant difference between continuous positive airway pressure (CPAP) and bilevel NPPV subgroups. Both NPPV forms may reduce hospital mortality compared to SMC. We found no significant difference between people with ACPE treated in the Emergency Room (ER) or intensive care unit (ICU) in our subgroup analysis. NPPV may reduce hospital mortality compared to $\mathrm{SMC}$ in both treatment locations. Our baseline $\mathrm{PaCO}_{2}$ subgroup analysis for people with ACPE treated with NPPV compared to SMC revealed a significant difference between studies with baseline average eucapnia and hypercapnia. Eucapnic people with ACPE treated with NPPV may have reduced hospital mortality, while hypercapnic people may have little or no difference in hospital mortality. The non-significant hospital mortality benefit with hypercapnia may have been due to the greater weight of the trial by Gray 2008 (conducted in the ER setting with baseline hypercapnia), which did not show any hospital mortality benefit with NPPV. Prior smaller studies have suggested enhanced benefit for people with baseline hypercapnia, due to their higher risk of complications and NPPV potentially preventing endotracheal intubation (Masip 2000; Moritz 2007; Nava 2003). Our baseline PaCO $\mathrm{Pabgroup}_{2}$ analysis did not support the idea that hypercapnic people with ACPE would benefit more compared to eucapnic people with ACPE. One possible reason for this discrepancy was that mean $\mathrm{PaCO}_{2}$ values could hide hypercapnic people who derived significant benefit from NPPV or clinical worsening with SMC. Finally, our sensitivity analysis limited to low-risk-of-bias studies found NPPV may make little or no difference in hospital mortality compared to SMC. In contrast, our sensitivity analysis limited to studies without missing data indicated that NPPV for ACPE may reduce hospital mortality compared to SMC alone.

NPPV in ACPE probably reduces ETI compared to SMC alone, with a NNTB of 13 (NNTB 11 to 18). We did not find a significant difference between trials comparing CPAP or bilevel NPPV in our subgroup analysis. Both forms of NPPV probably reduce ETI compared to SMC. We found no significant difference between trials comparing NPPV in the ER or ICU setting in our subgroup analysis. People with ACPE treated with NPPV in the ER or ICU probably have reduced ETI compared to SMC. Baseline $\mathrm{PaCO}_{2}$ subgroup analysis revealed a significant difference between baseline eucapnic and hypercapnic people with ACPE treated with NPPV compared to SMC. Both eucapnic and hypercapnic people with ACPE probably have reduced ETI compared to SMC. However, eucapnic people probably get more benefit compared to hypercapnic people. Sensitivity analysis limited to low-risk-of-bias studies found NPPV use probably makes little or no difference to ETI compared with SMC. In contrast, sensitivity analysis limited to studies without missing data indicated NPPV for ACPE probably reduces ETI compared to SMC alone. Our post hoc subgroup analysis which compared exclusive use of face masks to permissive use of nasal masks revealed no significant subgroup differences, and both NPPV subgroups probably reduce ETI compared to SMC alone.

Several trials (Mehta 1997; Rusterholtz 1999; Sharon 2000) reported increased AMI incidence with NPPV compared to SMC. We explored the safety of NPPV by identifying studies that reported AMI during or after NPPV initiation, compared to SMC. We found there was probably little or no difference in AMI incidence with NPPV. Subgroup analysis by NPPV type did not identify a difference between CPAP or bilevel NPPV studies. An important limitation of our AMI analysis was the inconsistent AMI definitions used across studies (e.g. ST elevation MI, ECG changes, biomarker positive, symptoms) and many studies only provided baseline AMI rates (Frontin 2011, L'Her 2004, Lin 1991, Lin 1995, Masip 2000, Räsänen 1985, Takeda 1997).

We were unable to perform an analysis of NPPV treatment intolerance compared to SMC in ACPE, due to the outcome not being reported. Furthermore, treatment failure which was reported had inconsistent definitions. Treatment failure data suggest that not all participants meeting treatment failure criteria were intubated. Possible reasons include changes to the underlying medical therapy, participant goals of care, and the difference between a quantitative description of failure based on vital signs and blood gas values and the clinical evaluation of treatment failure.

NPPV could reduce hospital and ICU length of stay for ACPE due to reduced ETI and avoidance of its complications (e.g. pneumonia and tracheal injury) (Gay 2009). Ideally, studies would have provided data on ICU or hospital-free days as participants who die early during the trial would have a short hospital or ICU length of stay, despite not benefiting from treatment. Unfortunately, hospital-free days were not reported. We are uncertain whether NPPV reduces hospital length of stay compared to SMC for ACPE. We found no subgroup differences between participants treated with CPAP or bilevel NPPV. In addition, we found no subgroup differences between studies comparing NPPV to SMC in the ER or ICU setting. Our subgroup analysis by baseline $\mathrm{PaCO}_{2}$ indicated a significant difference between eucapnic and hypercapnic studies.

However, given the very low quality of evidence we are uncertain whether NPPV reduces hospital length of stay in eucapnic people with ACPE. We were unable to pool ICU length-of-stay data due to significant heterogeneity. Based on the available data, we are uncertain whether NPPV reduces ICU length of stay.

We pooled mean blood pressure values obtained after one hour of therapy to identify differences between NPPV and SMC. In our comparison of NPPV to SMC in people with ACPE we found there is probably little or no difference between SBP, DBP, and MBP after one hour of therapy. These non-significant differences may represent a true lack of difference between therapies for reducing blood pressure, or the inability of mean blood pressure values to convey any potential benefit or harm with NPPV over SMC in individuals with significant hypertension or hypotension. Our analysis of mean respiratory rate data 
after one hour of therapy with NPPV or SMC found that NPPV probably reduces the respiratory rate compared to SMC in ACPE. Furthermore, our analysis of $\mathrm{PaO}_{2}$ after one hour of therapy demonstrated that NPPV may improve $\mathrm{PaO}_{2}$ slightly compared to SMC. Finally, 16 adverse event types were reported in 11 studies. We found higher rates of face discomfort when using NPPV compared to SMC.

\section{Overall completeness and applicability of evidence}

Our objective in performing this systematic review and meta-analysis update was to evaluate the impact of new literature published since the last version of this review (May 2013, Vital 2013) on the safety and effectiveness of NPPV compared to SMC for ACPE. Furthermore, we have updated the protocol and conduct of the review to recentlyrevised Cochrane standards (Higgins 2018). We reassessed the literature and performed a new assessment for study eligibility, which identified 24 RCTs for inclusion. Of these, seven are new studies published since the last version of this review (Austin 2013; Ducros 2011; El-Refay 2016; Hao 2002; Li 2005; Moritz 2003; Zokaei 2016). Three newlyincluded studies are based on a reassessment of previously excluded studies (Hao 2002; Li 2005; Moritz 2003), which lacked extractable outcomes. The outcomes in these trials were measured on different time scales for our secondary outcomes: $\underline{\mathrm{Li}} 2005\left(\mathrm{PaO}_{2}\right.$, respiratory rate), $\underline{\mathrm{HaO} 2002}\left(\mathrm{PaO}_{2}\right.$, respiratory rate, SBP), and Moritz 2003 (SBP, DBP). Only $\underline{\mathrm{HaO}}$ 2002 provided data on ETI as a primary outcome.

Importantly, we also excluded 15 studies that we had included in the previous version of this review but that no longer meet the revised inclusion criteria. For transparency, these were four quasi-randomised controlled trials (Bersten 1991; Moritz 2007; Sharon 2000; Weitz 2007), three studies conducted on an ineligible population (Bautin 2005; Delclaux 2000; Ferrer 2003) and eight studies which compared CPAP to bilevel NPPV without a SMC arm (Bellone 2004; Bellone 2005; Ferrari 2007; Ferrari 2010; Fontanella 2010; Liesching 2014; Martin-Bermudez 2002; Mehta 1997).

Overall, the evidence we identified was able to address our review objective. Studies that we identified focused on a single acute intervention (NPPV versus SMC) for people with ACPE provided during their hospital presentation. Our inclusion criteria for adults with ACPE were met. However, diagnosis of ACPE across studies was not standardised but based on a clinical assessment supported by clinical signs, chest x-ray, and exclusion of important alternative causes of dyspnoea (e.g. chronic obstructive pulmonary disease (COPD) and pneumonia). An important limitation of the studies we identified was the lack of baseline demographic data that could explain why certain recruited participants were at higher mortality risk than others (e.g. severe untreated valvular heart disease or AHA stage D heart failure). For example, the mortality rates reported by included studies were extremely disparate, ranging from 0 to $27.91 \%$ for NPPV (mean $9.64 \%$ ) and 0 to $63.64 \%$ for SMC (mean $21.06 \%$ ). These large variations in mortality may be influenced by the recruitment of ACPE participants with different underlying risks of mortality, regardless of their aggressive medical treatment with SMC or NPPV or both, and subtle differences in SMC between the different countries in which the included trials were performed.

Regarding the interventions under study, the trials included CPAP or bilevel NPPV or both, that had adjustable settings. We tried to ascertain whether the specific devices and pressure settings were reflective of contemporary practice. However, the NPPV device settings were not completely reported for all included trials. Where available, we have reported the mean inspiratory positive airway pressure (IPAP), expiratory positive airway pressure (EPAP), positive end-expiratory pressure (PEEP), and duration of NPPV used by each study (Table 1). For studies where this information was available, the devices and settings do reflect contemporary practice.

In addition, the ideal trial would have compared both forms of NPPV against SMC, given the possibility that CPAP versus bilevel NPPV may differ in their treatment efficacy. Only six of 24 included trials used a three-arm design. One such study (Gray 2008) was the largest RCT performed to date $(\mathrm{N}=1069)$. The other five studies had smaller sample sizes (range 26 to 129; mean 73). The remaining studies compared one type of NPPV (bilevel NPPV or CPAP) against SMC. Subgroup analysis by type of NPPV did not reveal any significant differences for the primary or main secondary outcomes. Current ACPE treatment practices vary from targeting an oxygen saturation of greater than $92 \%$ by titration of $\mathrm{FiO}_{2}$, initiation of NPPV, or endotracheal intubation (Ezekowitz 2017). Finally, we considered whether the SMC used in each trial reflected current treatment guidelines (Ezekowitz 2017; Ponikowski 2016). Such contemporary guidelines for acute heart failure recommend therapy with intravenous loop diuretics, supplemental oxygen, and nitrates, while maintaining an adequate blood pressure (Ezekowitz 2017; Ponikowski 2016). Our summary of the SMC used in each trial is listed in Table 2. All studies provided loop diuretics. However, the doses provided were unclear in nine studies. Nitrates were provided in all trials, but the form and dose was unclear in two studies. Similarly, each trial provided supplemental oxygen, but the specific $\mathrm{FiO}_{2}$ used was unclear in two studies. In summary, the NPPV and SMC used by the included studies generally reflected contemporary clinical practice

\section{Quality of the evidence}

All outcomes were assessed according to GRADE recommendations (Guyatt 2008; Higgins 2017). For the main outcomes, evidence quality ranged from moderate (ETI, AMI), to low (hospital mortality, adverse events), to very low (hospital length of stay). Hospital mortality was assessed in 21 studies that compared NPPV versus SMC and included 2484 patients. Key methodological limitations of the meta-analysis include the clinical heterogeneity of included studies, such as variation in the aetiology of cardiogenic pulmonary oedema (e.g. myocardial ischaemia, severe valvular heart disease) and the lack of clinical context for each individual participant (e.g. home therapies, ACC/AHA heart failure grade). Additional limitations were the impracticality of blinding participants, personnel, and outcome assessment, given the nature of NPPV. Lack of blinding may have influenced objective outcomes (e.g. hospital mortality or ETI) because participants treated with SMC could potentially cross over to NPPV if they appeared to be clinically deteriorating, thereby attenuating the benefit of NPPV when using intention-to-treat analysis. Another limitation of the included studies was the unclear risk of selective reporting bias, as 
reflected by the inconsistent reporting of outcomes. Finally, most studies recruited a low number of participants and their primary outcome was not hospital mortality. Interestingly, the well-powered study by Gray 2008 which had hospital mortality as a primary outcome did not detect a mortality difference between NPPV and SMC.

Our GRADE quality of evidence assessments for our primary outcomes were influenced by a number of factors, including risk of bias, imprecision, and inconsistency. Specifically, we rated the hospital mortality outcome as low quality, due to serious concerns with risks of bias and imprecision. We downgraded evidence quality by one level for risk of bias because most trials were rated as having unclear or high risk of bias for key domains, which included: randomisation sequence generation, allocation concealment, selective reporting bias, and other significant bias. We also downgraded this outcome for imprecision because there were few mortality events and the confidence interval included the appreciable benefit risk ratio of 0.75 . The funnel plot for hospital mortality (Figure 4 ) was also asymmetrical, which suggests the presence of publication bias. However, we did not further downgrade the evidence for this outcome, as the asymmetry could be explained by the poor design of smaller studies included in our review, clinical heterogeneity, and sampling variation. Furthermore, the findings were consistent in a post hoc fixed-effect sensitivity analysis (Analysis 1.7; Sterne 2011).

We rated the quality of evidence for ETI as moderate. We downgraded this outcome by one level, due to serious concerns with risks of bias. Most trials that provided ETI evidence had unclear or high risk of bias for key domains, which included: randomisation sequence generation, allocation concealment, selective reporting bias, and other significant bias. Our ETI funnel plot (Figure 5) was symmetrical, which suggests the absence of graphical evidence of publication bias. For AMI, the quality of evidence was moderate. We downgraded the evidence by one level for serious concerns with imprecision. We downgraded for imprecision because few trials reported AMI events, the confidence interval crossed a risk ratio of 1, and the AMI definition varied between trials. We rated hospital length-of-stay evidence quality as very low, and downgraded it for the following reasons: serious risk of bias due to lack of blinding, visually heterogeneous data, and high imprecision with few participants and a confidence interval crossing a mean difference of 0 . Our hospital length-of-stay funnel plot (Figure 6) was symmetrical and we therefore did not downgrade the evidence for publication bias. Adverse events evidence quality was low, and downgraded for the following reasons: serious risk of bias due to most studies having at least one domain at unclear or high risk of bias, and imprecision with wide confidence intervals crossing a risk ratio of 1 for many of the reported adverse events. For our secondary outcomes SBP, DBP, MBP, respiratory rate and $\mathrm{PaO}_{2}$, the quality of evidence was moderate. We downgraded SBP, DBP, MBP, and respiratory rate evidence quality by one level for imprecision because the included studies had few participants and wide confidence intervals. We downgraded $\mathrm{PaO}_{2}$ evidence quality by one level due to imprecision, because most trials had few participants and the confidence interval crossed a mean difference of 0 . In summary, the quality of evidence was low or very low for most primary outcomes, except for ETI and AMI, which were moderate and have important clinical significance.

\section{Potential biases in the review process}

Our review is strengthened by using prespecified methods to reduce bias. We reduced bias in our search strategy by searching eight databases including clinical trial databases without language restrictions. After obtaining reference lists, we minimised bias through duplicate independent screening, duplicate data abstraction, and prespecified criteria for appraising methodological quality. In addition, the study protocol was established prospectively and followed the Cochrane format for systematic reviews (Higgins 2018; Jadad 2000; McKibbon 2004). Furthermore, two of our review authors (NB, FV) obtained additional data from study authors for outcomes incompletely described in their initial publication (Agmy 2008; Austin 2013; Crane 2004; Gray 2008; Kelly 2002; Masip 2000; Nava 2003; Park 2004; Räsänen 1985; Takeda 1998; Thys 2002). Our meta-analysis includes the largest number of trials exploring the role of NPPV compared to SMC in ACPE and had increased power in pooling outcomes compared to earlier reviews (Potts 2009; Weng 2010). We performed extensive analysis of the impact of NPPV on a broad range of clinically important outcomes and physiological parameters. Furthermore, our results were robust to the exclusion of studies with missing data. The generalisability of our findings is enhanced by the broad range of treatment locations and countries included, representing international experience with NPPV for ACPE.

The small number of events (e.g. mortality, ETI, AMI) within identified trials is one important limitation of our review and meta-analysis. Additionally, the underlying heterogeneity of included ACPE participants may have influenced our findings on hospital mortality and ETI. Several important prognostic factors were not clearly reported by trial investigators, such as the participants' underlying heart failure severity, compliance with guideline-appropriate home therapy, and presence of heart failure aetiologies requiring surgical interventions (e.g. severe valvular heart disease). Furthermore, there were slight variations in SMC among studies, which suggest that clinical heterogeneity may have influenced some of the treatment effects. Additionally, the definition of AMI was inconsistent across studies. Finally, intubation criteria were not standardised and variations in clinical practice could have influenced the observed differences in ETI.

\section{Agreements and disagreements with other studies or reviews}

The first systematic review on NPPV for ACPE included three trials and reported a significant reduction in ETI with CPAP compared to SMC (Pang 1998). Hess 2004 expressed concern about the use of NPPV for ACPE, due to greater AMI rates in two studies and no significant benefit for mortality or ETI. Nadar 2005 identified reduced ETI for CPAP compared to SMC with no significant mortality difference. Several meta-analyses have reported similar conclusions to our own (Collins 2006; Ho 2006; Masip 2005; Peter 2006; Weng 2010; Winck 2006), despite small differences in methodology. The results of previous systematic reviews were challenged by a large new RCT (Gray 2008), which found no significant differences in hospital mortality or ETI between CPAP, bilevel NPPV, and SMC. Important caveats within Gray $\underline{2008}$ include exclusion of people requiring an emergent intervention who could possibly benefit from NPPV, exclusion 
0416 Non-invasive positive pressure ventilation (CPAP or bilevel NPPV) for cardiogenic pulmonary oedema

of people with AMI undergoing an intervention, and cross-overs between treatment arms of $19.9 \%$ (SMC), $16.2 \%$

(CPAP), and 24.1\% (bilevel NPPV) (Gray 2008). There was evidence in Gray 2008 that SMC cross-overs had more severe illness, and their cross-over to NPPV could have attenuated the benefit with NPPV compared to SMC. Nevertheless, as the largest single trial to date, Gray 2008 is an important trial in the meta-analysis and its results contrast with those of smaller included studies, which tend to show greater effect estimates favouring NPPV over SMC. The negative results of Gray 2008 make it imperative that we are cautious in interpreting the overall findings of our meta-analysis, which demonstrated that NPPV may reduce hospital mortality and probably reduces ETI when compared to SMC.

Our main findings are important and add support to current European heart failure guidelines (Ponikowski 2016). This guideline recommends that NPPV be considered and initiated promptly in people with ACPE presenting with tachypnoea (respiratory rate higher than 25 breaths a minute) and hypoxia $\left(\mathrm{SpO}_{2}\right.$ less than $\left.90 \%\right)$. In contrast, our findings may challenge Canadian heart failure guidelines which recommend against routine use of NPPV in ACPE (Ezekowitz 2017 ). The Canadian heart failure guideline suggests starting with SMC and considering NPPV if there is persistent hypoxia (Ezekowitz 2017). Based on our findings, their recommendation may be too conservative. Furthermore, NPPV is a relatively benign intervention. The main harms that were evident in our review were increased mask discomfort compared to SMC. Overall, the results of our review suggest that people with ACPE may experience more benefits than harms from the addition of NPPV to SMC for ACPE.

\section{Authors' conclusions}

\section{Implications for practice}

Meta-analysis of the best available evidence for NPPV versus SMC to treat ACPE demonstrates that NPPV may reduce hospital mortality and probably reduces ETI. NPPV probably has little or no influence on rates of AMI compared to SMC. We are uncertain whether NPPV reduces hospital length of stay compared to SMC. When considering the type of NPPV, the included studies demonstrated no significant differences between CPAP or bilevel NPPV compared to SMC. Thus, it is reasonable to consider the initiation of NPPV in people with ACPE who are already receiving optimal SMC. Limitations in the current evidence did not allow us to identify patient subgroups (e.g., eucapnic people or people treated in the ER or ICU) that derived more (or less) benefit from the initiation of NPPV.

\section{Implications for research}

Current evidence has allowed us to draw conclusions about the efficacy of NPPV (versus SMC) for treating ACPE. Nevertheless, certain shortcomings of the included studies have left some clinical questions unanswered. First, the optimal dosing of diuretics as part of SMC was not clear within the included studies. It is possible that the benefits of NPPV identified herein may be different (e.g. reduced or null), based on the clinical experience of a clinician providing SMC for ACPE. Second, it remains to be seen if certain types of people with ACPE (e.g. those with more severe ACC/AHA heart failure grade) would derive more benefit from the initiation of NPPV (in addition to SMC). Future studies should be judicious about explicitly defining intubation criteria, characterising the aetiology of ACPE, the underlying severity of heart failure, and guideline adherence for home heart-failure therapies prior to admission. Finally, individual patient-level data for blood gases with prespecified subgroups for hypercapnia or eucapnia can better characterise whether NPPV influences clinically important outcomes to a greater degree in people with hypercapnia compared to eucapnia.

\section{Acknowledgements}

We thank the Cochrane Heart group for a thoughtful and supportive editorial process. We are grateful to the authors of the studies we reviewed and to those who provided additional data (Räsänen, Bersten, Kelly, Nava, Park, Takeda, Thys, Masip, Bellone, Crane, Ferrari, Agmy, Gray, Weitz, Austin and Belenguer-Muncharaz). We are also grateful to previous authors of the first and second version of this review: Athallah AN, Burns K, Ladeira MT, Saconato H, Sen A, Hawkes CA, Soares B, and Vital F.

\section{Contributions of authors}

Nicolas Berbenetz proposed the systematic review update, updated the methods, performed study selection, data extraction, 'Risk of bias' assessment, GRADE quality assessment, co-ordinated the research team, and prepared and updated the review manuscript.

Yongjun Wang assisted with the review update, data extraction, 'Risk of bias' assessment, GRADE quality assessment, and reviewed the final manuscript.

Matthew Chong assisted with the review update, updated the methods, performed study selection, assisted in co-ordination of the research team, GRADE quality assessment, provided guidance with manuscript preparation, and edited the final manuscript.

Flávia Vital was involved as the lead author of the previous version of this review. She provided her correspondence with authors for unpublished findings.

Charlotte Godfrey assisted with data extraction and reviewed the final manuscript.

Mahmood Ahmad proposed the systematic review update, assisted with data extraction, and reviewed the final manuscript. James Brown, Pier Lambiase, Amitava Banerjee, and Ameet Bakhai reviewed the final manuscript.

\section{Declarations of interest}


0416 Non-invasive positive pressure ventilation (CPAP or bilevel NPPV) for cardiogenic pulmonary oedema

Yongjun Wang: none known

James Brown: none known

Charlotte Godfrey: none known

Mahmood Ahmad: none known

Flávia Vital: none known

Pier Lambiase: receives speaker fees and educational grant funding from Boston Scientific, and educational grant funding from Medtronic for work unrelated to the content of this Cochrane review.

Amitava Banerjee: none known

Ameet Bakhai: is employed within the NHS and also advises third sector companies (pharma, device, diagnostics, digital and Al) on trial design, economic models, technology adoption and acts as lecturer for cardiovascular topics. As research director, he also recruits to trials and supports research partnership work for his NHS employer, which attracts commercial research recruitment funding. There are no direct conflicts to the work presented however.

Matthew Chong: none known

\section{Differences between protocol and review}

In the previous version of this review ( $\mathrm{Vital} 2013$ ), we stated that acute myocardial infarction (AMI) was an outcome during and after intervention. In this update, we have combined these outcomes, because treatment with SMC or NPPV was not reported in a manner which allowed us to make causal determinations on when AMI occurred relative to the trial intervention (e.g. AMI during or after intervention was not specified). We were unable to include a subgroup analysis comparing AMI at trial inclusion or after NPPV, as the data were not reported consistently. Multiple vital signs were reported as outcomes in the original version of this review. For this update, we have focused on the most clinically relevant outcomes: systolic blood pressure, diastolic blood pressure, and mean blood pressure, which could be a contra-indication to starting NPPV therapy if too low, and could be expected to decrease with NPPV. Other vital signs such as heart rate are not useful compared to more objective markers of respiratory status such as respiratory rate and $\mathrm{PaO}_{2}$, which we have retained as outcomes. We did not perform a subgroup analysis of adverse events by study publication year before or after 2000. W did perform this analysis in the previous version of this review, but were unable to find a significant change in SMC or NPPV delivery which justified separating studies by any publication year.

\section{Differences between review version from 2013 and this update}

There has been a change in the authorship team since the last version of this review in 2013 (Vital 2013). In assuming authorship of this review, we have rerun searches of all databases outlined in the Methods section since 2013. We have also reassessed the inclusion criteria and risks of bias for all trials previously included. For data collection we have included means and standard deviations where available, if an outcome was reported as a median we have approximated it as being equivalent to the mean. We also converted standard error or interquartile ranges to standard deviations using formulae outlined in the Cochrane Handbook (Higgins 2011). In the previous version of this review we included quasi-randomised controlled trials. We defined quasi-randomised controlled trials as those where the allocation procedure was unlikely to be adequately randomised (e.g. randomisation according to odd or even numbers, day of the week, social security number, or medical record number). For this update, we have not included these studies, in order to use the highest level of evidence possible to guide the conclusions of our review.

Vital 2013 included studies comparing bilevel NPPV to CPAP without an additional standard medical therapy arm. In this update, we only include studies which compared bilevel NPPV or CPAP or both to standard medical care. These changes led to the inclusion of seven new studies and the exclusion of 15 previously included studies. Please see Included studies and Excluded studies for additional details.

The last authorship team (Vital 2013) performed a grey literature search by contacting authors of included articles for any additional articles on NPPV compared to SMC. We found all previously identified studies using our updated search strategy. In addition, we were able to identify seven new studies. We therefore did not repeat the grey literature search outside of the explicit databases named in our search strategy.

\section{Published notes}

\section{Characteristics of studies}

\section{Characteristics of included studies}

Agmy 2008 
0416 Non-invasive positive pressure ventilation (CPAP or bilevel NPPV) for cardiogenic pulmonary oedema

\begin{tabular}{|c|c|}
\hline Methods & $\begin{array}{l}\text { Single-centre randomised controlled trial, parallel design, unblinded, using ITT } \\
\text { approach. No participants were lost to follow-up } \\
\text { Setting: RICU or CCU } \\
\text { Country: Egypt } \\
\text { Funding: Assiut University } \\
\text { Study dates: not reported } \\
\text { Conflicts of interest: not reported }\end{array}$ \\
\hline Participants & $\begin{array}{l}129 \text { people with mean age } 67 \pm 4.8 \text { (CPAP arm } 66 \pm 6.9 \text {, bilevel arm } 68 \pm 3.8 \text {, and } \\
\text { SMC } 69 \pm 5.8) \text {. ACPE causes: systolic }(N=37) \text {, diastolic }(N=40) \text { or valvular heart } \\
\text { failure }(N=52) \\
\text { Excluded: immediate need for endotracheal intubation, acute MI, pneumothorax, } \\
\text { contraindications to NPPV, severe renal failure, ventricular arrhythmias }\end{array}$ \\
\hline Interventions & 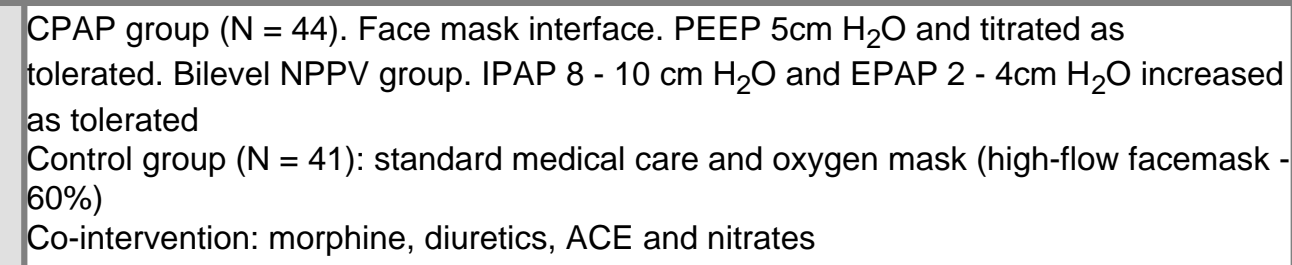 \\
\hline Outcomes & $\begin{array}{l}\text { 1. Primary outcome: Endotracheal intubation rate } \\
\text { 2. Mortality } \\
\text { 3. Arterial blood gases }\left(\mathrm{PaO}_{2}, \mathrm{PaCO}_{2}, \mathrm{pH}\right) \\
\text { 4. Vital signs }(\mathrm{RR}, \mathrm{BP}, \mathrm{HR}) \\
\text { 5. Length of hospital stay } \\
\text { 6. Length of ICU stay } \\
\text { 7. Intrapulmonary shunt } \\
\text { 3. A-a oxygen gradient } \\
\text { 9. Cardiac output } \\
\text { 1). Intolerance }\end{array}$ \\
\hline Notes & Trial available in abstract form only. Additional data from personal communication. \\
\hline
\end{tabular}

Risk of bias table

\begin{tabular}{|l|l|l|}
\hline Bias & $\begin{array}{l}\text { Authors' } \\
\text { iudgement }\end{array}$ & Support for judgement \\
\hline $\begin{array}{l}\text { Random sequence generation } \\
\text { (selection bias) }\end{array}$ & Unclear risk & No details provided \\
\hline $\begin{array}{l}\text { Allocation concealment (selection } \\
\text { bias) }\end{array}$ & Unclear risk & No details provided \\
\hline $\begin{array}{l}\text { Blinding of participants and } \\
\text { personnel (performance bias) }\end{array}$ & High risk & ClinicalTrials.gov "masking: none (Open label)" \\
\cline { 2 - 3 } $\begin{array}{l}\text { Blinding of outcome assessment } \\
\text { (detection bias) }\end{array}$ & Unclear risk & No details provided \\
\hline $\begin{array}{l}\text { Incomplete outcome data (attrition } \\
\text { bias) }\end{array}$ & Low risk & No participants were lost to follow-up (personal communication) \\
\hline Selective reporting (reporting bias) & High risk & $\begin{array}{l}\text { Registered at ClinicalTrials.gov NCT00912158, unclear if prospectively. } \\
\text { No data provided on duration of NPPV and mean settings. Outcomes } \\
\text { reported as a personal communication }\end{array}$ \\
\hline Other bias & High risk & $\begin{array}{l}\text { Data discrepancy between personal communication and } \\
\text { ClinicalTrials.gov entry for CPAP group intubation events }\end{array}$ \\
\cline { 2 - 3 } & & \\
\hline
\end{tabular}


0416 Non-invasive positive pressure ventilation (CPAP or bilevel NPPV) for cardiogenic pulmonary oedema

\begin{tabular}{|c|c|}
\hline Methods & $\begin{array}{l}\text { Single-centre, parallel-group design, and unblinded RCT } \\
\text { Setting: pre-hospital/Emergency Department } \\
\text { Country: Tasmania, Australia } \\
\text { Prospectively registered with ANZCTR. } \\
\text { Funding: National Health and Medical Research Council, Ambulance Tasmania } \\
\text { Study dates: July } 2009 \text { to July } 2010 \\
\text { Conflict of interest: not reported }\end{array}$ \\
\hline Participants & $\begin{array}{l}50 \text { adults with ACPE, with mean age } 79.8 \pm 11.9 \text { (control group } 78.3 \pm 11.8, \text { CPAP } \\
\text { group } 81.5 \pm 11.9 \text { ) } \\
\text { Pre-hospital setting with diagnosis of severe ACPE requiring ventilatory assistance. } 2 \\
\text { independent physicians blinded to group allocation retrospectively reviewed } \\
\text { randomised participant records to confirm they met the diagnostic criteria for severe } \\
\text { ACPE (crackles on auscultation, acute onset shortness of breath and hypoxia } \\
\text { requiring assisted ventilation) } \\
\text { Exclusion criteria: other respiratory conditions (asthma, COPD), people with } \\
\text { respiratory or cardiac arrest or with GCS }<12 \text { or systolic BP }<90\end{array}$ \\
\hline Interventions & $\begin{array}{l}\text { CPAP and standard medical therapy }(\mathrm{N}=26) \text {. CPAP setting } 10 \mathrm{~cm} \mathrm{H}_{2} \mathrm{O} \text { delivered by } \\
\text { "Whisperflow" } \\
\text { Standard medical therapy }(\mathrm{N}=24) \text { : nitrates, furosemide } 40 \mathrm{mg} \text { IV if transit time }>20 \\
\text { minutes, high-flow oxygen } 8 \text { - } 15 \mathrm{~L} \text { per minute }\end{array}$ \\
\hline Outcomes & $\begin{array}{l}\text { 1. Primary outcome: pre-hospital mortality, in-hospital mortality } \\
\text { 2. Endotracheal intubation rate } \\
\text { 3. Requirement for ICU admission } \\
\text { 4. Vital signs (BP, RR, oxygen saturation, HR, GCS) }\end{array}$ \\
\hline Notes & $\begin{array}{l}\text { Trial available in abstract form only. Additional data from personal communication } 19 \\
\text { January } 2018\end{array}$ \\
\hline
\end{tabular}

Risk of bias table

\begin{tabular}{|c|c|c|}
\hline Bias & $\begin{array}{l}\text { Authors' } \\
\text { judgement }\end{array}$ & Support for judgement \\
\hline $\begin{array}{l}\text { Random sequence generation } \\
\text { (selection bias) }\end{array}$ & Low risk & Computer-generated numbers \\
\hline $\begin{array}{l}\text { Allocation concealment (selection } \\
\text { bias) }\end{array}$ & Low risk & $\begin{array}{l}\text { Numbers placed on cards within sealed, sequentially-numbered } \\
\text { opaque envelopes and placed with ventilation equipment }\end{array}$ \\
\hline $\begin{array}{l}\text { Blinding of participants and } \\
\text { personnel (performance bias) }\end{array}$ & High risk & Masking not used \\
\hline $\begin{array}{l}\text { Blinding of outcome assessment } \\
\text { (detection bias) }\end{array}$ & Low risk & Outcome assessed by blinded physicians \\
\hline $\begin{array}{l}\text { Incomplete outcome data (attrition } \\
\text { bias) }\end{array}$ & Low risk & No missing outcome data \\
\hline Selective reporting (reporting bias) & Low risk & $\begin{array}{l}\text { Prospectively registered with ANZCTR: ACTRN12609000410257. All } \\
\text { prespecified outcomes were provided in a personal communication }\end{array}$ \\
\hline Other bias & Low risk & The study appears to be free of other sources of bias \\
\hline
\end{tabular}

Crane 2004 
0416 Non-invasive positive pressure ventilation (CPAP or bilevel NPPV) for cardiogenic pulmonary oedema

\begin{tabular}{|c|c|}
\hline Methods & $\begin{array}{l}\text { Multicentre, parallel design, unblinded RCT conducted at } 2 \text { university hospitals. Used } \\
\text { an ITT approach. No reported loss to follow-up. Participants or next-of-kin were aware } \\
\text { through informed consent, but in } 17 \text { cases, the participant gave verbal consent } \\
\text { Diagnosis of myocardial infarction if during } 3 \text { days after admission there were ECG } \\
\text { changes or a CK rise (> 280) } \\
\text { Setting: Emergency Department } \\
\text { Country: United Kingdom } \\
\text { Funding: ResMed, Abingdon, UK } \\
\text { Study dates: May } 2000 \text { and September } 2001 \\
\text { Conflict of interest: not reported }\end{array}$ \\
\hline Participants & $\begin{array}{l}60 \text { adults ( } 23 \text { men and } 37 \text { women) with mean age } 75.1 \pm 10.5 \text { ( } 74.6 \pm 11.1 \text { years in } \\
\text { SMC group, } 74.9 \pm 12.2 \text { in CPAP group and } 76 \pm 8.4 \text { in bilevel group) } \\
\text { Inclusion criteria: RR }>23 \text { breaths a minute, diagnosis consistent with pulmonary } \\
\text { oedema, } \mathrm{pH}<7.35 \text {, widespread pulmonary crepitations and diaphoresis. History: } \mathrm{HF} \text {, } \\
\text { IHD, diabetes mellitus, hypertension, COPD } \\
\text { Exclusion criteria: Hypotension (systolic } \mathrm{BP}<90 \mathrm{mmHg} \text { ), temperature }>38^{\circ} \mathrm{C} \text {, } \\
\text { requiring thrombolysis for myocardial infarction or dialysis for renal impairment, people } \\
\text { with impaired consciousness or with dementia }\end{array}$ \\
\hline Interventions & $\begin{array}{l}\text { CPAP group }(\mathrm{N}=20): \text { PEEP }=10 \mathrm{cmH}_{2} \mathrm{O} \\
\text { Bilevel group }(\mathrm{N}=20): \text { EPAP }=5 \mathrm{cmH}_{2} \mathrm{O} \text {; IPAP }=15 \mathrm{cmH}_{2} \mathrm{O} \\
\left.\text { Control group }(\mathrm{N}=20) \text { : } \mathrm{SMC} \text { and } \mathrm{O}_{2} \text { mask (to maintain } \mathrm{SaO}_{2}>90 \%\right) \text {; mask: full-face } \\
\text { Co-interventions: furosemide, nitrates and diamorphine (without restriction) }\end{array}$ \\
\hline Outcomes & $\begin{array}{l}\text { 1. Primary outcome: treatment success }\left(\mathrm{RR}<23 \text { a minute, } \mathrm{SpO}_{2}>90 \% \text {, arterial } \mathrm{pH}>\right. \\
7.35 \text { after } 2 \text { hours of treatment) } \\
\text { 2. Mortality } \\
\text { 3. Endotracheal intubation rate } \\
\text { 4. Arterial blood gases }\left(\mathrm{PaO}_{2}, \mathrm{PaCO}_{2}, \mathrm{pH}\right) \\
\text { 5. Vital signs (RR, } \mathrm{BP}, \mathrm{HR}) \\
\text { b. Incidence of acute myocardial infarction (follow-up) } \\
\text { 7. Participant compliance } \\
\text { 3. Treatment failure } \\
\text { 6. Side effects }\end{array}$ \\
\hline Notes & \\
\hline
\end{tabular}

Risk of bias table 
0416 Non-invasive positive pressure ventilation (CPAP or bilevel NPPV) for cardiogenic pulmonary oedema

\begin{tabular}{|c|c|c|}
\hline Bias & $\begin{array}{l}\text { Authors' } \\
\text { iudgement }\end{array}$ & Support for judgement \\
\hline $\begin{array}{l}\text { Random sequence generation } \\
\text { (selection bias) }\end{array}$ & Low risk & $\begin{array}{l}\text { Randomisation sequence was generated using random numbers } \\
\text { produced by Microsoft Excel }\end{array}$ \\
\hline $\begin{array}{l}\text { Allocation concealment (selection } \\
\text { bias) }\end{array}$ & Low risk & $\begin{array}{l}\text { Assignments were concealed in an opaque envelope, which was then } \\
\text { further concealed within another }\end{array}$ \\
\hline $\begin{array}{l}\text { Blinding of participants and } \\
\text { personnel (performance bias) }\end{array}$ & High risk & Impossible to mask treatment allocation \\
\hline $\begin{array}{l}\text { Blinding of outcome assessment } \\
\text { (detection bias) }\end{array}$ & Unclear risk & Not described \\
\hline $\begin{array}{l}\text { Incomplete outcome data (attrition } \\
\text { bias) }\end{array}$ & Low risk & All enrolled participants were accounted for \\
\hline Selective reporting (reporting bias) & Unclear risk & $\begin{array}{l}\text { Study was not prospectively registered in a trial registry. The primary } \\
\text { outcome of treatment success was not a standard outcome used in } \\
\text { similar trials, but includes secondary outcomes which could be used in } \\
\text { the meta-analysis }\end{array}$ \\
\hline Other bias & Unclear risk & No power calculation to explain the sample size used for the trial \\
\hline
\end{tabular}

Ducros 2011 
0416 Non-invasive positive pressure ventilation (CPAP or bilevel NPPV) for cardiogenic pulmonary oedema

\begin{tabular}{|c|c|}
\hline \multirow[t]{6}{*}{ Methods } & $\begin{array}{l}\text { Multicentre, parallel-group, unblinded RCT conducted in the pre-hospital setting } \\
\text { followed ITT analysis. Pre-hospital setting included mobile ICU/emergency medical } \\
\text { services including a physician and a nurse. } 2 \text { a priori defined subgroups: hypercapnic } \\
\text { status and left ventricular ejection fraction }\end{array}$ \\
\hline & Setting: Pre-hospital setting mobile ICU and later transferred to cardiac ICU \\
\hline & Country: Paris, France \\
\hline & $\begin{array}{l}\text { Funding: French Ministry of Health, Laurent Ducros conducted non-invasive } \\
\text { ventilation training sessions funded by Respironics Philips France }\end{array}$ \\
\hline & Study dates: October 2004 and October 2007 \\
\hline & $\begin{array}{l}\text { Conflict of interest: Yes. Laurent Ducros conducted NIV training sessions funded by } \\
\text { Respironics Philips France }\end{array}$ \\
\hline \multirow[t]{3}{*}{ Participants } & $\begin{array}{l}207 \text { people with ACPE were recruited. Mean age } 80.5 \pm 10.1 \text { ( } 81 \pm 9 \text { in control group, } \\
80 \pm 11 \text { in CPAP group) }\end{array}$ \\
\hline & $\begin{array}{l}\text { Inclusion criteria: ACPE symptoms including: orthopnoea, diffuse crackles (Killip } \\
\text { score? III), RR }>25 \text { a minute, and } \mathrm{SpO}_{2}<90 \% \text { on room air }\end{array}$ \\
\hline & $\begin{array}{l}\text { Exclusion criteria: History of COPD, asthma, severe stenotic valve disease, } \\
\text { immediate indication for intubation (severe impairment of consciousness, } \\
\text { bradypnoea), cardiovascular collapse or suspicion of ST segment elevation acute } \\
\text { coronary syndrome }\end{array}$ \\
\hline \multirow[t]{4}{*}{ Interventions } & Pre-hospital applied CPAP with standard therapy or standard therapy alone \\
\hline & $\begin{array}{l}\text { CPAP group ( } \mathrm{N}=107): 2.5 \text { to } 10 \mathrm{~cm} \mathrm{H}_{2} \mathrm{O} \text { provided by "Whisperflow" and delivered } \\
\text { using a face mask }\end{array}$ \\
\hline & Control group $(N=100)$ : co-intervention only \\
\hline & $\begin{array}{l}\text { Co-interventions: lasix } 40 \mathrm{mg}-120 \mathrm{mg} \text { IV or } 1-3 \mathrm{mg} \text { bumetanide, nitroglycerin }(1 \mathrm{mg} \\
\text { per } 3 \mathrm{~min} \text { ) and a continuous intravenous infusion unless systolic } \mathrm{BP}<110 \mathrm{mmHg} \text {; } \\
\text { supplemental oxygen } 15 \mathrm{~L} \text { per minute }\end{array}$ \\
\hline Outcomes & $\begin{array}{l}\text { 1. Primary combined outcome: death, endotracheal intubation, persistence of all } \\
\text { inclusion criteria or circulatory failure in hospital or reappearance in hospital during } \\
\text { first } 48 \text { hours } \\
\text { 2. Brain natriuretic factor value } \\
\text { 3. Hospital mortality } \\
\text { 4. Persistence of inclusion criteria } \\
\text { b. Acute MI rate } \\
\text { j. Adverse effects }\end{array}$ \\
\hline & \\
\hline
\end{tabular}

Risk of bias table 
0416 Non-invasive positive pressure ventilation (CPAP or bilevel NPPV) for cardiogenic pulmonary oedema

\begin{tabular}{|c|c|c|}
\hline Bias & $\begin{array}{l}\text { Authors' } \\
\text { judgement }\end{array}$ & Support for judgement \\
\hline $\begin{array}{l}\text { Random sequence generation } \\
\text { (selection bias) }\end{array}$ & Unclear risk & $\begin{array}{l}\text { Did not describe the method, but indicated that randomisation was } \\
\text { stratified using permuted block randomisation }\end{array}$ \\
\hline $\begin{array}{l}\text { Allocation concealment (selection } \\
\text { bias) }\end{array}$ & Unclear risk & $\begin{array}{l}\text { Used "sealed numbered envelopes kept in each ambulance and } \\
\text { opened on-scene" }\end{array}$ \\
\hline $\begin{array}{l}\text { Blinding of participants and } \\
\text { personnel (performance bias) }\end{array}$ & High risk & ClinicalTrials.gov: "Masking: None (Open Label)" \\
\hline $\begin{array}{l}\text { Blinding of outcome assessment } \\
\text { (detection bias) }\end{array}$ & Low risk & Independent Critical Event Validation Committee assessed the endpoint \\
\hline $\begin{array}{l}\text { Incomplete outcome data (attrition } \\
\text { bias) }\end{array}$ & Low risk & No missing outcome data \\
\hline Selective reporting (reporting bias) & High risk & $\begin{array}{l}\text { Prospectively registered at ClinicalTrials.gov: NCT00554580. Acute MI } \\
\text { rate is not reported, provide a median troponin for control and CPAP } \\
\text { groups, which cannot be included in meta-analysis }\end{array}$ \\
\hline Other bias & High risk & Premature termination due to poor recruitment \\
\hline
\end{tabular}

El-Refay 2016 
0416 Non-invasive positive pressure ventilation (CPAP or bilevel NPPV) for cardiogenic pulmonary oedema

\begin{tabular}{|c|c|}
\hline Methods & $\begin{array}{l}\text { Single-centre, parallel-group design, single-blind RCT. Analysis was per protocol as } \\
\text { participants were excluded from analysis after randomisation due to not tolerating } \\
\text { CPAP or bilevel NPPV. } 2 \text { participants in the CPAP group and } 1 \text { participant in the } \\
\text { bilevel NPPV group did not tolerate therapy and were excluded from analysis. } \\
\text { Informed consent obtained from the participant or their next-of-kin. } \\
\text { Setting: Emergency Department } \\
\text { Country: Giza, Egypt } \\
\text { Funding: Not reported } \\
\text { Study dates: May } 2007 \text { to November } 2008 \\
\text { Conflict of interest: not reported }\end{array}$ \\
\hline \multirow[t]{3}{*}{ Participants } & $\begin{array}{l}66 \text { participants analysed from } 69 \text { randomised. } 3 \text { participants did not tolerate NPPV and } \\
\text { were excluded. Included } 27 \text { men and } 39 \text { women, with mean age } 57.3 \pm 5.6 \text { ( } 57 \pm 5.3 \\
\text { in the control group, } 58.4 \pm 6.5 \text { in the CPAP group, and } 56.6 \pm 5.1 \text { in the bilevel group) }\end{array}$ \\
\hline & $\begin{array}{l}\text { Inclusion criteria: severe dyspnoea, bilateral rales on auscultation, and typical } \\
\text { findings of congestion on chest radiography without evidence of pulmonary aspiration } \\
\text { or pneumonia. Additional parameters: RR ? 30/min, } \mathrm{PaO}_{2} ? 80 \mathrm{mmHg}, \mathrm{PaCO}_{2} ? 45 \\
\mathrm{mmHg}\end{array}$ \\
\hline & $\begin{array}{l}\text { Exclusion criteria: systolic BP ? } 90 \mathrm{mmHg} \text {, requirement for percutaneous coronary } \\
\text { intervention, COPD, life-threatening arrhythmia, acute Ml or unstable angina, facial } \\
\text { trauma, oesophageal or gastric surgery, gastrointestinal bleeding, pregnant }\end{array}$ \\
\hline \multirow[t]{4}{*}{ Interventions } & 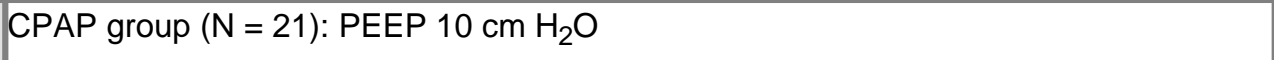 \\
\hline & BILEVEL group ( $\mathrm{N}=22)$. IPAP $15 \mathrm{~cm} \mathrm{H}_{2} \mathrm{O}$ and EPAP $10 \mathrm{~cm} \mathrm{H}_{2} \mathrm{O}$ \\
\hline & Control group $(\mathrm{N}=23): \mathrm{SMC}+\mathrm{O}_{2}$ facemask $\left(\mathrm{FiO}_{2} ? 50 \%\right)$ \\
\hline & $\begin{array}{l}\text { Co-intervention: supplemental oxygen up to } 15 \mathrm{~L} \text { per minute, nitroglycerine } 0.4 \mathrm{mg} \mathrm{SL} \\
\text { if systolic BP > } 100 \mathrm{mmHg} \text {, furosemide } 40 \mathrm{mg} \text { IV repeated as required, morphine } \\
\text { sulphate } 2 \mathrm{mg} \text { IV repeated once if needed. Dopamine sulphate for hypotension if } \\
\text { required }\end{array}$ \\
\hline Outcomes & $\begin{array}{l}\text { 1. Primary endpoint: blood gases }\left(\mathrm{PaCO}_{2}, \mathrm{PaO}_{2}, \mathrm{SaO}_{2}, \mathrm{pH} \text {, bicarbonate }\right. \\
\text { concentration). Collected at entry, after } 1 \text { hour of therapy and } 30 \text { minutes of therapy } \\
\text { discontinuation } \\
\text { 2. Physiologic parameters (HR, RR, systolic } \mathrm{BP} \text {, diastolic } \mathrm{BP}) \text {. Collected at entry, after } \\
1 \text { hour of therapy and } 30 \text { minutes of therapy discontinuation } \\
\text { 3. Adverse events }\end{array}$ \\
\hline Notes & \\
\hline
\end{tabular}

Risk of bias table 
0416 Non-invasive positive pressure ventilation (CPAP or bilevel NPPV) for cardiogenic pulmonary oedema

\begin{tabular}{|c|c|c|}
\hline Bias & $\begin{array}{l}\text { Authors' } \\
\text { iudgement }\end{array}$ & Support for judgement \\
\hline $\begin{array}{l}\text { Random sequence generation } \\
\text { (selection bias) }\end{array}$ & Unclear risk & Did not describe the method of randomisation \\
\hline $\begin{array}{l}\text { Allocation concealment (selection } \\
\text { bias) }\end{array}$ & Unclear risk & $\begin{array}{l}\text { Used opaque envelopes which were concealed within another } \\
\text { opaque envelope }\end{array}$ \\
\hline $\begin{array}{l}\text { Blinding of participants and } \\
\text { personnel (performance bias) }\end{array}$ & High risk & $\begin{array}{l}\text { Single-blinded, once enrolled impossible to mask treatment } \\
\text { allocation }\end{array}$ \\
\hline $\begin{array}{l}\text { Blinding of outcome assessment } \\
\text { (detection bias) }\end{array}$ & Low risk & Blinded laboratory investigators analysed samples. \\
\hline $\begin{array}{l}\text { Incomplete outcome data (attrition } \\
\text { bias) }\end{array}$ & High risk & $\begin{array}{l}\text { As-treated analysis performed, missing outcome data for exclusions } \\
\text { after randomisation }\end{array}$ \\
\hline Selective reporting (reporting bias) & Unclear risk & $\begin{array}{l}\text { Study was not prospectively registered. Unclear if all expected } \\
\text { outcomes were reported }\end{array}$ \\
\hline Other bias & High risk & Figures do not provide a standard deviation, only a mean value \\
\hline
\end{tabular}

Frontin 2011 
0416 Non-invasive positive pressure ventilation (CPAP or bilevel NPPV) for cardiogenic pulmonary oedema

\begin{tabular}{|c|c|}
\hline \multirow[t]{5}{*}{ Methods } & $\begin{array}{l}\text { Single-centre, parallel-group, unblinded RCT, analysed using ITT approach. } 2 \\
\text { participants (in the CPAP group) refused the ongoing use of their data once their } \\
\text { condition stabilised and were not analysed. Informed consent was obtained from } \\
\text { participants or their surrogates }\end{array}$ \\
\hline & $\begin{array}{l}\text { Setting: Pre-hospital care provided by "Service d'Aide Médicale Urgente" (SAMU) and } \\
\text { continued in the ICU } \\
\text { Country: Touslouse, France }\end{array}$ \\
\hline & Funding: University Hospital of Toulouse \\
\hline & Study dates: September 2006 to March 2008 \\
\hline & Conflict of interest: None \\
\hline \multirow[t]{3}{*}{ Participants } & $\begin{array}{l}124 \text { patients randomised, } 122 \text { analysed ( } 52 \text { men and } 70 \text { women), with mean age } 79.4 \\
\pm 10.6 \text { (79.3 } \pm 10.5 \text { years in SMC group, } 79.4 \pm 10.7 \text { in CPAP group) }\end{array}$ \\
\hline & $\begin{array}{l}\text { Inclusion criteria: } 18 \text { years or older with clinical symptoms of ACPE such as } \\
\text { orthopnoea, diffuse crackles without evidence of pulmonary aspiration or infection, } \\
\text { pulse oximetry }\left(\mathrm{SpO}_{2}\right)<90 \% \text { and a RR }>25 \text { breaths a minute }\end{array}$ \\
\hline & $\begin{array}{l}\text { Exclusion criteria: Cardiovascular collapse or an impaired level of consciousness, } \\
\text { AMI, or if they had an immediate need for intubation. People with a history of gastric } \\
\text { surgery ( }<8 \text { days) and people vomiting }\end{array}$ \\
\hline Interventions & $\begin{array}{l}\text { CPAP group ( } \mathrm{N}=60 \text { ): } \mathrm{PEEP} \text { of } 10 \mathrm{~cm} \mathrm{H} \mathrm{H}_{2} \mathrm{O} \\
\text { Control group ( } \mathrm{N}=62) \text { : } \mathrm{SMC} \text { and oxygen facemask } \\
\text { Co-intervention: furosemide } 1 \mathrm{mg} / \mathrm{kg} \text {, morphine pre-hospital, isosorbide dinitrate } \\
\text { infusion at } 2 \mathrm{mg} \text { an hour (range, } 3-5 \mathrm{mg} \text { an hour) in both groups }\end{array}$ \\
\hline Outcomes & $\begin{array}{l}\text { 1. Primary outcome: treatment success defined, a priori, as all of } \mathrm{RR}<25 \text { breaths a } \\
\text { minute and oxygen saturation }>90 \% \text { at the end of the } 1 \text {-hour study } \\
\text { 2. Vital signs (RR, BP, } \mathrm{HR}) \\
\text { 3. Dyspnoea } \\
\text { t. Endotracheal intubation rate } \\
\text { 5. Mortality at } 5 \text { and } 30 \text { days } \\
\text { 3. Arterial blood gases }\left(\mathrm{PaO}_{2}, \mathrm{PaCO}_{2}\right) \\
\text { 7. Adverse events } \\
\text { 3. Length of hospital stay }\end{array}$ \\
\hline & \\
\hline
\end{tabular}

Risk of bias table 
0416 Non-invasive positive pressure ventilation (CPAP or bilevel NPPV) for cardiogenic pulmonary oedema

\begin{tabular}{|c|c|c|}
\hline Bias & $\begin{array}{l}\text { Authors' } \\
\text { judgement }\end{array}$ & Support for judgement \\
\hline $\begin{array}{l}\text { Random sequence generation } \\
\text { (selection bias) }\end{array}$ & Low risk & Table of random numbers determined the randomisation sequence \\
\hline $\begin{array}{l}\text { Allocation concealment (selection } \\
\text { bias) }\end{array}$ & Low risk & $\begin{array}{l}\text { Group assignments were sealed in opaque envelopes and opened } \\
\text { sequentially by the SAMU dispatcher who then randomly assigned the } \\
\text { participant to } 1 \text { of } 2 \text { treatment groups }\end{array}$ \\
\hline $\begin{array}{l}\text { Blinding of participants and } \\
\text { personnel (performance bias) }\end{array}$ & High risk & Not blinded \\
\hline $\begin{array}{l}\text { Blinding of outcome assessment } \\
\text { (detection bias) }\end{array}$ & Unclear risk & Investigator was blinded \\
\hline $\begin{array}{l}\text { Incomplete outcome data (attrition } \\
\text { bias) }\end{array}$ & Low risk & All enrolled participants were accounted for \\
\hline Selective reporting (reporting bias) & Low risk & $\begin{array}{l}\text { Prospectively registered at ClinicalTrials.gov: NCT00439075. } \\
\text { Outcomes that are of interest in the review have been reported in the } \\
\text { prespecified manner }\end{array}$ \\
\hline Other bias & Low risk & The study appears to be free of other sources of bias \\
\hline
\end{tabular}

Gray 2008 
0416 Non-invasive positive pressure ventilation (CPAP or bilevel NPPV) for cardiogenic pulmonary oedema

\begin{tabular}{|c|c|}
\hline Methods & $\begin{array}{l}\text { Multicentre, prospective, parallel-group, unblinded RCT. No ITT analysis, as } \\
\text { participants not included despite being randomised. Included } 3 \text { treatment groups: } \\
\text { standard oxygen therapy, CPAP, and bilevel NPPV. Participants were randomly } \\
\text { assigned in a 1:1:1 ratio with the use of a 24-hour telephone randomisation service. } \\
\text { The randomisation sequence was stratified according to centre, with variable block } \\
\text { length. } 87 \text { participants were excluded after randomisation because of ineligibility or } \\
\text { previous recruitment into the trial. Informed written or witnessed oral consent was } \\
\text { obtained from the participant or relative } \\
\text { Setting: Emergency Department } \\
\text { Country: United Kingdom } \\
\text { Funding: National Institute for Health Research } \\
\text { Study dates: July } 2003 \text { to April } 2007 \\
\text { Conflict of interest: None }\end{array}$ \\
\hline \multirow[t]{2}{*}{ Participants } & $\begin{array}{l}1069 \text { participants, } 56.9 \% \text { female and mean age } 77.7 \pm 9.7 \text { years }(79 \pm 9 \text { years in SMC } \\
\text { group), pulmonary oedema shown by a chest radiograph, } \mathrm{RR}>20 \text {, and an arterial } \\
\text { hydrogen ion concentration of }>45 \text { nanomoles per litre }(\mathrm{pH}<7.35)\end{array}$ \\
\hline & $\begin{array}{l}\text { Exclusion criteria: requirement for emergency intervention, such as primary } \\
\text { percutaneous coronary intervention; inability to give consent; or previous recruitment } \\
\text { into the trial }\end{array}$ \\
\hline Interventions & $\begin{array}{l}\text { CPAP group }(\mathrm{N}=346) \text { : } \mathrm{PEEP}=10 \pm 4 \mathrm{~cm} \mathrm{H}_{2} \mathrm{O} \text {. Time }=2.2 \pm 1.5 \text { hours. CPAP was } \\
\text { delivered using a face mask } \\
\text { Bilevel NPPV group }(\mathrm{N}=356) \text { : EPAP }=7 \pm 3 \mathrm{~cm} \mathrm{H} \mathrm{H}_{2} \mathrm{O} \text { and IPAP }=14 \pm 5 \mathrm{~cm} \mathrm{H} \mathrm{H}_{2} \mathrm{O} \text {. } \\
\text { Time }=2.0 \pm 1.3 \text { hours. Bilevel NPPV was delivered using a face mask } \\
\text { Control group }(\mathrm{N}=367) \text { : SMC and } \mathrm{O}_{2} \text { mask with a reservoir } \\
\text { Co-intervention: nitrates, diuretics and opioids }\end{array}$ \\
\hline Outcomes & $\begin{array}{l}\text { 1. Primary outcome: 7-day mortality } \\
\text { 2. Primary outcome: } 7 \text {-day tracheal intubation rate } \\
\text { 3. 30-day mortality } \\
\text { 4. Arterial blood gases }\left(\mathrm{PaO}_{2}, \mathrm{PaCO}_{2}, \mathrm{pH}\right) \\
\text { 5. Vital signs (RR, } \mathrm{BP}, \mathrm{HR}) \\
\text { 6. Incidence of acute myocardial infarction } \\
\text { 7. Compliance of participants with NPPV } \\
\text { 3. Side effects and complications } \\
\text { 9. Length of hospital stay }\end{array}$ \\
\hline Notes & $\begin{array}{l}\text { Note: additional data were obtained from the authors through a personal } \\
\text { communication on the following dates: } 3 \text { April 2018, } 24 \text { September 2018, } 11 \text { October } \\
2018\end{array}$ \\
\hline
\end{tabular}

Risk of bias table 
0416 Non-invasive positive pressure ventilation (CPAP or bilevel NPPV) for cardiogenic pulmonary oedema

\begin{tabular}{|c|c|c|}
\hline Bias & $\begin{array}{l}\text { Authors' } \\
\text { judgement }\end{array}$ & Support for judgement \\
\hline $\begin{array}{l}\text { Random sequence generation } \\
\text { (selection bias) }\end{array}$ & Low risk & $\begin{array}{l}\text { Randomisation sequence was generated by an independent } \\
\text { statistician }\end{array}$ \\
\hline $\begin{array}{l}\text { Allocation concealment (selection } \\
\text { bias) }\end{array}$ & Low risk & 24-hour telephone randomisation service \\
\hline $\begin{array}{l}\text { Blinding of participants and } \\
\text { personnel (performance bias) }\end{array}$ & High risk & Open study \\
\hline $\begin{array}{l}\text { Blinding of outcome assessment } \\
\text { (detection bias) }\end{array}$ & High risk & Open study \\
\hline $\begin{array}{l}\text { Incomplete outcome data (attrition } \\
\text { bias) }\end{array}$ & Low risk & All enrolled participants were accounted for \\
\hline Selective reporting (reporting bias) & Low risk & $\begin{array}{l}\text { Prospectively registered with ISRCTN: ISRCTN07448447. All of the } \\
\text { prespecified outcomes have been reported adequately }\end{array}$ \\
\hline Other bias & Low risk & The study appears to be free of other sources of bias \\
\hline
\end{tabular}

\section{HaO 2002}

\begin{tabular}{|c|c|}
\hline Methods & $\begin{array}{l}\text { Single-centre, parallel-group RCT. No details reported on ITT analysis, loss to follow- } \\
\text { up, or informed consent } \\
\text { Setting: not reported } \\
\text { Country: China } \\
\text { Funding: not reported } \\
\text { Study dates: January } 1991 \text { to December } 1995 \\
\text { Conflict of interest: not reported }\end{array}$ \\
\hline Participants & $\begin{array}{l}51 \text { participants. Mean age } 68 \pm 6 \text { (CPAP arm } 68 \pm 7 \text {, control arm } 67 \pm 5 \text { ) } \\
\text { Inclusion criteria: ACPE defined by: 1) clinical signs of severe dyspnoea such as } \\
\text { tripoding, intercostal muscle use, and sternal notch retraction; } 2 \text { ) RR }>25 / \text { min; } 3 \text { ) } \\
\mathrm{PaO}_{2}<8.0 \mathrm{kPa} \text { on room air } \\
\text { Exclusion criteria: } 1 \text { ) Change in level of consciousness; 2) Excessive airway } \\
\text { secretions that cause airway obstruction; } 3 \text { ) COPD; } 4 \text { ) Severe shock, valvular } \\
\text { stenosis, cardiopulmonary arrest; 5) Severe pulmonary infection }\end{array}$ \\
\hline Interventions & $\begin{array}{l}\text { CPAP group ( } \mathrm{N}=25) \text { : nasal mask with ventilator (Siemens } 900 \mathrm{c} \text { ventilator). CPAP } \\
\text { settings were } 6 \text { to } 10 \mathrm{~cm} \mathrm{H} \mathrm{H}_{2} \mathrm{O}, \mathrm{FiO}_{2} 45 \% \\
\text { Control group ( } \mathrm{N}=26) \text { : oxygen delivered by nasal prongs } \\
\text { Co-intervention: IV diuretics ( } 20-40 \mathrm{mg} \text { ), morphine } 2 \mathrm{mg} \text {, buccal nitroglycerin } 0.5 \mathrm{mg} \\
\text { or IV } 1 \mathrm{mg}(0.2-0.4 \mathrm{mg} \text { if no angina) }\end{array}$ \\
\hline Outcomes & $\begin{array}{l}\text { 1. Treatment effectiveness rate (mix of dyspnoea, tripoding, intercostal muscle use, } \\
\text { and resolution of sternal notch retraction, resolution of pulmonary adventitious } \\
\text { sounds) } \\
\text { 2. Vital signs ( } \mathrm{HR}, \mathrm{BP}, \mathrm{RR}) \\
\text { 3. Arterial blood gas }\left(\mathrm{pH}, \mathrm{PaO}_{2}, \mathrm{PaCO}_{2}\right) \text { monitored pre-treatment and after } 30 \\
\text { minutes of therapy } \\
\text { 4. Intubation rate }\end{array}$ \\
\hline lotes & \\
\hline
\end{tabular}

Risk of bias table 
0416 Non-invasive positive pressure ventilation (CPAP or bilevel NPPV) for cardiogenic pulmonary oedema

\begin{tabular}{|l|l|l|}
\hline Bias & $\begin{array}{l}\text { Authors' } \\
\text { iudgement }\end{array}$ & Support for judgement \\
\hline $\begin{array}{l}\text { Random sequence generation } \\
\text { (selection bias) }\end{array}$ & Unclear risk & No details provided \\
\hline $\begin{array}{l}\text { Allocation concealment (selection } \\
\text { bias) }\end{array}$ & Unclear risk & No details provided \\
\hline $\begin{array}{l}\text { Blinding of participants and } \\
\text { personnel (performance bias) }\end{array}$ & Unclear risk & No details provided \\
\hline $\begin{array}{l}\text { Blinding of outcome assessment } \\
\text { (detection bias) }\end{array}$ & Unclear risk & No details provided \\
\hline $\begin{array}{l}\text { Incomplete outcome data (attrition } \\
\text { bias) }\end{array}$ & Unclear risk & No details provided \\
\hline Selective reporting (reporting bias) & Unclear risk & No details provided \\
\hline Other bias & High risk & $\begin{array}{l}\text { This study provides insufficient detail to evaluate the type of patients } \\
\text { included, therapy provided, and efficacy of the therapy provided }\end{array}$ \\
\hline
\end{tabular}

\section{Kelly 2002}

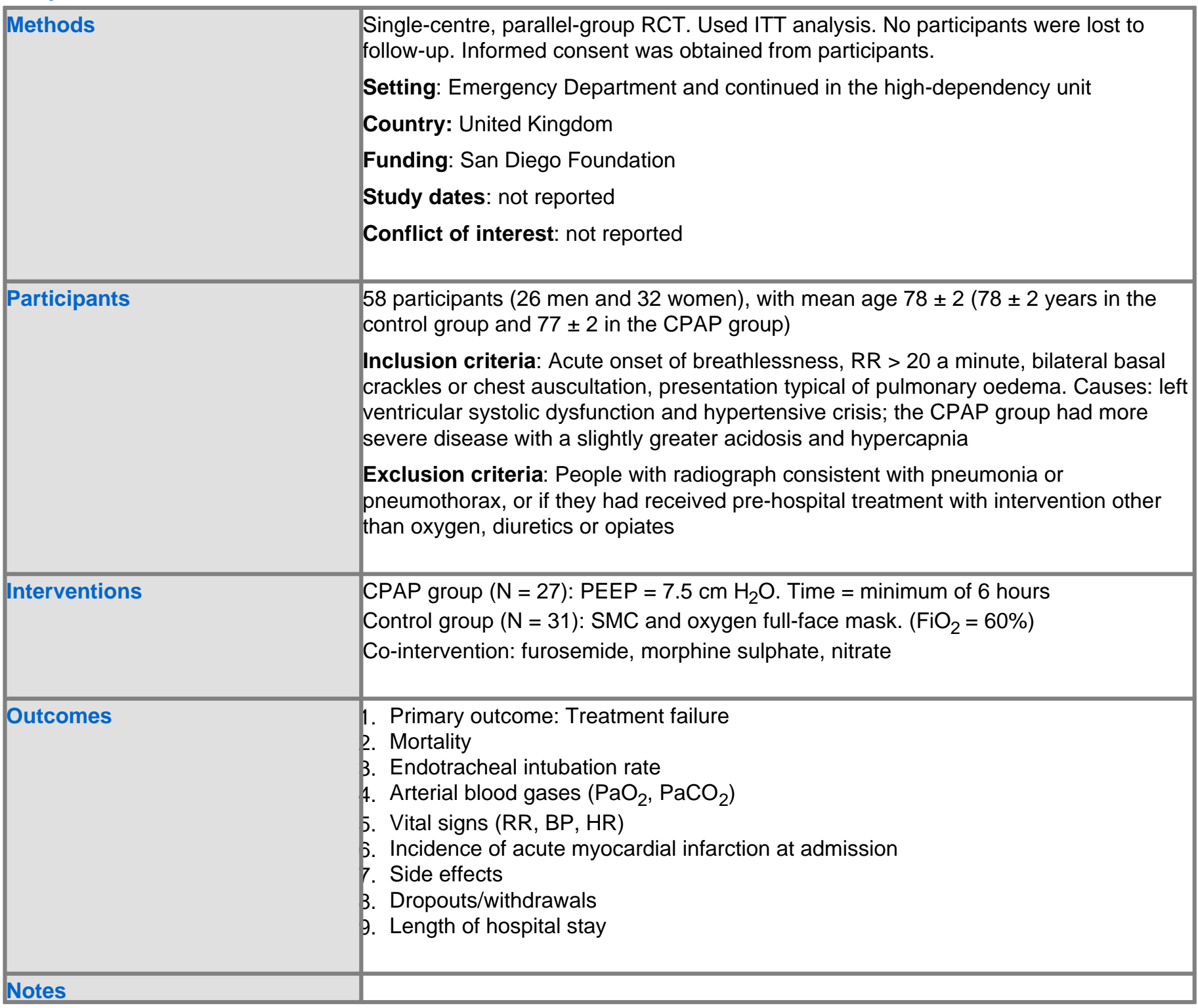

Risk of bias table 
0416 Non-invasive positive pressure ventilation (CPAP or bilevel NPPV) for cardiogenic pulmonary oedema

\begin{tabular}{|c|c|c|}
\hline Bias & $\begin{array}{l}\text { Authors' } \\
\text { judgement }\end{array}$ & Support for judgement \\
\hline $\begin{array}{l}\text { Random sequence generation } \\
\text { (selection bias) }\end{array}$ & Unclear risk & Randomisation sequence generation was not reported \\
\hline $\begin{array}{l}\text { Allocation concealment (selection } \\
\text { bias) }\end{array}$ & Unclear risk & Sealed envelopes \\
\hline $\begin{array}{l}\text { Blinding of participants and } \\
\text { personnel (performance bias) }\end{array}$ & Unclear risk & Not described \\
\hline $\begin{array}{l}\text { Blinding of outcome assessment } \\
\text { (detection bias) }\end{array}$ & Unclear risk & Not described \\
\hline $\begin{array}{l}\text { Incomplete outcome data (attrition } \\
\text { bias) }\end{array}$ & Low risk & All enrolled participants were accounted for \\
\hline Selective reporting (reporting bias) & Unclear risk & $\begin{array}{l}\text { Trial protocol was not prospectively registered. Unclear if all expected } \\
\text { outcomes are reported }\end{array}$ \\
\hline Other bias & Unclear risk & $\begin{array}{l}\text { Insufficient information to assess whether an important risk of bias } \\
\text { exists. No power calculation to explain the sample size used for the } \\
\text { trial }\end{array}$ \\
\hline
\end{tabular}

\section{L'Her 2004}


0416 Non-invasive positive pressure ventilation (CPAP or bilevel NPPV) for cardiogenic pulmonary oedema

\begin{tabular}{|c|c|}
\hline \multirow[t]{6}{*}{ Methods } & $\begin{array}{l}\text { Multicentre, parallel-group, unblinded RCT conducted in } 3 \text { teaching hospitals. Analsyis } \\
\text { completed using ITT approach. No participants were lost to follow-up. Participants or } \\
\text { their next of kin provided informed consent }\end{array}$ \\
\hline & Setting: Emergency Department \\
\hline & Country: France \\
\hline & $\begin{array}{l}\text { Funding: Technical support (material and ventilatory circuits) was provided by } \\
\text { Allegiance SA (Paris, France) }\end{array}$ \\
\hline & Study dates: not reported \\
\hline & Conflict of interest: not reported \\
\hline \multirow[t]{3}{*}{ Participants } & $\begin{array}{l}89 \text { participants ( } 37 \text { men and } 52 \text { women), with mean age } 84 \pm 6 \text { ( } 84 \pm 6 \text { years in both } \\
\text { SMC and CPAP groups) }\end{array}$ \\
\hline & $\begin{array}{l}\text { Inclusion criteria: Age similar or }>75 \text { years, acute hypoxaemic respiratory } \\
\text { failure }\left(\mathrm{PaO}_{2} / \mathrm{FiO}_{2}<300 \text { despite } \mathrm{O}_{2}>8 \mathrm{~L} \text { a minute for } 15 \text { minutes }\right), \mathrm{RR}>25 \text {, } \\
\text { contraction of accessory muscles, clinical examination: systolic and/or diastolic } \\
\text { hypertension, widespread crackles or wheezing; medical record: previous } \\
\text { cardiomyopathy, and/or acute dyspnoea with progressive orthopnoea; } \\
\text { electrocardiographic tracing }(\mathrm{Q} \text { waves and/or abnormalities in the T wave and ST } \\
\text { segment; left ventricular hypertrophy, bundle branch block, atrial fibrillation); and chest } \\
\text { radiography (cardiac enlargement with a cardiothoracic ratio }>50 \% \text {, and/or pulmonary } \\
\text { congestion with Kerley B lines, alveolar filing, pleural effusions) compatible with a } \\
\text { diagnosis of cardiogenic pulmonary oedema. Causes: tachyarrhythmia, acute IHD, } \\
\text { hypertensive crises, respiratory tract infection, undiagnosed }\end{array}$ \\
\hline & $\begin{array}{l}\text { Exclusion criteria: GCS ? } 7, \mathrm{SpO}_{2} ? 85 \% \text { despite oxygen, haemodynamic instability, } \\
\text { chronic respiratory insufficiency }\end{array}$ \\
\hline Interventions & $\begin{array}{l}\text { CPAP group }(\mathrm{N}=43) \text { : } \mathrm{PEEP}=7.5 \mathrm{~cm} \mathrm{H}_{2} \mathrm{O} \text {. Time }=8 \pm 6 \text { hours } \\
\text { Control group }(\mathrm{N}=46) \text { : } \mathrm{SMC} \text { with oxygen facemask } \\
\text { Co-intervention: furosemide, nitroglycerin, glyceryl-trinitrate, morphine, isosorbide } \\
\text { dinitrate }\end{array}$ \\
\hline Outcomes & $\begin{array}{l}\text { 1. Primary outcome: } 48 \text {-hour mortality } \\
\text { 2. Endotracheal intubation rate } \\
\text { 3. Arterial blood gases }\left(\mathrm{PaCO}_{2}, \mathrm{pH}\right) \\
\text { 4. Vital signs (RR, } \mathrm{BP}, \mathrm{HR}) \\
\text { 5. Treatment failure } \\
\text { 5. Side effects } \\
\text { 7. Droupouts/withdrawals } \\
\text { 3. Length of hospital stay } \\
\text { 9. Compliance of participant }\end{array}$ \\
\hline Notes & \\
\hline
\end{tabular}

Risk of bias table 
0416 Non-invasive positive pressure ventilation (CPAP or bilevel NPPV) for cardiogenic pulmonary oedema

\begin{tabular}{|c|c|c|}
\hline Bias & $\begin{array}{l}\text { Authors' } \\
\text { judgement }\end{array}$ & Support for judgement \\
\hline $\begin{array}{l}\text { Random sequence generation } \\
\text { (selection bias) }\end{array}$ & Low risk & $\begin{array}{l}\text { The randomisation protocol was computer-generated and equalised } \\
\text { in groups of } 10 \text { participants }\end{array}$ \\
\hline $\begin{array}{l}\text { Allocation concealment (selection } \\
\text { bias) }\end{array}$ & Low risk & Assigned using a phone call to a randomisation centre \\
\hline $\begin{array}{l}\text { Blinding of participants and } \\
\text { personnel (performance bias) }\end{array}$ & High risk & Not possible \\
\hline $\begin{array}{l}\text { Blinding of outcome assessment } \\
\text { (detection bias) }\end{array}$ & High risk & Not possible \\
\hline $\begin{array}{l}\text { Incomplete outcome data (attrition } \\
\text { bias) }\end{array}$ & Low risk & No missing outcome data \\
\hline Selective reporting (reporting bias) & Unclear risk & $\begin{array}{l}\text { Trial protocol was not prospectively registered. Unclear if all } \\
\text { prespecified outcomes are reported }\end{array}$ \\
\hline Other bias & High risk & $\begin{array}{l}\text { Early termination after performing an interim analysis (not pre- } \\
\text { specified) and detecting improved survival with CPAP. }\end{array}$ \\
\hline
\end{tabular}

\section{Levitt 2001}

\begin{tabular}{|c|c|}
\hline \multirow[t]{6}{*}{ Methods } & $\begin{array}{l}\text { Single-centre, parallel-group, RCT. No ITT analysis. } 4 \text { participants were lost to follow- } \\
\text { up. Informed consent was obtained from the participants. }\end{array}$ \\
\hline & Setting: Emergency Department \\
\hline & Country: USA \\
\hline & Funding: not reported \\
\hline & Study dates: December 1995 to June 1997 \\
\hline & Conflict of interest: not reported \\
\hline \multirow[t]{2}{*}{ Participants } & $\begin{array}{l}38 \text { participants. } 42 \text { people were randomised, but } 4 \text { did not meet inclusion criteria } \\
\text { following randomisation. Therefore, at study entry } 38 \text { participants ( } 13 \text { men and } 25 \\
\text { women), with mean age } 67.9 \pm 14.8 \text { ( } 68.5 \pm 15 \text { years in SMC group and } 67.4 \pm 15 \text { in } \\
\text { bilevel group) }\end{array}$ \\
\hline & $\begin{array}{l}\text { Inclusion criteria: Tachypnoea, } \mathrm{RR}>30 \text { breaths a minute, diaphoresis or accessory } \\
\text { muscle use, pulmonary rales, distended neck veins, peripheral oedema, history of } \\
\text { congestive heart failure and radiographic findings of pulmonary oedema. Causes: } \\
\text { acute congestive heart failure. Exclusion criteria: People with a radiograph not } \\
\text { consistent with congestive heart failure or required immediate intubation }\end{array}$ \\
\hline Interventions & $\begin{array}{l}\text { Bilevel group ( } \mathrm{N}=21 \text { ): started with EPAP of } 3 \mathrm{~cm} \mathrm{H}_{2} \mathrm{O} \text { and IPAP of } 8 \mathrm{~cm} \mathrm{H}_{2} \mathrm{O} \text {. } \\
\text { These pressures could be adjusted in } 2 \mathrm{~cm} \mathrm{H}_{2} \mathrm{O} \text { increments. Time }=2 \text { hours. Bilevel } \\
\mathrm{NPPV} \text { was mostly delivered by facemask, but switching to nasal mask was permitted } \\
\text { for participant comfort } \\
\text { Control group }(\mathrm{N}=17) \text { : } \mathrm{SMC} \text { and oxygen nasal or facemask } \\
\text { Co-intervention: morphine, furosemide, nitroglycerin }\end{array}$ \\
\hline Outcomes & $\begin{array}{l}\text { 1. Primary outcome: endotracheal intubation rate } \\
\text { 2. Mortality } \\
\text { 3. Treatment failure } \\
\text { t. Incidence of acute myocardial infarction (follow-up) } \\
\text { b. Length of hospital stay } \\
\text { b. Vital signs (RR, } \mathrm{BP}, \mathrm{HR}) \\
\text { - Pulse oximetry } \\
\text { 3. Arterial blood gases }\left(\mathrm{PaCO}_{2}, \mathrm{pH}\right)\end{array}$ \\
\hline Notes & \\
\hline
\end{tabular}


0416 Non-invasive positive pressure ventilation (CPAP or bilevel NPPV) for cardiogenic pulmonary oedema

Risk of bias table

\begin{tabular}{|l|l|l|}
\hline Bias & $\begin{array}{l}\text { Authors' } \\
\text { judgement }\end{array}$ & Support for judgement \\
\hline $\begin{array}{l}\text { Random sequence generation } \\
\text { (selection bias) }\end{array}$ & Low risk & Randomised from a previously computer-generated list \\
\hline $\begin{array}{l}\text { Allocation concealment (selection } \\
\text { bias) }\end{array}$ & Unclear risk & Details not provided \\
\hline $\begin{array}{l}\text { Blinding of participants and } \\
\text { personnel (performance bias) }\end{array}$ & Unclear risk & Details not provided \\
\hline $\begin{array}{l}\text { Blinding of outcome assessment } \\
\text { (detection bias) }\end{array}$ & Unclear risk & Details not provided \\
\hline $\begin{array}{l}\text { Incomplete outcome data (attrition } \\
\text { bias) }\end{array}$ & Unclear risk & Insufficient information provided \\
\hline Selective reporting (reporting bias) & Unclear risk & $\begin{array}{l}\text { Trial protocol was not prospectively registered. Unclear if all expected } \\
\text { outcomes were reported }\end{array}$ \\
\hline Other bias & High risk & $\begin{array}{l}\text { Early termination after author became aware of study by Mehta et al. } \\
\text { and wanted to present preliminary findings: no increased rate in acute } \\
\text { myocardial infarction rates. }\end{array}$ \\
\hline
\end{tabular}

\section{Li 2005}

\begin{tabular}{|c|c|}
\hline Methods & $\begin{array}{l}\text { Single-entre, parallel-group RCT. No details reported about ITT analysis, study } \\
\text { location, loss to follow-up, or informed consent } \\
\text { Setting: not reported } \\
\text { Country: China } \\
\text { Funding: not reported } \\
\text { Study dates: January } 2001 \text { to October } 2004 \\
\text { Conflict of interest: not reported }\end{array}$ \\
\hline Participants & $\begin{array}{l}42 \text { participants. Mean age } 71.7 \text { (range } 60 \text { - } 82 \text { ) in the NPPV arm; and mean age was } \\
69.9 \text { (range } 60 \text { - 82) in the control therapy arm } \\
\text { Inclusion criteria: acute cardiogenic pulmonary oedema. Exclusion criteria: not } \\
\text { provided. }\end{array}$ \\
\hline Interventions & $\begin{array}{l}\text { CPAP group ( } \mathrm{N}=22 \text { ): ventilator (Servo } 300 \mathrm{~A} \text { or NPB } 7200 \mathrm{~A} \text { ) in PSV and PEEP } \\
\text { ventilation mode. PSV at } 10 \mathrm{~cm} \mathrm{H}_{2} \mathrm{O} \text { and gradually increased to } 15-18 \mathrm{~cm} \mathrm{H}_{2} \mathrm{O} \\
\text { within } 15 \text { minutes. PEEP was started at } 2 \text { to } 3 \mathrm{~cm} \mathrm{H} \mathrm{H}_{2} \mathrm{O} \text {, then gradually increased to } \\
\text { between } 5 \text { and } 8 \mathrm{~cm} \mathrm{H}_{2} \mathrm{O} \text {. } \mathrm{FiO}_{2} \text { was } 60 \% \\
\text { Control group: Oxygen delivered by mask } \\
\text { Co-intervention: vasodilators, diuretics, cardiotonic, and sedative }\end{array}$ \\
\hline Outcomes & $\begin{array}{l}\text { 1. Treatment efficacy (dyspnoea, difficulty breathing, lip cyanosis, adventitious sound } \\
\text { reduction, or pinky frothy sputum reduction) } \\
\text { 2. Arterial blood gas indicators }\left(\mathrm{pH}, \mathrm{PaO}_{2}, \mathrm{PaCO}_{2}\right) \text { monitored pre-treatment, } 2 \text { hours } \\
\text { post-treatment, and } 24 \text { hours post-treatment } \\
\text { 3. Vital signs: HR and RR }\end{array}$ \\
\hline Notes & \\
\hline
\end{tabular}

Risk of bias table 
0416 Non-invasive positive pressure ventilation (CPAP or bilevel NPPV) for cardiogenic pulmonary oedema

\begin{tabular}{|l|l|l|}
\hline Bias & $\begin{array}{l}\text { Author' } \\
\text { judgement }\end{array}$ & Support for judgement \\
\hline $\begin{array}{l}\text { Random sequence generation } \\
\text { (selection bias) }\end{array}$ & Unclear risk & No details provided \\
\hline $\begin{array}{l}\text { Allocation concealment (selection } \\
\text { bias) }\end{array}$ & Unclear risk & No details provided \\
\hline $\begin{array}{l}\text { Blinding of participants and } \\
\text { personnel (performance bias) }\end{array}$ & Unclear risk & No details provided \\
\hline $\begin{array}{l}\text { Blinding of outcome assessment } \\
\text { (detection bias) }\end{array}$ & Unclear risk & No details provided \\
\hline $\begin{array}{l}\text { Incomplete outcome data (attrition } \\
\text { bias) }\end{array}$ & Unclear risk & No details provided \\
\hline Selective reporting (reporting bias) & Unclear risk & No details provided \\
\hline Other bias & High risk & $\begin{array}{l}\text { This study provides insufficient detail to evaluate the type of } \\
\text { participants included, therapy provided, and efficacy of therapy } \\
\text { provided }\end{array}$ \\
\hline
\end{tabular}

\section{Lin 1991}


0416 Non-invasive positive pressure ventilation (CPAP or bilevel NPPV) for cardiogenic pulmonary oedema

\begin{tabular}{|c|c|}
\hline Methods & $\begin{array}{l}\text { Single-centre, parallel-design, unblinded RCT. There was no ITT analysis of results. } \\
15 \text { participants in the CPAP group and } 10 \text { in the oxygen group were lost to follow-up. } \\
\text { Informed consent was obtained } \\
\text { Setting: ICU; Wash-out of } 30 \text { minutes } \\
\text { Country: Taiwan } \\
\text { Funding: not reported } \\
\text { Study dates: January } 1,1985 \text { to January } 31,1987 \\
\text { Conflict of interest: not reported }\end{array}$ \\
\hline \multirow[t]{4}{*}{ Participants } & $\begin{array}{l}55 \text { participants. } 80 \text { people were randomised, but } 25 \text { did not meet inclusion criteria } \\
\text { following randomisation. Therefore, at study entry } 55 \text { participants ( } 50 \text { men and } 5 \\
\text { women), with mean age } 73.8 \pm 8.5 \text { ( } 74.1 \pm 8.8 \text { years in SMC group and } 73.4 \pm 8.2 \text { in } \\
\text { CPAP group) }\end{array}$ \\
\hline & $\begin{array}{l}\text { Inclusion criteria: Radiologic evidence of acute interstitial or alveolar oedema } \\
\text { of cardiac origin, tachypnoea, } \mathrm{RR}>22 \text { a minute, intercostal or suprasternal } \\
\text { retractions, } \mathrm{PaO}_{2} / \mathrm{FiO}_{2}>200, \mathrm{P}(\mathrm{A}-\mathrm{a}) \mathrm{O}_{2}>200\end{array}$ \\
\hline & $\begin{array}{l}\text { Causes: congestive heart failure, dilated cardiomyopathy, Ischaemic heart disease, } \\
\text { hypertensive cardiovascular disease, acute myocardial infarction }\end{array}$ \\
\hline & $\begin{array}{l}\text { Exclusion criteria: People unresponsive to speech or unable to maintain a patent } \\
\text { airway and who had cardiogenic shock, signs of lung infection, evidence of pulmonary } \\
\text { embolism, chronic lung disease with carbon dioxide retention at rest }\end{array}$ \\
\hline Interventions & 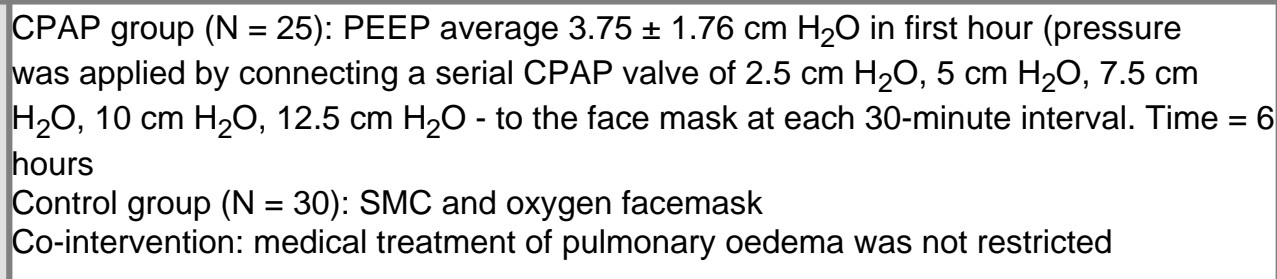 \\
\hline Outcomes & $\begin{array}{l}\text { 1. Primary outcome: endotracheal intubation rate } \\
\text { 2. Mortality } \\
\text { 3. Arterial blood gases }\left(\mathrm{PaO}_{2}, \mathrm{PaCO}_{2}, \mathrm{pH}\right) \\
\text { 4. Vital signs (RR, } \mathrm{BP}, \mathrm{HR}) \\
\text { b. Dropouts/withdrawals } \\
\text { b. Treatment failure }\end{array}$ \\
\hline Notes & \\
\hline
\end{tabular}

Risk of bias table 
0416 Non-invasive positive pressure ventilation (CPAP or bilevel NPPV) for cardiogenic pulmonary oedema

\begin{tabular}{|l|l|l|}
\hline Bias & $\begin{array}{l}\text { Authors' } \\
\text { judgement }\end{array}$ & Support for judgement \\
\hline $\begin{array}{l}\text { Random sequence generation } \\
\text { (selection bias) }\end{array}$ & Unclear risk & The method used was not reported \\
\hline $\begin{array}{l}\text { Allocation concealment (selection } \\
\text { bias) }\end{array}$ & Unclear risk & The method used was not reported \\
\hline $\begin{array}{l}\text { Blinding of participants and } \\
\text { personnel (performance bias) }\end{array}$ & High risk & Not possible \\
\hline $\begin{array}{l}\text { Blinding of outcome assessment } \\
\text { (detection bias) }\end{array}$ & Unclear risk & Not described \\
\hline $\begin{array}{l}\text { Incomplete outcome data (attrition } \\
\text { bias) }\end{array}$ & High risk & $\begin{array}{l}\text { Proportion of missing outcome data, only } 20 \text { participants from each } \\
\text { group of } 40 \text { completed the protocol, compared to the observed event risk } \\
\text { is enough to induce clinically relevant bias in the intervention effect } \\
\text { estimate. Did not adhere to ITT principle, used as-treated analysis }\end{array}$ \\
\hline Selective reporting (reporting bias) & Unclear risk & $\begin{array}{l}\text { Trial protocol was not prospectively registered. Unclear if all expected } \\
\text { outcomes were reported }\end{array}$ \\
\hline Other bias & Unclear risk & $\begin{array}{l}\text { Insufficient information to assess whether an important risk of bias } \\
\text { exists. No power calculation to explain the sample size used for the trial }\end{array}$ \\
\hline
\end{tabular}

Lin 1995 
0416 Non-invasive positive pressure ventilation (CPAP or bilevel NPPV) for cardiogenic pulmonary oedema

\begin{tabular}{|c|c|}
\hline Methods & $\begin{array}{l}\text { Single-centre, parallel-design, unblinded RCT. Analysed using an ITT approach. No } \\
\text { losses to follow-up were reported. Informed consent not reported. } 85 \% \text { of participants } \\
\text { were recruited from the ED and } 15 \% \text { were recruited from a hospital ward. After } \\
\text { recruitment there was a } 30 \text {-minute wash-out } \\
\text { Setting: CCU } \\
\text { Country: Taiwan } \\
\text { Funding: not reported } \\
\text { Study dates: January } 1,1986 \text { to December } 31,1992 \\
\text { Conflict of interest: not reported }\end{array}$ \\
\hline \multirow[t]{4}{*}{ Participants } & $\begin{array}{l}100 \text { participants ( } 90 \text { men and } 10 \text { women), with mean age } 73 \pm 9 \text { (73 } \pm 9 \text { in SMC group } \\
\text { and } 72 \pm 8 \text { in CPAP group) }\end{array}$ \\
\hline & $\begin{array}{l}\text { Inclusion criteria: dyspnoea and tachypnoea, } \mathrm{RR}>22 \text { breaths a minute, use of } \\
\text { accessory respiratory muscles, } \mathrm{PaO}_{2} / \mathrm{FiO}_{2} \text { between } 200 \text { and } 400, \mathrm{P}(\mathrm{A}-\mathrm{a}) \mathrm{O}_{2}<250 \text {. } \\
\text { Chest } x \text {-ray bilateral diffuse interstitial or alveolar oedema and most rales, and without } \\
\text { history aspiration or infection }\end{array}$ \\
\hline & $\begin{array}{l}\text { Causes: congestive heart failure, dilated cardiomyopathy, ischaemic heart disease, } \\
\text { hypertensive crisis, acute myocardial infarction }\end{array}$ \\
\hline & $\begin{array}{l}\text { Exclusion criteria: People unresponsive, unable to maintain a patent airway and who } \\
\text { had cardiogenic shock, ventricular septal rupture, any severe stenotic valvular disease } \\
\text { or chronic lung disease }\end{array}$ \\
\hline Interventions & 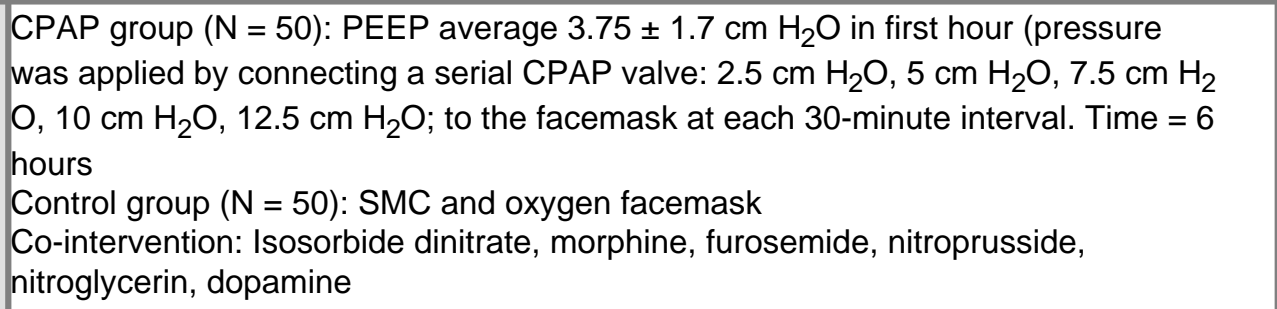 \\
\hline Outcomes & $\begin{array}{l}\text { 1. Primary outcome: mortality } \\
\text { 2. Endotracheal intubation rate } \\
\text { 3. Arterial blood gases }\left(\mathrm{PaO}_{2}, \mathrm{PCO}_{2}, \mathrm{pH}\right) \\
\text { 4. Vital signs (RR, BP, } \mathrm{HR}) \\
\text { 5. Dropouts or withdrawals } \\
\text { j. Length of hospital stay } \\
\text { 7. Length of ICU stay } \\
\text { 3. Treatment failure }\end{array}$ \\
\hline Notes & \\
\hline
\end{tabular}

Risk of bias table 
0416 Non-invasive positive pressure ventilation (CPAP or bilevel NPPV) for cardiogenic pulmonary oedema

\begin{tabular}{|l|l|l|}
\hline Bias & $\begin{array}{l}\text { Authors' } \\
\text { iudgement }\end{array}$ & Support for judgement \\
\hline $\begin{array}{l}\text { Random sequence generation } \\
\text { (selection bias) }\end{array}$ & Unclear risk & Details are not provided \\
\hline $\begin{array}{l}\text { Allocation concealment (selection } \\
\text { bias) }\end{array}$ & Unclear risk & Details are not provided \\
\hline $\begin{array}{l}\text { Blinding of participants and } \\
\text { personnel (performance bias) }\end{array}$ & High risk & Not possible \\
\hline $\begin{array}{l}\text { Blinding of outcome assessment } \\
\text { (detection bias) }\end{array}$ & Unclear risk & Not described \\
\hline $\begin{array}{l}\text { Incomplete outcome data (attrition } \\
\text { bias) }\end{array}$ & Low risk & No missing outcome data \\
\hline Selective reporting (reporting bias) & Unclear risk & $\begin{array}{l}\text { Trial protocol was not prospectively registered. Unclear if all expected } \\
\text { outcomes were reported }\end{array}$ \\
\hline Other bias & & $\begin{array}{l}\text { Insufficient information to assess whether an important risk of bias } \\
\text { exists. No power calculation to explain the sample size used for the } \\
\text { trial }\end{array}$ \\
\hline
\end{tabular}

Masip 2000 
0416 Non-invasive positive pressure ventilation (CPAP or bilevel NPPV) for cardiogenic pulmonary oedema

\begin{tabular}{|c|c|}
\hline \multirow[t]{6}{*}{ Methods } & $\begin{array}{l}\text { Single-centre, unblinded RCT, using ITT analysis. Participants or next-of-kin provided } \\
\text { informed consent }\end{array}$ \\
\hline & Setting: Recruited from ED or ward and transferred to the ICU \\
\hline & Country: Barcelona, Spain \\
\hline & $\begin{array}{l}\text { Funding: Fondo de Investigación Sanitaria (FIS Grant 1996), Ministerio de Sanidad y } \\
\text { Consumo }\end{array}$ \\
\hline & Study dates: April 1996 to December 1998 \\
\hline & Conflict of interest: not reported \\
\hline \multirow[t]{4}{*}{ Participants } & $\begin{array}{l}37 \text { participants. } 40 \text { were randomised, but } 3 \text { were excluded from the analysis. At study } \\
\text { entry } 37 \text { participants ( } 19 \text { men and } 18 \text { women), with mean age } 76.9 \pm 8.7 \text { ( } 78.5 \pm 5 \text { in } \\
\text { the SMC group, } 75.3 \pm 11 \text { years in the bilevel group) }\end{array}$ \\
\hline & $\begin{array}{l}\text { Inclusion criteria: dyspnoea of sudden onset with physical findings consistent with } \\
\text { pulmonary oedema (widespread rales with or without 3rd heart sound) and typical } \\
\text { findings of congestion on a chest radiograph. History: heart failure, acute myocardial } \\
\text { infarction, hypertension, diabetes mellitus, COPD }\end{array}$ \\
\hline & $\begin{array}{l}\text { Causes: acute myocardial infarction, hypertensive crisis, hypervolaemia, unstable } \\
\text { angina, tachyarrhythmia, respiratory tract infection, treatment non-compliance }\end{array}$ \\
\hline & $\begin{array}{l}\text { Exclusion criteria: cardiogenic shock (systolic } \mathrm{BP}<90 \mathrm{mmHg} \text { ), severe acute or } \\
\text { chronic airflow obstruction without evidence of cardiogenic pulmonary oedema, severe } \\
\text { chronic renal failure, neurological impairment, acute myocardial infarction } \\
\text { necessitating thrombolysis, evidence of pneumonia, immediate need for intubation, } \\
\text { and absence of pulmonary oedema on the first chest radiograph }\end{array}$ \\
\hline Interventions & 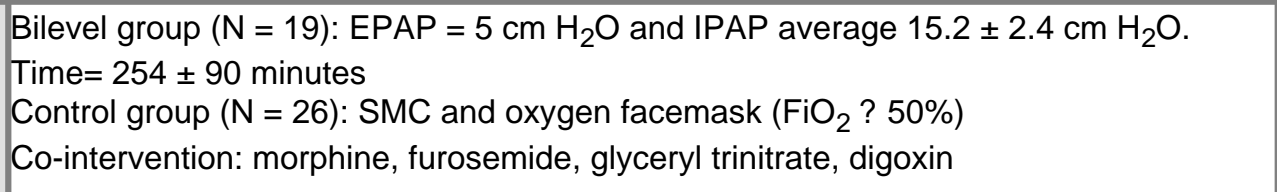 \\
\hline Outcomes & $\begin{array}{l}\text { 1. Primary outcome: endotracheal intubation rate } \\
\text { 2. Mortality } \\
\text { 3. Arterial blood gases }(\mathrm{pH}) \\
\text { 4. Vital signs (RR, BP, HR) } \\
\text { 3. Incidence of acute myocardial infarction (follow-up) } \\
\text { 3. Dropouts/withdrawals } \\
\text { 7. Side effects } \\
\text { 3. Length of hospital }\end{array}$ \\
\hline Notes & \\
\hline
\end{tabular}

Risk of bias table 
0416 Non-invasive positive pressure ventilation (CPAP or bilevel NPPV) for cardiogenic pulmonary oedema

\begin{tabular}{|l|l|l|}
\hline Bias & $\begin{array}{l}\text { Authors' } \\
\text { judgement }\end{array}$ & Support for judgement \\
\hline $\begin{array}{l}\text { Random sequence generation } \\
\text { (selection bias) }\end{array}$ & Low risk & $\begin{array}{l}\text { Randomisation sequence was generated by a table of random } \\
\text { numbers }\end{array}$ \\
\hline $\begin{array}{l}\text { Allocation concealment (selection } \\
\text { bias) }\end{array}$ & High risk & $\begin{array}{l}\text { Assignments were placed in closed envelopes attached to rounding } \\
\text { sheets }\end{array}$ \\
\hline $\begin{array}{l}\text { Blinding of participants and } \\
\text { personnel (performance bias) }\end{array}$ & High risk & Not blinded \\
\hline $\begin{array}{l}\text { Blinding of outcome assessment } \\
\text { (detection bias) }\end{array}$ & Unclear risk & Not described \\
\hline $\begin{array}{l}\text { Incomplete outcome data (attrition } \\
\text { bias) }\end{array}$ & Low risk & No missing outcome data \\
\hline Selective reporting (reporting bias) & Unclear risk & $\begin{array}{l}\text { Trial protocol was not prospectively registered. Unclear if all } \\
\text { expected outcomes were reported }\end{array}$ \\
\hline Other bias & Unclear risk & $\begin{array}{l}\text { Insufficient information to assess whether an important risk of bias } \\
\text { exists }\end{array}$ \\
\hline
\end{tabular}

\section{Moritz 2003}

\begin{tabular}{|c|c|}
\hline \multirow[t]{6}{*}{ Methods } & $\begin{array}{l}\text { Single-centre randomised controlled trial, parallel-design, and per protocol analysis. } \\
\text { Informed consent obtained in writing either from participant or relative. No participants } \\
\text { were lost to follow-up }\end{array}$ \\
\hline & Setting: Emergency Department \\
\hline & Country: France \\
\hline & Funding: Unclear \\
\hline & Study dates: August 2000 to February 2001 \\
\hline & Conflict of interest: not reported \\
\hline \multirow[t]{3}{*}{ Participants } & $\begin{array}{l}52 \text { consecutive patients with ACPE were considered for the study and } 30 \text { were } \\
\text { enrolled. Mean study age was } 81 \pm 11 \text {. ACPE defined as 1) past history of } \\
\text { cardiovascular disease, 2) auscultation with crepitations, 3) Chest } x \text {-ray consistent } \\
\text { with pulmonary oedema (bilateral alveolar and interstitial opacities) }\end{array}$ \\
\hline & $\begin{array}{l}\text { Inclusion eligibility: } \mathrm{ACPE} \text { and } \mathrm{RR}>25 \text { breaths a minute, pulse oximetry }<90 \% \text { on } \\
\text { room air. Intubation criteria: haemodynamic instability, cardiac or respiratory arrest, } \\
\text { refractory and progressive hypoxaemia }\left(\mathrm{SpO}_{2}<80 \% \text { on } \mathrm{FiO}_{2} 100 \%\right)\end{array}$ \\
\hline & $\begin{array}{l}\text { Exclusions: history suggesting pneumonia or aspiration, fever }>38^{\circ} \mathrm{C} \text {, cardiogenic } \\
\text { shock, altered mental status, COPD, acute myocardial infarction requiring primary } \\
\text { angioplasty. }\end{array}$ \\
\hline Interventions & $\begin{array}{l}\text { CPAP group }(\mathrm{N}=15) \text { : Boussignac-CPAP valve and oxygen with full facemask. } \\
\text { PEEP } 10 \mathrm{~cm} \mathrm{H}_{2} \mathrm{O} \text { with average } 9.3 \pm 0.3 \mathrm{~cm} \mathrm{H}_{2} \mathrm{O} \text {. } \mathrm{FiO}_{2} 65 \% \text {. Applied for } 30 \text { minutes } \\
\text { Control group }(\mathrm{N}=15) \text { : full facemask and oxygen } \\
\text { Co-intervention: furosemide } 40 \mathrm{mg} \text { IV or twice normal dose (mean dose } 115 \pm 6.5 \\
\text { mg), nitroglycerin infusion } 0.125 \text { to } 0.25 \mathrm{mcg} / \mathrm{kg} / \mathrm{min} \text { mean total furosemide dose } \\
\text { (mean dose } 18 \pm 2 \mathrm{mg} / \mathrm{min} \text { ) }\end{array}$ \\
\hline Outcomes & $\begin{array}{l}\text { 1. Tidal volume at baseline and } 30 \text { minutes } \\
\text { 2. Accessory muscle use }(\mathrm{Patrick} \text { s scale }) \\
\text { 3. Arterial blood gases }\left(\mathrm{PaO}_{2} / \mathrm{FiO}_{2}, \mathrm{PaCO}_{2}, \mathrm{pH}\right) \text { at baseline and } 30 \text { minutes } \\
\text { 4. Vitals }\left(\mathrm{FiO}_{2}, \mathrm{SpO}_{2}, \mathrm{RR}, \mathrm{HR} \text {, systolic } \mathrm{BP} \text {, diastolic } \mathrm{BP}\right) \text { at baseline and } 30 \text { minutes }\end{array}$ \\
\hline Notes & \\
\hline
\end{tabular}


0416 Non-invasive positive pressure ventilation (CPAP or bilevel NPPV) for cardiogenic pulmonary oedema

\begin{tabular}{|l|l|l|}
\hline $\begin{array}{l}\text { Bias } \\
\begin{array}{l}\text { Random sequence generation } \\
\text { (selection bias) }\end{array}\end{array}$ & Unclear risk & No details provided \\
\hline $\begin{array}{l}\text { Allocation concealment (selection } \\
\text { bias) }\end{array}$ & Unclear risk & Sealed envelopes \\
\hline $\begin{array}{l}\text { Blinding of participants and } \\
\text { personnel (performance bias) }\end{array}$ & Unclear risk & No details provided \\
\hline $\begin{array}{l}\text { Blinding of outcome assessment } \\
\text { (detection bias) }\end{array}$ & Unclear risk & No details provided \\
\hline $\begin{array}{l}\text { Incomplete outcome data (attrition } \\
\text { bias) }\end{array}$ & Unclear risk & No details provided \\
\hline Selective reporting (reporting bias) & Unclear risk & No details provided \\
\hline Other bias & Unclear risk & Per protocol analysis was used. Data only at 0 and 30 minutes \\
\hline
\end{tabular}

Nava 2003 
0416 Non-invasive positive pressure ventilation (CPAP or bilevel NPPV) for cardiogenic pulmonary oedema

\begin{tabular}{|c|c|}
\hline Methods & $\begin{array}{l}\text { Multicentre, parallel-group RCT analysed using ITT approach. Randomisation using a } \\
\text { block design for each centre. Balanced according to initial } \mathrm{PaCO}_{2} \text { above or below } 45 \\
\text { mmHg. No participants were lost to follow-up. Informed consent from participant or } \\
\text { next-of-kin } \\
\text { Setting: ED } \\
\text { Country: Italy } \\
\text { Funding: not reported } \\
\text { Study dates: not reported } \\
\text { Conflict of interest: None }\end{array}$ \\
\hline \multirow[t]{4}{*}{ Participants } & $\begin{array}{l}130 \text { participants (101 men and } 29 \text { women), with mean age } 72.6 \pm 8.7(73.1 \pm 8.3 \\
\text { years in the SMC group and } 72.1 \pm 9.1 \text { in the bilevel group) }\end{array}$ \\
\hline & $\begin{array}{l}\text { Inclusion criteria: Dyspnoea of sudden onset with } \mathrm{RR}>30 \text { breaths a minute, } \\
\mathrm{PaO}_{2} / \mathrm{FiO}_{2}<250 \text { after being on }>10 \mathrm{~L} \text { a minute oxygen for at least } 15 \text { minutes. } \\
\mathrm{Congestion} \text { on chest radiograph and physical signs of pulmonary oedema (widespread } \\
\text { rales) without a history suggesting pulmonary aspiration or infection }\end{array}$ \\
\hline & $\begin{array}{l}\text { Causes: Acute myocardial infarction, hypertension, hyperthermia (but not showing any } \\
\text { signs of pulmonary infection), arrhythmia, aortic stenosis, mitral regurgitation }\end{array}$ \\
\hline & $\begin{array}{l}\text { Exclusion criteria: Immediate need for endotracheal intubation, severe sensorial } \\
\text { impairment, shock, ventricular arrhythmias, life-threatening hypoxia }\left(\mathrm{SpO}_{2}<80 \%\right) \text {, } \\
\text { acute myocardial infarction necessitating thrombolysis, severe chronic renal failure } \\
\text { and pneumothorax }\end{array}$ \\
\hline Interventions & $\begin{array}{l}\text { Bilevel group ( } \mathrm{N}=65) \text { : Started on IPAP of } 10 \mathrm{~cm} \mathrm{H} \mathrm{H}_{2} \mathrm{O} \text { and EPAP of } 5 \mathrm{~cm} \mathrm{H} \mathrm{H}_{2} \mathrm{O} \text { and } \\
\text { adjusted as tolerated. Mean settings: EPAP } 6.1 \pm 3.2 \mathrm{cmH}_{2} \mathrm{O} \text { and IPAP }=14.5 \pm \\
21.1 \mathrm{~cm} \mathrm{H}_{2} \mathrm{O} \text {. Time }=11.4 \pm 3.6 \text { hours } \\
\text { Control group }\left(\mathrm{N}=65 \text { ): } \mathrm{SMC} \text { and oxygen full facemask (to maintain an } \mathrm{SpO}_{2}>90 \% \text { ) }\right. \\
\text { Co-intervention: morphine sulphate up to } 4 \mathrm{mg} \text {, furosemide } 40 \mathrm{mg} \text { IV or double home } \\
\text { dose repeated if necessary, glyceryl trinitrate at initial rate } 1.5 \mathrm{mg} \text { an hour and titrated } \\
\text { if systolic } \mathrm{BP}>180 \mathrm{mmHg}\end{array}$ \\
\hline Outcomes & $\begin{array}{l}\text { 1. Primary outcome: endotracheal intubation rate } \\
\text { 2. Mortality } \\
\text { 3. Arterial blood gases }\left(\mathrm{PaO}_{2}, \mathrm{PaCO}_{2}, \mathrm{pH}\right) \\
\text { 4. Vital signs (RR, } \mathrm{BP}, \mathrm{HR}) \\
\text { 5. Incidence of acute myocardial infarction (follow-up) } \\
\text { b. Compliance of participant } \\
\text { 7. Side effects } \\
\text { 3. Length of hospital stay }\end{array}$ \\
\hline Notes & \\
\hline
\end{tabular}

Risk of bias table 
0416 Non-invasive positive pressure ventilation (CPAP or bilevel NPPV) for cardiogenic pulmonary oedema

\begin{tabular}{|c|c|c|}
\hline Bias & $\begin{array}{l}\text { Authors' } \\
\text { judgement }\end{array}$ & Support for judgement \\
\hline $\begin{array}{l}\text { Random sequence generation } \\
\text { (selection bias) }\end{array}$ & Low risk & $\begin{array}{l}\text { Block design for each centre, random numbers generated by an } \\
\text { independent statistician, equal distribution below and above } \mathrm{PaCO}_{2}> \\
45\end{array}$ \\
\hline $\begin{array}{l}\text { Allocation concealment (selection } \\
\text { bias) }\end{array}$ & Low risk & Opaque sealed envelopes \\
\hline $\begin{array}{l}\text { Blinding of participants and } \\
\text { personnel (performance bias) }\end{array}$ & Unclear risk & Not described \\
\hline $\begin{array}{l}\text { Blinding of outcome assessment } \\
\text { (detection bias) }\end{array}$ & Unclear risk & Not described \\
\hline $\begin{array}{l}\text { Incomplete outcome data (attrition } \\
\text { bias) }\end{array}$ & Low risk & No missing outcome data \\
\hline Selective reporting (reporting bias) & Unclear risk & $\begin{array}{l}\text { Trial protocol was not prospectively registered. Unclear if all expected } \\
\text { outcomes were reported }\end{array}$ \\
\hline Other bias & Low risk & The study appears to be free of other sources of bias \\
\hline
\end{tabular}

\section{Park 2001}

\begin{tabular}{|c|c|}
\hline Methods & $\begin{array}{l}\text { Single-centre, parallel-design, unblinded RCT. Analysis did not use an ITT approach. } \\
\text { Loss to follow-up not reported. Participants or guardians provided informed consent } \\
\text { Setting: not reported } \\
\text { Country: Sao Paulo, Brazil } \\
\text { Funding: not reported } \\
\text { Study dates: May } 1997 \text { to October } 1997 \\
\text { Conflict of interest: not reported }\end{array}$ \\
\hline \multirow[t]{4}{*}{ Participants } & 26 participants ( 10 men and 16 women), with mean age $69 \pm 7$ years \\
\hline & $\begin{array}{l}\text { Inclusion criteria: Dyspnoea of acute onset or worsening, RR ? } 25 \text { breaths a minute, } \\
\text { diagnosis compatible with pulmonary congestion }\end{array}$ \\
\hline & $\begin{array}{l}\text { Causes: Acute myocardial infarction, hypertensive emergencies, acute ischaemic } \\
\text { heart disease, infectious endocarditis or undetermined }\end{array}$ \\
\hline & $\begin{array}{l}\text { Exclusion criteria: Systolic BP }<90 \mathrm{mmHg} \text {, arrhythmias requiring electric } \\
\text { cardioversion, decreased consciousness level, bradypnoea, lack of co-operation or } \\
\text { agitation, repetitive vomiting, upper digestive haemorrhage, facial deformities or any } \\
\text { other decompensated respiratory disease }\end{array}$ \\
\hline Interventions & $\begin{array}{l}\text { CPAP group }(\mathrm{N}=9) \text { : } \mathrm{PEEP}=7.5 \mathrm{~cm} \mathrm{H}_{2} \mathrm{O} \text {. Average duration of treatment was } 170 \pm \\
90 \text { minutes; closed face mask } \\
\text { Bilevel group }(\mathrm{N}=7) \text { : } \mathrm{EPAP}=4 \mathrm{~cm} \mathrm{H} \mathrm{H}_{2} \mathrm{O}, \mathrm{IPAP}=12 \mathrm{~cm} \mathrm{H}_{2} \mathrm{O} \text {. Average duration of } \\
\text { treatment was } 155 \pm 38 \text { minutes; nasal mask } \\
\text { Control group }(\mathrm{N}=10) \text { : SMC and oxygen mask }(15 \mathrm{~L} \text { a minute) } \\
\text { Co-intervention: isosorbide dinitrate }(5 \mathrm{mg}) \text { and standard medications }\end{array}$ \\
\hline Outcomes & $\begin{array}{l}\text { 1. Primary outcome: endotracheal intubation rate } \\
\text { 2. Mortality } \\
\text { 3. Arterial blood gases }\left(\mathrm{PaO}_{2}, \mathrm{PaCO}_{2}, \mathrm{pH}\right) \\
\text { t. Vital signs (RR, } \mathrm{BP}, \mathrm{HR}) \\
\text { b. Incidence of acute myocardial infarction (follow-up) } \\
\text { b. Compliance of participant } \\
\text { 7. Dropouts and withdrawals }\end{array}$ \\
\hline Notes & \\
\hline
\end{tabular}


0416 Non-invasive positive pressure ventilation (CPAP or bilevel NPPV) for cardiogenic pulmonary oedema

Risk of bias table

\begin{tabular}{|l|l|l|}
\hline Bias & $\begin{array}{l}\text { Authors' } \\
\text { judgement }\end{array}$ & Support for judgement \\
\hline $\begin{array}{l}\text { Random sequence generation } \\
\text { (selection bias) }\end{array}$ & Unclear risk & No details provided \\
\hline $\begin{array}{l}\text { Allocation concealment (selection } \\
\text { bias) }\end{array}$ & Unclear risk & No details provided \\
\hline $\begin{array}{l}\text { Blinding of participants and } \\
\text { personnel (performance bias) }\end{array}$ & Unclear risk & No details provided \\
\hline $\begin{array}{l}\text { Blinding of outcome assessment } \\
\text { (detection bias) }\end{array}$ & Unclear risk & Not details provided \\
\hline $\begin{array}{l}\text { Incomplete outcome data (attrition } \\
\text { bias) }\end{array}$ & Unclear risk & No details provided \\
\hline Selective reporting (reporting bias) & Unclear risk & $\begin{array}{l}\text { Trial protocol was not prospectively registered. Unclear if all expected } \\
\text { outcomes were reported }\end{array}$ \\
\hline Other bias & & Unclear risk \\
\hline
\end{tabular}

Park 2004 
0416 Non-invasive positive pressure ventilation (CPAP or bilevel NPPV) for cardiogenic pulmonary oedema

\begin{tabular}{|c|c|}
\hline \multirow[t]{6}{*}{ Methods } & $\begin{array}{l}\text { Single-centre, parallel-group design RCT. Analysis was per protocol and not with ITT. } \\
\text { Participants were excluded from analysis after randomisation due to identification of } \\
\text { an alternative cause of respiratory failure. } 2 \text { participants in the Bilevel group and } 1 \\
\text { participant in the oxygen group were lost to follow-up. Informed consent obtained from } \\
\text { the participant's next-of-kin }\end{array}$ \\
\hline & Setting: ED \\
\hline & Country: Sao Paulo, Brazil \\
\hline & Funding: not reported \\
\hline & Study dates: January 1999 to August 2000 \\
\hline & Conflict of interest: not reported \\
\hline \multirow[t]{4}{*}{ Participants } & $\begin{array}{l}80 \text { participants. } 83 \text { people randomised, but } 3 \text { did not meet study inclusion criteria. } \\
\text { Included } 34 \text { men and } 46 \text { women, with mean age } 64.0 \pm 15.3 \text { ( } 65 \pm 15 \text { in the control } \\
\text { group, } 61 \pm 17 \text { in the CPAP group, and } 66 \pm 14 \text { in the Bilevel group) }\end{array}$ \\
\hline & $\begin{array}{l}\text { Inclusion criteria: Age }>16 \text { years, acute onset of severe respiratory distress }(\mathrm{RR}> \\
25 \text { breaths a minute), associated tachycardia, diaphoresis, and findings of pulmonary } \\
\text { congestion on physical examination and chest } x \text {-ray } 2 \text { hours after randomisation }\end{array}$ \\
\hline & $\begin{array}{l}\text { Causes: Acute myocardial infarction, hypertensive emergency, progressive heart } \\
\text { failure, hypervolaemia }\end{array}$ \\
\hline & $\begin{array}{l}\text { Exclusion criteria: Systolic } \mathrm{BP}<90 \mathrm{mmHg} \text {, decreased level of consciousness, } \\
\text { intractable vomiting, acute myocardial infarction with persistent ST segment elevation, } \\
\text { pulmonary embolism, COPD, pneumonia or pneumothorax }\end{array}$ \\
\hline Interventions & $\begin{array}{l}\text { CPAP group }(\mathrm{N}=27) \text { : Initial PEEP } 10 \mathrm{~cm} \mathrm{H}_{2} \mathrm{O} \text {. Average PEEP of } 11 \pm 2 \mathrm{~cm} \mathrm{H}_{2} \mathrm{O} \text {. } \\
\text { Average duration of therapy was } 102 \pm 41 \text { minutes } \\
\text { Bilevel group }(\mathrm{N}=27) \text {. Initial IPAP } 15 \mathrm{~cm} \mathrm{H}_{2} \mathrm{O} \text { and initial EPAP } 10 \mathrm{~cm} \mathrm{H} \mathrm{H}_{2} \mathrm{O} \text {. } \\
\text { Average EPAP was } 11 \pm 2 \mathrm{~cm} \mathrm{H}_{2} \mathrm{O} \text { and average IPAP was } 17 \pm 2 \mathrm{~cm} \mathrm{H}_{2} \mathrm{O} \text {. Duration } \\
\text { of therapy was } 124 \pm 62 \text { minutes } \\
\text { Control group }(\mathrm{N}=26) \text { : SMC and oxygen facemask }\left(\mathrm{FiO}_{2} \text { ? } 50 \%\right) \\
\text { Co-intervention: isosorbide dinitrate, morphine, furosemide, nitroprusside, nitroglycerin }\end{array}$ \\
\hline Outcomes & $\begin{array}{l}\text { 1. Primary endpoint: endotracheal intubation rate } \\
\text { 2. Mortality at } 15 \text { days and } 60 \text { days. } \\
\text { 3. Incidence of acute myocardial infarction (baseline) } \\
\text { 4. Compliance of participant } \\
\text { 5. Dropouts and withdrawals } \\
\text { 5. Treatment failure } \\
\text { 7. Side effects } \\
\text { 3. Length of hospital stay } \\
\text { 9. Vitals: RR, mean } \mathrm{BP}, \mathrm{HR} \\
\text { 1). Arterial blood gases: } \mathrm{PaO}_{2} / \mathrm{FiO}_{2}, \mathrm{PaCO}_{2}, \mathrm{pH} \text { at baseline, } 30 \text { minutes, } 60 \text { minutes, } \\
180 \text { minutes, and } 360 \text { minutes }\end{array}$ \\
\hline & \\
\hline
\end{tabular}

Risk of bias table 
0416 Non-invasive positive pressure ventilation (CPAP or bilevel NPPV) for cardiogenic pulmonary oedema

\begin{tabular}{|l|l|l|}
\hline Bias & $\begin{array}{l}\text { Authors' } \\
\text { judgement }\end{array}$ & Support for judgement \\
\hline $\begin{array}{l}\text { Random sequence generation } \\
\text { (selection bias) }\end{array}$ & Unclear risk & Not described \\
\hline $\begin{array}{l}\text { Allocation concealment (selection } \\
\text { bias) }\end{array}$ & Unclear risk & Sealed envelopes \\
\hline $\begin{array}{l}\text { Blinding of participants and } \\
\text { personnel (performance bias) }\end{array}$ & Unclear risk & Not described \\
\hline $\begin{array}{l}\text { Blinding of outcome assessment } \\
\text { (detection bias) }\end{array}$ & Unclear risk & Not described \\
\hline $\begin{array}{l}\text { Incomplete outcome data (attrition } \\
\text { bias) }\end{array}$ & High risk & $\begin{array}{l}\text { As-treated analysis performed, missing outcome data for exclusions } \\
\text { after randomisation }\end{array}$ \\
\hline Selective reporting (reporting bias) & Unclear risk & $\begin{array}{l}\text { Trial protocol was not prospectively registered. Unclear if all expected } \\
\text { outcomes were reported }\end{array}$ \\
\hline Other bias & Unclear risk & $\begin{array}{l}\text { Early termination during second interim analysis identified a significant } \\
\text { difference in endotracheal intubation rates among groups. Insufficient } \\
\text { information to assess whether an important risk of bias exists }\end{array}$ \\
\hline
\end{tabular}

\section{Räsänen 1985}


0416 Non-invasive positive pressure ventilation (CPAP or bilevel NPPV) for cardiogenic pulmonary oedema

\begin{tabular}{|c|c|}
\hline Methods & $\begin{array}{l}\text { Single-centre, parallel-group RCT. Analysis performed using ITT approach. Loss to } \\
\text { follow-up and informed consent not reported } \\
\text { Setting: ICU } \\
\text { Country: Helsinki, Finland } \\
\text { Funding: not reported } \\
\text { Study dates: not reported } \\
\text { Conflict of interest: not reported }\end{array}$ \\
\hline \multirow[t]{4}{*}{ Participants } & $\begin{array}{l}40 \text { participants ( } 13 \text { men and } 27 \text { women), with mean age } 74 \pm 9 \text { ( } 73 \pm 9 \text { in the control } \\
\text { group and } 74 \pm 9 \text { in the CPAP group) }\end{array}$ \\
\hline & $\begin{array}{l}\text { Inclusion criteria: Respiratory failure with clinical and radiologic evidence of } \\
\text { ACPE. Required evidence of dyspnoea, increased work of breathing (intercostal } \\
\text { and suprasternal retractions or use of accessory respiratory muscles), RR }>25 \\
\text { breaths a minute or } \mathrm{PaO}_{2} / \mathrm{FiO}_{2}<200\end{array}$ \\
\hline & $\begin{array}{l}\text { Causes: Severe heart failure primarily after acute myocardial infarction, or acute } \\
\text { exacerbation of chronic left ventricular dysfunction }\end{array}$ \\
\hline & $\begin{array}{l}\text { Exclusion criteria: People unresponsive to speech or unable to maintain patent } \\
\text { airway, with lung infection, pulmonary embolism, chronic lung disease with carbon } \\
\text { dioxide retention at rest }\end{array}$ \\
\hline Interventions & $\begin{array}{l}\text { CPAP group }(\mathrm{N}=20) \text { : PEEP }=10 \mathrm{~cm} \mathrm{H}_{2} \mathrm{O} \text {. Maximum length of treatment was } 180 \\
\text { minutes } \\
\text { Control group }(\mathrm{N}=20) \text { : } \mathrm{SMC} \text { and oxygen facemask }\left(\mathrm{FiO}_{2} \text { of } 28 \%-30 \%\right) \\
\text { Co-intervention: furosemide, morphine, diazepam, chlorpromazine, nitroglycerin, } \\
\text { nitroprusside, digitalis, dopamine, and dobutamine }\end{array}$ \\
\hline Outcomes & $\begin{array}{l}\text { 1. Mortality } \\
\text { 2. Endotracheal intubation rate } \\
\text { 3. Arterial blood gases at baseline, } 10 \text { minutes, } 60 \text { minutes, } 180 \text { minutes }\left(\mathrm{PaO}_{2} \text {, }\right. \\
\left.\mathrm{PaCO}_{2}, \mathrm{pH}\right) \\
\text { 4. Vital signs (RR, } \mathrm{BP}, \mathrm{HR}) \\
\text { 5. Incidence of acute myocardial infarction (baseline) } \\
\text { 5. Treatment failure } \\
\text { 7. Side effects }\end{array}$ \\
\hline N & \\
\hline
\end{tabular}

Risk of bias table 
0416 Non-invasive positive pressure ventilation (CPAP or bilevel NPPV) for cardiogenic pulmonary oedema

\begin{tabular}{|c|c|c|}
\hline Bias & $\begin{array}{l}\text { Authors' } \\
\text { iudgement }\end{array}$ & Support for judgement \\
\hline $\begin{array}{l}\text { Random sequence generation } \\
\text { (selection bias) }\end{array}$ & Unclear risk & Not described \\
\hline $\begin{array}{l}\text { Allocation concealment (selection } \\
\text { bias) }\end{array}$ & Unclear risk & $\begin{array}{l}\text { Randomly assigned to } 1 \text { of } 2 \text { group by opening } 1 \text { of } 40 \text { sealed } \\
\text { envelopes }\end{array}$ \\
\hline $\begin{array}{l}\text { Blinding of participants and } \\
\text { personnel (performance bias) }\end{array}$ & Unclear risk & No details provided \\
\hline $\begin{array}{l}\text { Blinding of outcome assessment } \\
\text { (detection bias) }\end{array}$ & Unclear risk & No details provided \\
\hline $\begin{array}{l}\text { Incomplete outcome data (attrition } \\
\text { bias) }\end{array}$ & Low risk & No missing outcome data \\
\hline Selective reporting (reporting bias) & Unclear risk & $\begin{array}{l}\text { Trial protocol was not prospectively registered. Unclear if all expected } \\
\text { outcomes were reported. }\end{array}$ \\
\hline Other bias & Unclear risk & $\begin{array}{l}\text { Insufficient information to assess whether an important risk of bias } \\
\text { exists. No power calculation to explain the sample size used for the } \\
\text { trial }\end{array}$ \\
\hline
\end{tabular}

\section{Takeda 1997}

\begin{tabular}{|c|c|}
\hline \multirow[t]{6}{*}{ Methods } & $\begin{array}{l}\text { Single-centre, parallel-design RCT. Analysis completed using ITT approach. Loss to } \\
\text { follow-up not reported. Informed consent from next-of-kin }\end{array}$ \\
\hline & Setting: ICU \\
\hline & Country: Tokyo, Japan \\
\hline & Funding: not reported \\
\hline & Study dates: not reported \\
\hline & Conflict of interest: not reported \\
\hline \multirow[t]{3}{*}{ Participants } & $\begin{array}{l}30 \text { participants ( } 22 \text { men and } 8 \text { women), with mean age } 66.5 \pm 9.7 \text { (64 } \pm 9 \text { in the contro } \\
\text { group and } 69 \pm 10 \text { in the CPAP group) }\end{array}$ \\
\hline & $\begin{array}{l}\text { Inclusion criteria: Dyspnoea of sudden onset, } \mathrm{PaO}_{2}<80 \mathrm{mmHg} \text { with } \mathrm{FiO}_{2} \text { ? } 50 \% \text {, } \\
\text { typical findings on chest radiographs, and widespread rales Causes: Acute myocardia } \\
\text { infarction, prior myocardial infarction, cardiomyopathy, mitral valve regurgitation }\end{array}$ \\
\hline & Exclusion criteria: History suggesting infection or pulmonary aspiration \\
\hline Interventions & $\begin{array}{l}\text { CPAP group }(\mathrm{N}=15) \text { : PEEP of } 4 \text { to } 10 \mathrm{~cm} \mathrm{H}_{2} \mathrm{O} \\
\text { Control group }(\mathrm{N}=15) \text { : } \mathrm{SMC} \text { and nasal oxygen mask } \\
\text { Co-intervention: furosemide, morphine, nitroglycerin, digitalis, dopamine, dobutamine, } \\
\text { norepinephrine }\end{array}$ \\
\hline Outcomes & $\begin{array}{l}\text { 1. Primary outcome: plasma endothelin- } 1 \text { concentrations } \\
\text { 2. Haemodynamics at baseline, } 6 \text { hours, } 12 \text { hours, } 24 \text { hours: mean pulmonary artery } \\
\text { pressure, pulmonary artery wedge pressure, central venous pressure, cardiac } \\
\text { index, and stroke volume index } \\
\text { 3. Blood gases: } \mathrm{PaO}_{2} / \mathrm{FiO}_{2}, \mathrm{PaCO}_{2} \\
\text { 4. Vitals: mean arterial pressure, } \mathrm{HR}, \mathrm{RR} \text { at baseline, } 6 \text { hours, } 12 \text { hours, } 24 \text { hours } \\
\text { b. Mortality } \\
\text { 6. Endotracheal intubation rate } \\
\text { 7. Length of ICU stay }\end{array}$ \\
\hline & \\
\hline
\end{tabular}


0416 Non-invasive positive pressure ventilation (CPAP or bilevel NPPV) for cardiogenic pulmonary oedema

\begin{tabular}{|l|l|l|}
\hline Bias & $\begin{array}{l}\text { Authors' } \\
\text { iudgement }\end{array}$ & Support for judgement \\
\hline $\begin{array}{l}\text { Random sequence generation } \\
\text { (selection bias) }\end{array}$ & Unclear risk & No details provided \\
\hline $\begin{array}{l}\text { Allocation concealment (selection } \\
\text { bias) }\end{array}$ & Unclear risk & No details provided \\
\hline $\begin{array}{l}\text { Blinding of participants and } \\
\text { personnel (performance bias) }\end{array}$ & Unclear risk & No details provided \\
\hline $\begin{array}{l}\text { Blinding of outcome assessment } \\
\text { (detection bias) }\end{array}$ & Unclear risk & No details provided \\
\hline $\begin{array}{l}\text { Incomplete outcome data (attrition } \\
\text { bias) }\end{array}$ & Unclear risk & Loss to follow-up was not reported \\
\hline Selective reporting (reporting bias) & Unclear risk & $\begin{array}{l}\text { Trial protocol was not prospectively registered. Unclear if all expected } \\
\text { outcomes were reported }\end{array}$ \\
\hline Other bias & & $\begin{array}{l}\text { Insufficient information to assess whether an important risk of bias } \\
\text { exists. No power calculation to explain the sample size used for the } \\
\text { trial }\end{array}$ \\
\hline
\end{tabular}

\section{Takeda 1998}

\begin{tabular}{|c|c|}
\hline \multirow[t]{6}{*}{ Methods } & $\begin{array}{l}\text { Single-centre, parallel-group design, unblinded RCT. Analysis completed using ITT } \\
\text { approach. No participants were lost after randomisation. Informed consent obtained } \\
\text { from next of kin }\end{array}$ \\
\hline & Setting: CCU \\
\hline & Country: Tokyo, Japan \\
\hline & Funding: not reported \\
\hline & Study dates: not reported \\
\hline & Conflict of interest: not reported \\
\hline \multirow[t]{3}{*}{ Participants } & $\begin{array}{l}22 \text { participants admitted to the CCU with acute myocardial infarction. } 17 \text { men and } 5 \\
\text { women with mean age of } 75 \pm 10 \text { ( } 75 \pm 10 \text { in the SMC group and } 74 \pm 11 \text { in the CPAP } \\
\text { group) }\end{array}$ \\
\hline & $\begin{array}{l}\text { Inclusion criteria: Dyspnoea of sudden onset, } \mathrm{PaO}_{2}<80 \mathrm{mmHg} \text { on } \mathrm{FiO}_{2}=50 \% \text {, } \\
\text { typical findings on chest radiograph, and widespread rales without a history } \\
\text { suggesting pulmonary aspiration or infection. Acute myocardial infarction was } \\
\text { diagnosed by typical chest pain lasting at least } 30 \text { minutes, CK at least twice the } \\
\text { normal value, and ECG changes consistent with an acute myocardial infarction }\end{array}$ \\
\hline & $\begin{array}{l}\text { Exclusion criteria: Left ventricular free wall rupture, immediate need for endotracheal } \\
\text { intubation, shock }\end{array}$ \\
\hline Interventions & $\begin{array}{l}\text { CPAP group }(\mathrm{N}=11) \text { : } \mathrm{PEEP} \text { of } 4 \text { to } 10 \mathrm{~cm} \mathrm{H}_{2} \mathrm{O} \\
\text { Control group }(\mathrm{N}=11) \text { : } \mathrm{SMC} \text { and nasal oxygen mask } \\
\text { Co-intervention: furosemide, morphine, nitroglycerin, dopamine, dobutamine, } \\
\text { norepinephrine, epinephrine }\end{array}$ \\
\hline Outcomes & $\begin{array}{l}\text { 1. Primary outcome: haemodynamics at baseline, } 24 \text { hours, } 48 \text { hours (mean arterial } \\
\text { pressure, } \mathrm{HR}, \mathrm{RR} \text {, mean pulmonary artery pressure, pulmonary artery wedge } \\
\text { pressure, cardiac index, stroke volume index) } \\
\text { 2. Mortality } \\
\text { 3. Endotracheal intubation rate } \\
\text { 4. Arterial blood gases at baseline } 24 \text { hours, } 48 \text { hours }\left(\mathrm{PaO}_{2} / \mathrm{FiO}_{2}\right)\end{array}$ \\
\hline Notes & \\
\hline
\end{tabular}


0416 Non-invasive positive pressure ventilation (CPAP or bilevel NPPV) for cardiogenic pulmonary oedema

\begin{tabular}{|l|l|l|}
\hline Bias & $\begin{array}{l}\text { Authors' } \\
\text { iudgement }\end{array}$ & Support for judgement \\
\hline $\begin{array}{l}\text { Random sequence generation } \\
\text { (selection bias) }\end{array}$ & Unclear risk & Not described \\
\hline $\begin{array}{l}\text { Allocation concealment (selection } \\
\text { bias) }\end{array}$ & Unclear risk & 2 groups by envelope method \\
\hline $\begin{array}{l}\text { Blinding of participants and } \\
\text { personnel (performance bias) }\end{array}$ & Unclear risk & Not described \\
\hline $\begin{array}{l}\text { Blinding of outcome assessment } \\
\text { (detection bias) }\end{array}$ & Unclear risk & Not described \\
\hline $\begin{array}{l}\text { Incomplete outcome data (attrition } \\
\text { bias) }\end{array}$ & Low risk & No missing outcome data \\
\hline Selective reporting (reporting bias) & Unclear risk & $\begin{array}{l}\text { Trial protocol was not prospectively registered. Unclear if all expected } \\
\text { outcomes were reported. }\end{array}$ \\
\hline Other bias & & $\begin{array}{l}\text { Insufficient information to assess whether an important risk of bias } \\
\text { exists. No power calculation to explain the sample size used for the } \\
\text { trial }\end{array}$ \\
\hline
\end{tabular}

Thys 2002 
0416 Non-invasive positive pressure ventilation (CPAP or bilevel NPPV) for cardiogenic pulmonary oedema

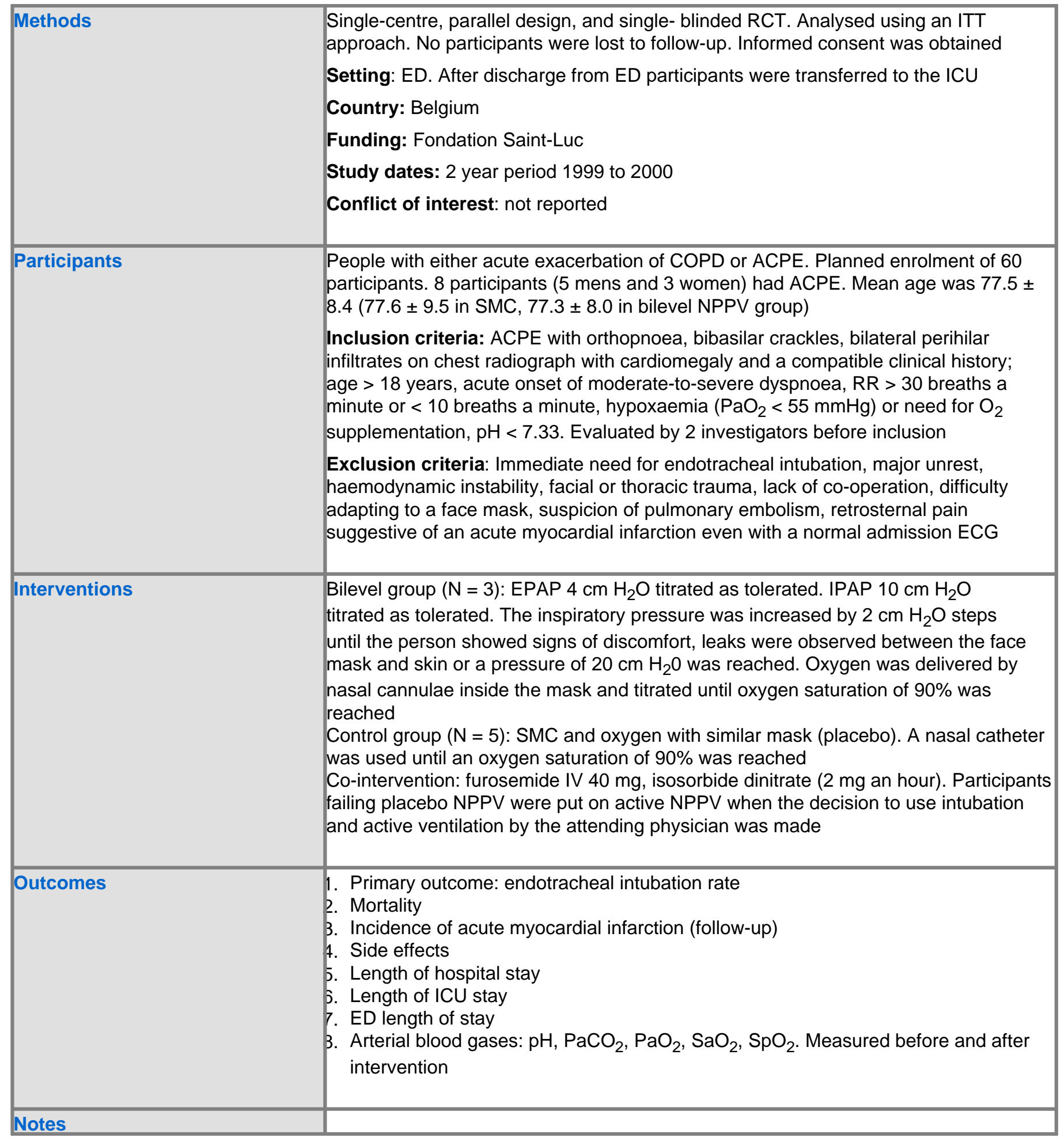

Risk of bias table 
0416 Non-invasive positive pressure ventilation (CPAP or bilevel NPPV) for cardiogenic pulmonary oedema

\begin{tabular}{|c|c|c|}
\hline Bias & $\begin{array}{l}\text { Authors' } \\
\text { judgement }\end{array}$ & Support for judgement \\
\hline $\begin{array}{l}\text { Random sequence generation } \\
\text { (selection bias) }\end{array}$ & Unclear risk & Not described \\
\hline $\begin{array}{l}\text { Allocation concealment (selection } \\
\text { bias) }\end{array}$ & Low risk & $\begin{array}{l}\text { Sealed, opaque envelopes, opened at time of inclusion in batches of } \\
20 \text { envelopes }\end{array}$ \\
\hline $\begin{array}{l}\text { Blinding of participants and } \\
\text { personnel (performance bias) }\end{array}$ & High risk & $\begin{array}{l}\text { Attempt made to use same machine with modifications for BPAP and } \\
\text { control for participant, but physician not blinded }\end{array}$ \\
\hline $\begin{array}{l}\text { Blinding of outcome assessment } \\
\text { (detection bias) }\end{array}$ & Unclear risk & Not described \\
\hline $\begin{array}{l}\text { Incomplete outcome data (attrition } \\
\text { bias) }\end{array}$ & Low risk & No missing outcomes data \\
\hline Selective reporting (reporting bias) & Unclear risk & $\begin{array}{l}\text { Trial protocol was not prospectively registered. Unclear if all expected } \\
\text { outcomes were reported }\end{array}$ \\
\hline Other bias & Unclear risk & $\begin{array}{l}\text { Early termination during first interim analysis as the differences in } \\
\text { treatment failure were significant. Insufficient information to assess } \\
\text { whether an important risk of bias exists }\end{array}$ \\
\hline
\end{tabular}

\section{Zokaei 2016}

\begin{tabular}{|c|c|}
\hline Methods & $\begin{array}{l}\text { Single-centre, parallel-group RCT. Written informed consent was obtained } \\
\text { Setting: CCU } \\
\text { Country: Iran } \\
\text { Funding: not reported } \\
\text { Study dates: not reported } \\
\text { Conflict of interest: not reported }\end{array}$ \\
\hline \multirow[t]{2}{*}{ Participants } & $\begin{array}{l}120 \text { participants with ACPE, age }>20 \text { years, diagnosed by a cardiologist. Mean age } \\
\text { was } 71 \text { (control group mean age } 72 \text { and bilevel group mean age } 70 \text { ) }\end{array}$ \\
\hline & $\begin{array}{l}\text { Exclusion criteria: reduced GCS ? } 11 \text {, hypotensive systolic } \mathrm{BP}<80 \mathrm{mmHg} \text {, } \\
\text { bradycardia } \mathrm{HR}<45 \text {, tachycardia } \mathrm{HR}>120 \text {, ventricular arrhythmia, recent } \\
\text { oesophageal, facial, cranial trauma, or surgery. Lack of co-operation, inability to clear } \\
\text { secretions, tracheostomy, active gastrointestinal bleeding, need for emergent } \\
\text { intubation, and severe organ dysfunction in addition to respiratory failure (respiratory } \\
\text { rate }>35 \text { breaths a minute and } \mathrm{PaO}_{2}<50 \mathrm{mmHg}, \mathrm{PaCO}_{2}>50 \mathrm{mmHg} \text { ) }\end{array}$ \\
\hline \multirow[t]{2}{*}{ Interventions } & 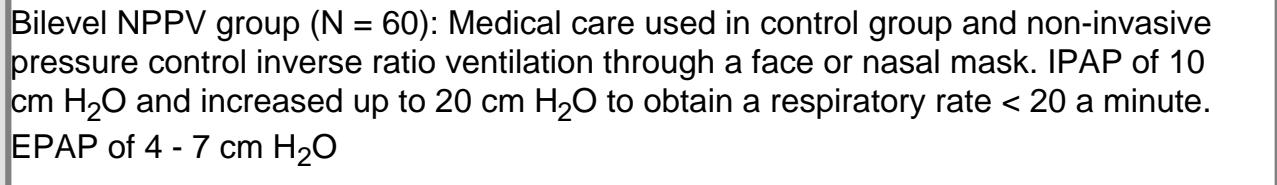 \\
\hline & $\begin{array}{l}\text { Control group }(\mathrm{N}=60) \text { : Venturi mask with } 10 \mathrm{~L} \text { a minute oxygen. Both groups were } \\
\text { given IV furosemide } 40-320 \mathrm{mg} \text { to achieve satisfactory urine output, IV nitroglycerin } 5 \\
-50 \mathrm{mcg} / \mathrm{kg} / \mathrm{min} \text { if systolic } \mathrm{BP}>100 \mathrm{mmHg} \text {, morphine sulphate } 5-10 \mathrm{mg} \text {, SC or IV } \\
\text { heparin and ASA if ECG suggestive of ischaemia. Dopamine or dobutamine or } \\
\text { adrenaline used if systolic BP }<60 \mathrm{mmHg} \text {, urine output }<0.5 \mathrm{~mL} / \mathrm{kg} / \mathrm{h}\end{array}$ \\
\hline Outcomes & $\begin{array}{l}\text { 1. Primary outcome: } 7 \text {-day mortality, endotracheal intubation rate } \\
\text { 2. Hospital mortality } \\
\text { 3. Endotracheal intubation rate } \\
\text { 4. CCU length of stay and recovery time } \\
\text { j. Arterial blood gas data at } 15 \text {-minute intervals for } 1 \text { hour }\left(\mathrm{pH}, \mathrm{SaO}_{2}, \mathrm{PaO}_{2}, \mathrm{PaCO}_{2}\right)\end{array}$ \\
\hline Notes & \\
\hline
\end{tabular}


0416 Non-invasive positive pressure ventilation (CPAP or bilevel NPPV) for cardiogenic pulmonary oedema

Risk of bias table

\begin{tabular}{|c|c|c|}
\hline Bias & $\begin{array}{l}\text { Authors' } \\
\text { iudgement }\end{array}$ & Support for judgement \\
\hline $\begin{array}{l}\text { Random sequence generation } \\
\text { (selection bias) }\end{array}$ & Unclear risk & Not described \\
\hline $\begin{array}{l}\text { Allocation concealment (selection } \\
\text { bias) }\end{array}$ & Unclear risk & Not described \\
\hline $\begin{array}{l}\text { Blinding of participants and } \\
\text { personnel (performance bias) }\end{array}$ & Unclear risk & Not described \\
\hline $\begin{array}{l}\text { Blinding of outcome assessment } \\
\text { (detection bias) }\end{array}$ & Unclear risk & Not described \\
\hline $\begin{array}{l}\text { Incomplete outcome data (attrition } \\
\text { bias) }\end{array}$ & Unclear risk & No details provided \\
\hline Selective reporting (reporting bias) & High risk & $\begin{array}{l}\text { Trial protocol was not prospectively registered. Expected outcomes } \\
\text { such as adverse events are not described, mortality at } 7 \text { days (primary } \\
\text { outcome) is not reported }\end{array}$ \\
\hline Other bias & Unclear risk & $\begin{array}{l}\text { Insufficient information to assess whether an important risk of bias } \\
\text { exists. No power calculation to explain the sample size used for the } \\
\text { trial }\end{array}$ \\
\hline
\end{tabular}

\section{Footnotes}

A-a: alveolar arterial; ACPE: acute cardiogenic pulmonary oedema; BP: blood pressure; CCU: coronary care unit; CK: creatinine kinase; CPAP: continuous positive airway pressure; DBP: diastolic blood pressure; ECG: electrocardiogram; EPAP: expiratory positive airway pressure; $\mathrm{FiO}_{2}$ : fraction of inspired oxygen; GCS: Glasgow Coma Scale; $\mathrm{H}_{2} \mathrm{O}$ : water; $\mathrm{HF}$ : heart failure; HR: heart rate; ICU: intensive care unit; IHD: ischaemic heart disease; IPAP: inspiratory positive airway

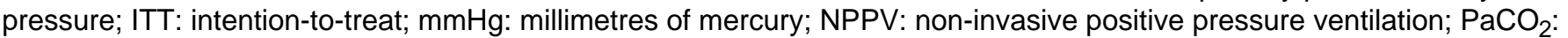
arterial partial pressure of carbon dioxide; $\mathrm{PaO}_{2}$ : arterial partial pressure of oxygen; PEEP: positive end-expiratory pressure; $\mathrm{RCT}$ : randomised controlled trial; RICU: respiratory intensive care unit; RR: respiratory rate; SBP: systolic blood pressure; SMC: standard medical care

\section{Characteristics of excluded studies}

\section{ACTRN12610000487011}

\begin{tabular}{|l|l|}
\hline Reason for exclusion & $\begin{array}{l}\text { Proposed trial comparing continuous positive airway pressure to standard medical } \\
\text { care in the pre-hospital setting for acute cardiogenic pulmonary oedema. The trial was } \\
\text { not started and is currently suspended }\end{array}$
\end{tabular}

\section{ACTRN12610000528055}

Reason for exclusion

Proposed trial comparing continuous positive airway pressure to standard medical care in acute cardiogenic pulmonary oedema. The trial was suspended prior to completing an ethics review

Baratz 1992

\begin{tabular}{l|l}
\hline Reason for exclusion & Ineligible study type: no control arm, not a randomised controlled trial
\end{tabular}

Bautin 2005

\begin{tabular}{|l|l|}
\hline Reason for exclusion & $\begin{array}{l}\text { Ineligible population: post-cardiac surgery patients developing heart failure after } \\
\text { extubation }\end{array}$ \\
\hline
\end{tabular}

Belenguer-Muncharaz 2017

\begin{tabular}{|l|l|}
\hline Reason for exclusion & $\begin{array}{l}\text { Ineligible intervention: continuous positive airway pressure compared to bilevel non- } \\
\text { invasive positive pressure ventilation without a control arm }\end{array}$ \\
\hline
\end{tabular}


0416 Non-invasive positive pressure ventilation (CPAP or bilevel NPPV) for cardiogenic pulmonary oedema

Bellone 2002

\begin{tabular}{|l|l|}
\hline Reason for exclusion & $\begin{array}{l}\text { Ineligible intervention: randomised cross-over study that compared continuous positive } \\
\text { airway pressure and bilevel non-invasive positive pressure ventilation for reducing } \\
\text { mitral regurgitation severity in acute exacerbation of heart failure. Did not have a } \\
\text { standard therapy control arm }\end{array}$ \\
\hline
\end{tabular}

\section{Bellone 2004}

\begin{tabular}{|l|l|}
\hline Reason for exclusion & $\begin{array}{l}\text { Ineligible intervention: compared bilevel non-invasive positive pressure ventilation to } \\
\text { continuous positive airway pressure in people with acute pulmonary oedema. Did not } \\
\text { have a standard therapy control arm }\end{array}$ \\
\hline
\end{tabular}

\section{Bellone 2005}

\begin{tabular}{|l|l|}
\hline Reason for exclusion & $\begin{array}{l}\text { Ineligible intervention: compared bilevel noninvasive positive pressure ventilation to } \\
\text { continuous positive airway pressure with acute pulmonary oedema. Did not have a } \\
\text { standard therapy control arm }\end{array}$ \\
\end{tabular}

\section{Bendjelid 2005}

\begin{tabular}{|l|l|}
\hline Reason for exclusion & $\begin{array}{l}\text { Ineligible study type: observational study evaluating effect of continuous positive } \\
\text { airway pressure on left ventricular function in cardiogenic pulmonary oedema }\end{array}$ \\
\hline
\end{tabular}

\section{Bersten 1991}

\begin{tabular}{|l|l|}
\hline Reason for exclusion & $\begin{array}{l}\text { Ineligible study type: quasi-randomised controlled trial comparing continuous positive } \\
\text { airway pressure to standard medical therapy. Participants were allocated to a } \\
\text { treatment group through the selection of a coloured cap }\end{array}$
\end{tabular}

\section{Blanco 2015}

\begin{tabular}{|l|l|}
\hline Reason for exclusion & $\begin{array}{l}\text { Ineligible study type: not a randomised controlled trial, a summary of an article } \\
\text { describing an observational study }\end{array}$ \\
\hline
\end{tabular}

\section{Chadda 2002}

Reason for exclusion

Ineligible study type: randomised cross-over study that compared continuous positive airway pressure to bilevel non-invasive positive pressure ventilation for acute cardiogenic pulmonary oedema

\section{Craven 2000}

\begin{tabular}{|l|l|}
\hline Reason for exclusion & $\begin{array}{l}\text { Ineligible study type: not a randomised controlled trial but a sequential trial comparing } \\
\text { ambulances equipped with either bilevel non-invasive positive pressure ventilation or } \\
\text { control therapy }\end{array}$ \\
\hline
\end{tabular}

\section{Delclaux 2000}

\begin{tabular}{|l|l|}
\hline Reason for exclusion & $\begin{array}{l}\text { Ineligible population: acute lung injury with hypoxaemic respiratory failure due to } \\
\text { infection, direct lung injury, indirect lung injury, and cardiac causes }\end{array}$ \\
\hline
\end{tabular}

Dib 2012

\begin{tabular}{|l|l|}
\hline Reason for exclusion & $\begin{array}{l}\text { Ineligible study type: review article on the pre-hospital use of continuous positive } \\
\text { airway pressure for acute heart failure }\end{array}$ \\
\hline
\end{tabular}


0416 Non-invasive positive pressure ventilation (CPAP or bilevel NPPV) for cardiogenic pulmonary oedema

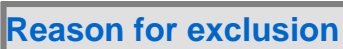

Ineligible intervention: continuous positive airway pressure compared to bilevel noninvasive positive pressure ventilation for people with acute cardiogenic pulmonary oedema. No control therapy arm

\section{Ferrari 2010}

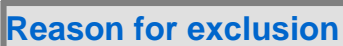

Ineligible intervention: continuous positive airway pressure compared to bilevel noninvasive positive pressure ventilation without additional standard medical care group in people with acute cardiogenic pulmonary oedema

\section{Ferrer 2003}

\begin{tabular}{|l|l|}
\hline Reason for exclusion & $\begin{array}{l}\text { Ineligible population, hypoxaemic respiratory failure, did not stratify by cause, included } \\
30 \% \text { cardiogenic pulmonary oedema }\end{array}$ \\
\hline
\end{tabular}

\section{Fontanella 2010}

\begin{tabular}{|l|l|}
\hline Reason for exclusion & $\begin{array}{l}\text { Ineligible intervention: continuous positive airway pressure compared to bilevel non- } \\
\text { invasive positive pressure ventilation without additional standard medical care group }\end{array}$ \\
\hline
\end{tabular}

\section{Foti 2009}

\begin{tabular}{|l|l|}
\hline Reason for exclusion & $\begin{array}{l}\text { Ineligible study type: not a randomised controlled trial, all patients received continuous } \\
\text { positive airway pressure in the pre-hospital setting with or without standard medical } \\
\text { care }\end{array}$ \\
\hline
\end{tabular}

\section{Gorbunova 2007}

\begin{tabular}{|l|l|}
\hline Reason for exclusion & $\begin{array}{l}\text { Ineligible study type: not a randomised controlled trial. Evaluated patients with } \\
\text { cardiogenic pulmonary oedema due to acute myocardial infarction and } \\
\text { haemodynamics with use of continuous positive airway pressure }\end{array}$ \\
\hline
\end{tabular}

\section{Hubble 2006}

\begin{tabular}{|l|l|}
\hline Reason for exclusion & $\begin{array}{l}\text { Ineligible study type: not a randomised controlled trial. Compared } 2 \text { emergency } \\
\text { medical services interventions control and continuous positive airway pressure }\end{array}$ \\
\hline
\end{tabular}

\section{L'Her 2003}

\begin{tabular}{|l|l|}
\hline Reason for exclusion & Wrong study type: review article \\
\hline
\end{tabular}

\section{Leman 2005}

Reason for exclusion Ineligible study type: no control arm. Compared continuous positive airway pressure delivery mechanisms in the management of acute pulmonary oedema

\section{Liesching 2014}

\begin{tabular}{|l|l|}
\hline Reason for exclusion & $\begin{array}{l}\text { Ineligible intervention: compared bilevel noninvasive positive pressure ventilation to } \\
\text { continuous positive airway pressure in acute cardiogenic pulmonary oedema }\end{array}$ \\
\hline
\end{tabular}

\section{Martin-Bermudez 2002}

Reason for exclusion Ineligible intervention: compared bilevel noninvasive positive pressure ventilation to continuous positive airway pressure in acute cardiogenic pulmonary oedema 
0416 Non-invasive positive pressure ventilation (CPAP or bilevel NPPV) for cardiogenic pulmonary oedema

\begin{tabular}{|l|l|}
\hline Reason for exclusion & $\begin{array}{l}\text { Ineligible intervention: continuous positive airway pressure compared to bilevel } \\
\text { noninvasive positive pressure ventilation without a control treatment group }\end{array}$ \\
\hline
\end{tabular}

\section{Minuto 2003}

\begin{tabular}{|l|l|}
\hline Reason for exclusion & $\begin{array}{l}\text { Ineligible study type: cohort study comparing continuous positive airway pressure vs } \\
\text { bilevel noninvasive positive pressure ventilation for people with acute cardiogenic } \\
\text { pulmonary oedema that had failed medical therapy. }\end{array}$ \\
\hline
\end{tabular}

\section{Moritz 2007}

\begin{tabular}{|l|l|}
\hline Reason for exclusion & Ineligible study type: quasi-randomised controlled trial, participants randomised to \\
consecutive study numbers as either CPAP or bilevel NPPV. Ineligible intervention: \\
compared continuous positive airway pressure to bilevel noninvasive positive pressure \\
ventilation without a control group
\end{tabular}

\section{NCT00375154}

\begin{tabular}{|l|l|}
\hline Reason for exclusion & Study withdrawn due to difficulties in training investigators in other centres \\
\hline
\end{tabular}

\section{Nouira 2011}

\begin{tabular}{|l|l|}
\hline Reason for exclusion & $\begin{array}{l}\text { Ineligibleg intervention: compared bilevel non-invasive positive pressure ventilation to } \\
\text { continuous positive airway pressure }\end{array}$
\end{tabular}

Oliver 2013

\begin{tabular}{|l|l|}
\hline Reason for exclusion $\quad$ Wrong study type: a review article. \\
\hline
\end{tabular}

\section{Ozsancak 2013}

\begin{tabular}{|l|l|}
\hline Reason for exclusion & $\begin{array}{l}\text { Ineligible intervention: compared total face mask or oronasal mask noninvasive } \\
\text { ventilation }\end{array}$
\end{tabular}

\section{Pagano 2018}

Reason for exclusion

Wrong study type: observational study of bilevel noninvasive positive pressure ventilation and continuous positive airway pressure for people with acute cardiogenic pulmonary oedema

\section{Philip-Joet 1999}

\begin{tabular}{|l|l|}
\hline Reason for exclusion & Ineligible intervention: continuous positive airway pressure or bilevel noninvasive \\
positive pressure ventilation without control group. Ineligible population: people with or \\
without congestive heart failure. Ineligible study type: not a randomised controlled trial, \\
a comparative cohort study
\end{tabular}

\section{Plaisance 2007}

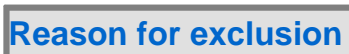

Ineligible study type: cross-over randomised controlled trial that compared continuous positive airway pressure starting at different times

\section{Popova 2010}

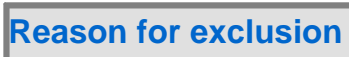

Ineligible population: decompensated heart failure. Evaluated exercise effects, 6minute walking distance, of non-invasive ventilation or standard care

\section{Rusterholtz 1999}


0416 Non-invasive positive pressure ventilation (CPAP or bilevel NPPV) for cardiogenic pulmonary oedema

\begin{tabular}{|l|l|}
\hline Reason for exclusion & $\begin{array}{l}\text { Wrong study type: uncontrolled prospective study. Wrong intervention: no control } \\
\text { group }\end{array}$ \\
\hline
\end{tabular}

Sharon 2000

\begin{tabular}{|l|l|}
\hline Reason for exclusion & $\begin{array}{l}\text { Ineligible study type: quasi-randomised controlled trial with randomisation performed } \\
\text { by assigning consecutive patients to one or other treatment groups according to their } \\
\text { numerical order on a list that had been predetermined by lot. Ineligible intervention: } \\
\text { compared bilevel non-invasive positive pressure ventilation against high-dose } \\
\text { intravenous nitrate standard medical therapy }\end{array}$
\end{tabular}

\section{Somauroo 2000}

\begin{tabular}{l|l} 
Reason for exclusion & $\begin{array}{l}\text { Ineligible population: chronic congestive heart failure. Ineligible intervention: compared } \\
\text { continuous positive airway pressure to bilevel non-invasive positive pressure } \\
\text { ventilation }\end{array}$
\end{tabular}

Uy 2004

\begin{tabular}{|l|l|}
\hline Reason for exclusion & $\begin{array}{l}\text { Ineligible intervention: compared continuous positive airway pressure to mechanical } \\
\text { ventilation for people with acute cardiogenic pulmonary oedema }\end{array}$ \\
\hline
\end{tabular}

\section{Vaisanen 1987}

\begin{tabular}{|l|l|}
\hline Reason for exclusion & $\begin{array}{l}\text { Ineligible study type: cross-over study comparing participants randomised to the } \\
\text { sequence of continuous positive airway pressure or standard medical therapy first } \\
\text { followed by standard medical therapy or continuous positive airway pressure }\end{array}$
\end{tabular}

Weitz 2007

\begin{tabular}{|l|l|}
\hline Reason for exclusion & $\begin{array}{l}\text { Ineligible study type: quasi-randomised controlled trial with randomisation by birth } \\
\text { year. Compared non-invasive ventilation to standard medical therapy }\end{array}$
\end{tabular}

Footnotes

\section{Characteristics of studies awaiting classification}

Footnotes

\section{Characteristics of ongoing studies}

Footnotes

\section{Summary of findings tables}

\section{NPPV compared to SMC for cardiogenic pulmonary oedema}

\section{NPPV compared to standard medical care for cardiogenic pulmonary oedema}

Patient or population: People with cardiogenic pulmonary oedema

Setting: Pre-hospital intensive care, emergency department, coronary care unit, or intensive care unit Intervention: NPPV

Comparison: Standard medical care (SMC)

\begin{tabular}{|c|c|c|c|c|c|c|}
\hline \multirow[b]{2}{*}{ Outcomes } & \multicolumn{2}{|c|}{ Anticipated absolute effects ${ }^{\star}(95 \% \mathrm{Cl})$} & \multirow{2}{*}{$\begin{array}{l}\text { Relative } \\
\text { effect } \\
(95 \% \mathrm{Cl})\end{array}$} & \multirow{2}{*}{$\begin{array}{l}1 \text { of } \\
\text { participants } \\
\text { (studies) }\end{array}$} & \multirow{2}{*}{$\begin{array}{l}\text { Certainty of } \\
\text { the evidence } \\
\text { (GRADE) }\end{array}$} & \multirow{2}{*}{ Comments } \\
\hline & Risk with SMC & $\begin{array}{l}\text { Risk with } \\
\text { NPPV }\end{array}$ & & & & \\
\hline HOSPITAL & \multicolumn{2}{|l|}{ Study population } & \multirow{2}{*}{$\begin{array}{l}\text { RR } 0.65 \\
(0.51 \text { to } \\
0.82)\end{array}$} & \multirow{2}{*}{$\begin{array}{l}2484 \\
\text { (21 RCTs) }\end{array}$} & \multirow{2}{*}{$\begin{array}{l}\text { ???? } \\
\text { LOWa,b }\end{array}$} & \multirow[t]{2}{*}{ - } \\
\hline $\begin{array}{l}\text { follow-up: median } \\
13 \text { days; range } 1 \\
\text { day - } 41 \text { days }\end{array}$ & 176 per 1000 & $\begin{array}{l}114 \text { per } 1000 \\
(90 \text { to } 144)\end{array}$ & & & & \\
\hline
\end{tabular}


0416 Non-invasive positive pressure ventilation (CPAP or bilevel NPPV) for cardiogenic pulmonary oedema

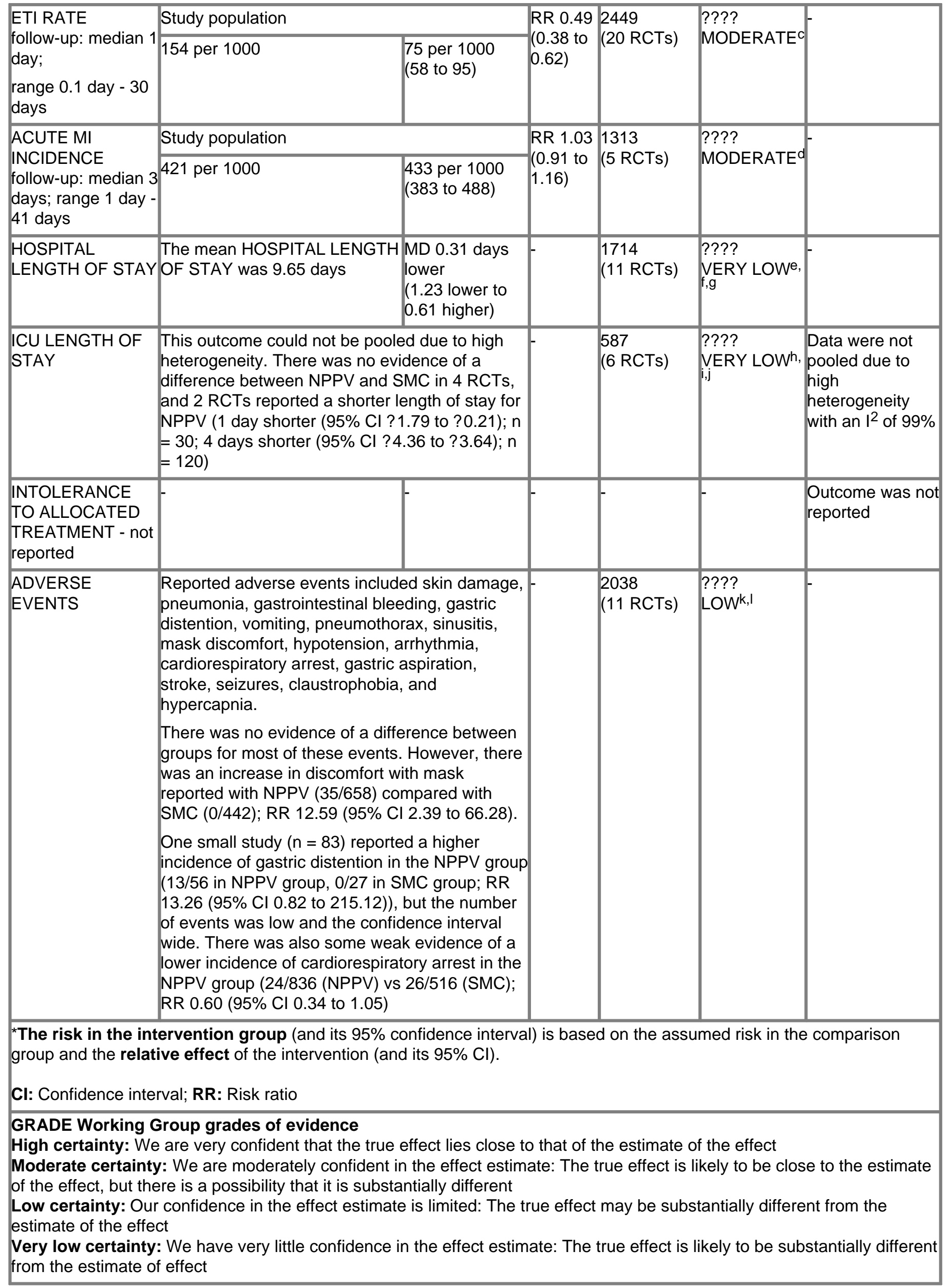

aDowngraded by one level for risk of bias. Most trials providing hospital mortality evidence were at unclear or high risk of bias 
0416 Non-invasive positive pressure ventilation (CPAP or bilevel NPPV) for cardiogenic pulmonary oedema

for key domains, including: randomisation sequence, allocation concealment, selective reporting bias, and other significant bias.

bowngraded by one level for imprecision. Most trials had few participants and few mortality events, with a confidence interval crossing a RR of 0.75 .

'Downgraded by one level for risk of bias. Most trials providing ETI evidence were rated as having unclear or high risk of bias for key domains, which included randomisation sequence generation, allocation concealment, selective reporting bias, and other significant bias.

dDowngraded by one level for imprecision. Most trials had few participants and few acute Ml events, with a confidence interval crossing a RR of 1.0. In addition, the definition of acute MI varied between trials, with some trials using creatinine kinase and others using troponin.

eDowngraded by one level for risk of bias. Most trials were at low or unclear risk of bias. Potential limitations from lack of blinding are likely to lower confidence in hospital length of stay.

fDowngraded by one level for inconsistency. Hospital length of stay was heterogeneous, with an $\mathrm{I}^{2}$ of $58 \%$ and visuallyevident heterogeneity.

gDowngraded by one level for imprecision. Most trials had few participants, with a confidence interval crossing a MD of 0 . hDowngraded by one level for risk of bias. Most information was from studies at low or unclear risk of bias. Potential limitations from lack of blinding are likely to lower confidence in ICU length of stay.

'Downgraded by one level for imprecision. Most trials had few participants, with a confidence interval crossing a MD of 0 . jDowngraded by one level for inconsistency. ICU length of stay was heterogeneous, with an $I^{2}$ of $99 \%$ and visually-evident heterogeneity.

kDowngraded by one level for risk of bias. Most studies had at least one domain at high or unclear risk of bias.

'Downgraded by one level for imprecision, as confidence intervals included both directions of effect for many of the adverse events.

\section{Additional tables}

1 NPPV intervention summary: EPAP, IPAP, and PEEP settings, duration of therapy. 
0416 Non-invasive positive pressure ventilation (CPAP or bilevel NPPV) for cardiogenic pulmonary oedema

\begin{tabular}{|c|c|c|c|c|c|c|}
\hline Study & Mask type & $\begin{array}{l}\text { IPAP level } \\
(\mathrm{cmH} 2 \mathrm{O}) \pm \mathrm{SD}\end{array}$ & $\begin{array}{l}\text { EPAP in bilevel } \\
\text { NPPV }(\mathrm{cmH} 2 \mathrm{O}) \pm \\
\text { SD }\end{array}$ & $\begin{array}{l}\text { PEEP in CPAP } \\
(\mathrm{cmH} 2 \mathrm{O}) \pm \mathrm{SD}\end{array}$ & $\begin{array}{l}\text { Time of bilevel } \\
\text { NPPV }(h) \pm \text { SD }\end{array}$ & $\begin{array}{l}\text { Time of } \\
\text { CPAP }(h) \pm \\
\text { SD }\end{array}$ \\
\hline$\frac{\text { Agmy }}{2008}$ & Face mask & NA & NA & NA & NA & NA \\
\hline$\frac{\text { Austin }}{2013}$ & Face mask & NA & NA & 10 & NA & 0.583333 \\
\hline$\frac{\text { Crane }}{2004}$ & Face mask & 15 & 5 & 10 & NA & NA \\
\hline \begin{tabular}{|l} 
Ducros \\
2011
\end{tabular} & Face mask & NA & NA & 10 & NA & 3 \\
\hline $\begin{array}{l}\text { El-Refay } \\
2016 \\
\end{array}$ & Face mask & 15 & 10 & 10 & 1 & - \\
\hline$\frac{\text { Frontin }}{2011}$ & Face mask & NA & NA & 10 & NA & NA \\
\hline Gray 2008 & Face mask & $14 \pm 5$ & $7 \pm 3$ & $10 \pm 4$ & $2 \pm 1.3$ & $2.2 \pm 1.5$ \\
\hline Hao 2002 & Face mask & NA & NA & 6 to 10 & NA & $4.6 \pm 2.8$ \\
\hline Kelly 2002 & Face mask & NA & NA & 7.5 & NA & NA \\
\hline L'Her 2004 & Face mask & NA & NA & 7.5 & NA & NA \\
\hline$\frac{\text { Levitt }}{2001}$ & $\begin{array}{l}\text { Face mask selected for } \\
\text { mouth breathers Nasal } \\
\text { available }\end{array}$ & NA & NA & NA & 2 & 2 \\
\hline Li 2005 & Face mask & 15 to 18 & 5 to 8 & NA & 2 & NA \\
\hline Lin 1991 & Face mask & NA & NA & 12.5 & NA & 6 \\
\hline Lin 1995 & Face mask & NA & NA & 12.5 & NA & 6 \\
\hline$\frac{\text { Masip }}{2000}$ & Face mask & $15.2 \pm 2.4$ & 5 & NA & $4.2 \pm 1.5$ & NA \\
\hline$\frac{\text { Moritz }}{2003}$ & Face mask & NA & NA & $9.3 \pm 0.3$ & 0.5 & NA \\
\hline Nava 2003 & Face mask & $14.5 \pm 21.1$ & $6.1 \pm 3.2$ & NA & $11.4 \pm 3.6$ & NA \\
\hline Park 2001 & $\begin{array}{l}\text { Nasal bilevel and face } \\
\text { mask for CPAP }\end{array}$ & 12 & 4 & 7.5 & $2.6 \pm 0.6$ & $2.8 \pm 1.5$ \\
\hline Park 2004 & Face mask & $17 \pm 2$ & $11 \pm 2$ & $11 \pm 2$ & $2.1 \pm 1$ & $1.7 \pm 0.7$ \\
\hline$\frac{\text { Räsänen }}{1985}$ & Face mask & NA & NA & 10 & NA & NA \\
\hline $\begin{array}{l}\text { Takeda } \\
1997 \\
\end{array}$ & Nasal & NA & NA & 4 to 10 & $11.9 \pm 8.4$ & NA \\
\hline $\begin{array}{l}\text { Takeda } \\
1998 \\
\end{array}$ & Nasal & NA & NA & 4 to 10 & NA & NA \\
\hline Thys 2002 & Face mask & $16.5 \pm 3.3$ & $6.1 \pm 1.5$ & NA & $1.3 \pm 0.3$ & NA \\
\hline $\begin{array}{l}\text { Zokaei } \\
2016 \\
\end{array}$ & Face mask 1st, nasal 2nd & 10 to 20 & 4 to 7 & NA & 1 & NA \\
\hline
\end{tabular}

\section{Footnotes}

Not all papers provided a mean and standard deviation. Where unavailable, the range represents the IPAP/EPAP/CPAP settings described in the Methods. NA: not applicable

\section{Standard medical therapy for each trial}


0416 Non-invasive positive pressure ventilation (CPAP or bilevel NPPV) for cardiogenic pulmonary oedema

\begin{tabular}{|c|c|c|c|c|c|c|}
\hline Study & Lasix & Lasix dose & Nitrate & $\begin{array}{l}\mathrm{FiO}_{2} \text { mask } \\
\text { and } \% \mathrm{FiO}_{2}\end{array}$ & Other & $\begin{array}{l}\text { Additional } \\
\text { differences } \\
\text { between SMC } \\
\text { received in } \\
\text { treatment group }\end{array}$ \\
\hline$\frac{\text { Agmy }}{2008}$ & Unclear & Unclear & Unclear & Unclear & Unclear & Unclear \\
\hline$\frac{\text { Austin }}{2013}$ & yes & $40 \mathrm{mg}$ & $\begin{array}{l}\text { Sublingual } 400 \text { - } 1600 \mathrm{mcg} \\
\text { q5min }\end{array}$ & $\begin{array}{l}\text { Yes, } 8 \text { - } 15 \\
\text { Lpm }\end{array}$ & $\begin{array}{l}\text { Morphine } 1 \text { - } 2 \\
\text { mg IV }\end{array}$ & None \\
\hline$\frac{\text { Crane }}{2004}$ & yes & Unclear & nitrates & Yes, 10 Lpm & diamorphine & None \\
\hline $\begin{array}{l}\text { Ducros } \\
2011\end{array}$ & yes & $\begin{array}{l}\text { Lasix } 40 \mathrm{mg}-120 \mathrm{mg} \\
\text { IV or } 1-3 \mathrm{mg} \\
\text { bumetanide }\end{array}$ & $\begin{array}{l}\text { nitroglycerin ( } 1 \mathrm{mg} \text { per } 3 \mathrm{~min}) \\
\text { and a continuous IV infusion } \\
\text { unless systolic } \mathrm{BP}<110 \\
\mathrm{mmHg}\end{array}$ & $15 \mathrm{Lpm}$ & NA & None \\
\hline $\begin{array}{l}\text { El-Refay } \\
2016 \\
\end{array}$ & yes & Lasix $40 \mathrm{mg} \mathrm{IV}$ & $\begin{array}{l}\text { nitroglycerin } 0.4 \mathrm{mg} \\
\text { sublingual }\end{array}$ & 15 Lpm & $\begin{array}{l}\text { Morphine } 2 \\
\text { mg IV }\end{array}$ & None \\
\hline$\frac{\text { Frontin }}{2011}$ & yes & $1 \mathrm{mg} / \mathrm{kg} \mathrm{IV}$ & $\begin{array}{l}\text { isosorbide dinitrate IV } 2 \mathrm{mg} \text { if } \\
\mathrm{SBP}>180 \mathrm{mmHg}\end{array}$ & $15 \mathrm{Lpm}$ & NA & None \\
\hline$\frac{\text { Gray }}{2008}$ & yes & $\begin{array}{l}50 \mathrm{mg} \text { above usual } \\
\text { dose to max } 100 \mathrm{mg} \\
\text { IV }\end{array}$ & Buccal nitrates 2 - $5 \mathrm{mg}$ & 15 Lpm & Opiates & None \\
\hline Hao 2002 & yes & $20-40$ mg IV & $\begin{array}{l}\text { Buccal nitrates } 0.5 \mathrm{mg} \text { to } 1 \\
\mathrm{mg} \text { IV }\end{array}$ & $6 \mathrm{Lpm}$ & $\begin{array}{l}\text { Morphine } 2 \\
\text { mg IV }\end{array}$ & None \\
\hline$\frac{\text { Kelly }}{2002}$ & yes & $50-100 \mathrm{mg}$ IV & $\begin{array}{l}\text { buccal nitrate } 5 \mathrm{mg} \text { if systolic } \\
\mathrm{BP}>90 \mathrm{mmHg}\end{array}$ & $\begin{array}{l}\text { oxygen } 60 \% \text { by } \\
\text { venturi mask }\end{array}$ & $\begin{array}{l}\text { morphine IV } \\
2.5-10 \mathrm{mg}\end{array}$ & None \\
\hline Li 2005 & yes & Unclear & nitroglycerin & $\begin{array}{l}\text { Mask high } \\
\text { concentration }\end{array}$ & Unclear & None \\
\hline Levitt & yes & Unclear & nitroglycerin IV & Mask high flow & Morphine & None \\
\hline $\begin{array}{l}\text { 'Her } \\
2004 \\
\end{array}$ & yes & $80 \mathrm{mg} \mathrm{IV}$ & $\begin{array}{l}\text { nitroglycerin IV infusion } 1 \\
\mathrm{mg} / \text { hour }\end{array}$ & $8 \mathrm{Lpm}$ & $\begin{array}{l}\text { Morphine } 2 \text { - } \\
10 \mathrm{mg} \text { IV }\end{array}$ & None \\
\hline Lin 1991 & Unclear & Unclear & Unclear & $\mathrm{FiO}_{2} 100 \%$ & Unclear & Unclear \\
\hline Lin 1995 & yes & $\begin{array}{l}40 \mathrm{mg} \text { IV or double } \\
\text { home dose }\end{array}$ & $\begin{array}{l}\text { nitroglycerin sublingual } 0.6 \\
\text { mg or isosorbide } 10-20 \mathrm{mg} \text {, } \\
\text { or nitro infusion } 10-50 \\
\mathrm{mcg} / \mathrm{min}\end{array}$ & $\mathrm{FiO}_{2} 100 \%$ & $\begin{array}{l}\text { Morphine } 2 \text { - } \\
10 \mathrm{mg} \text { IV }\end{array}$ & None \\
\hline$\frac{\text { Masip }}{2000}$ & yes & $40 \mathrm{mg}$ IV & $\begin{array}{l}\text { IV glyceryl trinitrate } 1 \mathrm{mg} \text { if } \\
\text { systolic } \mathrm{BP}>180 \mathrm{mmHg}\end{array}$ & $\mathrm{FiO}_{2} 50 \%$ & $\begin{array}{l}\text { Morphine } 4 \\
\text { mg IV }\end{array}$ & None \\
\hline Moritz & yes & $\begin{array}{l}40 \mathrm{mg} \text { IV or double } \\
\text { home dose }\end{array}$ & $\begin{array}{l}\text { IV nitroglycerin infusion } 0.125 \\
-0.25 \mathrm{mcg} / \mathrm{kg} / \mathrm{min}\end{array}$ & $\mathrm{FiO}_{2} 100 \%$ & Unclear & None \\
\hline$\frac{\text { Nava }}{2003}$ & yes & $\begin{array}{l}40 \mathrm{mg} \text { IV or double } \\
\text { usual dose, repeated, } \\
\text { if necessary, every } 20 \\
\text { mins, up to } 320 \mathrm{mg}\end{array}$ & $\begin{array}{l}\text { continuous glyceryl trinitrate } \\
\text { at an initial rate of } 1.5 \\
\mathrm{mg} / \text { hour. A bolus dose of } 1 \\
\mathrm{mg} \text { IV was added if systolic } \\
\mathrm{BP}>180 \mathrm{mmHg}\end{array}$ & 10 Lpm & $\begin{array}{l}\text { morphine } \\
\text { sulphate up to } \\
4 \mathrm{mg}\end{array}$ & None \\
\hline $\begin{array}{l}\text { Park } \\
2001 \\
\end{array}$ & Unclear & Unclear & $\begin{array}{l}5 \mathrm{mg} \text { isosorbide dinitrite if } \\
\text { systolic } \mathrm{BP}>100 \mathrm{~mm} \mathrm{Hg}\end{array}$ & $15 \mathrm{Lpm}$ & Unclear & Unclear \\
\hline Park & Unclear & Unclear & $\begin{array}{l}5 \mathrm{mg} \text { isosorbide dinitrate was } \\
\text { given sublingually and if } \\
\text { necessary titrated up to } 15 \mathrm{mg}\end{array}$ & $\mathrm{FiO}_{2} 50 \%$ & Unclear & Unclear \\
\hline$\frac{\text { Räsänen }}{1985}$ & yes & $40-80 \mathrm{mg}$ IV & Nitroprusside, nitroglycerine & $\mathrm{FiO}_{2} 30 \%$ & Morphine & Unclear \\
\hline
\end{tabular}


0416 Non-invasive positive pressure ventilation (CPAP or bilevel NPPV) for cardiogenic pulmonary oedema

\begin{tabular}{|c|c|c|c|c|c|c|}
\hline Study & Lasix & Lasix dose & Nitrate & $\begin{array}{l}\mathrm{FiO}_{2} \text { mask } \\
\text { and } \% \mathrm{FiO}_{2}\end{array}$ & Other & $\begin{array}{l}\text { Additional } \\
\text { differences } \\
\text { between SMC } \\
\text { received in } \\
\text { treatment group }\end{array}$ \\
\hline $\begin{array}{l}\text { Takeda } \\
1997\end{array}$ & yes & Unclear & Nitroglycerin infusion & $\mathrm{FiO} 250 \%$ & Morphine & Unclear \\
\hline $\begin{array}{l}\text { Takeda } \\
1998 \\
\end{array}$ & yes & Unclear & Nitroglycerin infusion & $\mathrm{FiO}_{2} 70 \%$ & Morphine & Unclear \\
\hline $\begin{array}{l}\text { Thys } \\
2002\end{array}$ & yes & $40 \mathrm{mg}$ IV & isosorbide dinitrate $2 \mathrm{mg} / \mathrm{hour}$ & Unclear & Unclear & Unclear \\
\hline$\frac{\text { Zokaei }}{2016}$ & yes & $40-320 \mathrm{mg}$ & $\begin{array}{l}\text { IV nitroglycerin } 5 \text { - } 50 \\
\mathrm{mcg} / \mathrm{kg} / \mathrm{min}\end{array}$ & $10 \mathrm{Lpm}$ & $\begin{array}{l}\text { morphine } 5 \text { - } \\
10 \mathrm{mg}\end{array}$ & Unclear \\
\hline
\end{tabular}

\section{Footnotes}

BP: blood pressure; $\mathrm{FiO}_{2}$ : fraction of inspired oxygen; IV: intravenous; Lpm: litres per minute; NA: not available; mcg: micrograms; $\mathrm{mcg} / \mathrm{kg} / \mathrm{min}$ : micrograms per kilogram per minute; $\mathrm{mg}$ : milligrams; min: minutes; $\mathrm{mmHg}=$ millimetres of mercury 3 In-hospital mortality duration of follow-up

\begin{tabular}{|l|l|}
\hline Study & Follow-up (days) \\
\hline Agmy 2008 & Unclear \\
\hline Austin 2013 & $7.2^{\mathrm{a}}$ \\
\hline Crane 2004 & $41^{\mathrm{b}}$ \\
\hline Ducros 2011 & $>7$ \\
\hline El-Refay 2016 & 1 \\
\hline Frontin 2011 & 30 \\
\hline Gray 2008 & 30 \\
\hline Hao 2002 & NA \\
\hline Kelly 2002 & $15^{\mathrm{a}}$ \\
\hline Li 2005 & NA \\
\hline Levitt 2001 & $38^{\mathrm{b}}$ \\
\hline L'Her 2004 & $12^{\mathrm{a}}$ \\
\hline Lin 1991 & 1 \\
\hline Lin 1995 & 9 \\
\hline Masip 2000 & $14^{\mathrm{a}}$ \\
\hline Moritz 2003 & NA \\
\hline Nava 2003 & $5.4^{\mathrm{a}}$ \\
\hline Park 2001 & $3^{\mathrm{b}}$ \\
\hline Park 2004 & 15 \\
\hline Räsänen 1985 & Unclear \\
\hline Takeda 1997 & $7.7^{\mathrm{a}}$ \\
\hline Takeda 1998 & Unclear \\
\hline Thys 2002 & $17.6^{\mathrm{a}}$ \\
\hline Zokaei 2016 & 7 \\
\hline & \\
\hline
\end{tabular}

Footnotes

aEstimated based on longest reported mean hospital length of stay; bBased on latest death reported in trial 4 Intubation criteria for trials reporting endotracheal intubation rates 
0416 Non-invasive positive pressure ventilation (CPAP or bilevel NPPV) for cardiogenic pulmonary oedema

\begin{tabular}{|c|c|}
\hline Study & Intubation Criteria \\
\hline$\frac{\text { Agmy }}{2008}$ & Unclear \\
\hline Austin & Unclear \\
\hline$\frac{\text { Crane }}{2004}$ & $\mathrm{RR}>40, \mathrm{RR}<10$, altered level of consciousness, arterial $\mathrm{pH}<7.2$ \\
\hline$\frac{\text { Ducros }}{2011}$ & $\begin{array}{l}\mathrm{SpO}_{2}<85 \% \text { after } 30 \text { mins of } 15 \mathrm{Lpm} \text { or } \mathrm{FiO}_{2} 60 \% \text { CPAP, respiratory arrest, psychomotor agitation, SBP }<80 \\
\mathrm{mmHg}\end{array}$ \\
\hline El-Refay & Unclear \\
\hline Frontin & $\begin{array}{l}\text { Worsening } \mathrm{SpO}_{2} \text { despite effective treatment, loss of airway protective reflexes (cough, swallow), decreased } \\
\text { level of consciousness, haemodynamic instability, intolerance/poor fit of face mask for the CPAP group, medical } \\
\text { clinical impression of deterioration, or participant request }\end{array}$ \\
\hline Gray 2008 & At discretion of treating clinician \\
\hline$\frac{\text { L'Her }}{2004}$ & $\begin{array}{l}\text { Cardiac or respiratory arrest, severe haemodynamic instability (SBP }<80) \text {, administration of } \\
\text { epinephrine/norepinephrine, refractory hypoxaemia } \mathrm{SaO}_{2}<92 \% \text { despite face mask, clinical signs of respiratory } \\
\text { exhaustion (accessory muscle use with paradoxical abdominal motion), coma or seizures, agitation requiring } \\
\text { sedation }\end{array}$ \\
\hline$\frac{\text { Levitt }}{2001}$ & $\begin{array}{l}\text { Clinical or arterial blood gas findings. Severe respiratory distress, deterioration in mental status, or further } \\
\text { deterioration in vital signs with increasing } \mathrm{HR} \text {, RR, or a decrease in } \mathrm{BP} \text {. Decrease in } \mathrm{pO}_{2}<60 \text { or rise in } \mathrm{pCO}_{2}> \\
50 \text { along with signs of clinical deterioration warranted intubation }\end{array}$ \\
\hline Lin 1991 & Clinician discretion. Loss of consciousness or airway obstruction were indications for intubation \\
\hline Lin 1995 & $\begin{array}{l}\text { Cardiopulmonary resuscitation or clinical deterioration with any } 2 \text { of the following: (1) a rise in arterial carbon } \\
\text { dioxide tension to more than } 55 \mathrm{~mm} \mathrm{Hg} \text {; (2) arterial blood oxygen partial pressure divided by fraction of inspired } \\
\text { oxygen content less than } 200 \mathrm{~mm} \mathrm{Hg} \text {; and (3) respiratory rate over } 35 \text { breaths/min. }\end{array}$ \\
\hline$\frac{\text { Masip }}{2000}$ & Patients were intubated when the criteria for treatment failure were met. Details not specified. \\
\hline Nava 2003 & 3 Unclear \\
\hline Park 2001 & Clinical judgement \\
\hline Park 2004 & Clinical judgement \\
\hline$\frac{\text { Räsänen }}{1985}$ & Clinical judgement. Loss of consciousness or airway obstruction were indications for intubation at any time. \\
\hline$\frac{\text { Takeda }}{1997}$ & $\begin{array}{l}\text { Clinical deterioration and either a decrease in the } \mathrm{PaO}_{2} / \mathrm{FiO}_{2}<100 \text { with an } \mathrm{FIO}_{2} ? 70 \% \text { or a increase in the } \\
\mathrm{PaCO}_{2}>55 \mathrm{mmHg}\end{array}$ \\
\hline$\frac{\text { Takeda }}{1998}$ & Clinical deterioration and either a fall in $\mathrm{PaO}_{2} / \mathrm{FiO}_{2}<100$ with an $\mathrm{FiO}_{2}$ of $70 \%$ or a rise in $\mathrm{PaCO}_{2}$ to $>55 \mathrm{mmHg}$. \\
\hline Thys 2002 & $\begin{array}{l}\text { Deterioration in clinical status including all of the following: dyspnoea, respiratory or heart frequency or both, } \\
\text { sweating and agitation or deterioration in blood gases or in haemodynamic status or both }\end{array}$ \\
\hline$\frac{\text { Zokaei }}{2016}$ & $\begin{array}{l}\text { RR after } 1 \text { hour of bilevel NPPV }>30 \text {, persistent hypoxaemia, haemodynamic instability (systolic BP }<70 \text { ), } \\
\text { agitation, or worsened neurologic status, inability to tolerate mask or aspiration of gastric content }\end{array}$ \\
\hline
\end{tabular}

Footnotes

BP: blood pressure; CPAP: continuous positive airway pressure; $\mathrm{FiO}_{2}$ : fraction of inspired oxygen; HR: heart rate; Lpm: litres per minute; $\mathrm{PaCO}_{2}$ : arterial partial pressure of carbon dioxide; $\mathrm{PaO}_{2}$ : arterial partial pressure of oxygen; RR: respiratory rate; SBP: systolic blood pressure

\section{References to studies}

\section{Included studies}

\section{Agmy 2008}

Published and unpublished data [CRSSTD: 3006925] 


\section{Non-invasive positive pressure ventilation (CPAP or bilevel NPPV) for cardiogenic pulmonary oedema}

* Agmy G, Makhlouf H, Mohammed A, Ghanem M, Mohammed H. CPAP versus BiPAP in acute cardiogenic pulmonary edema experience with 129 patients. In: European Respiratory Society Annual Congress; 2008-10-04; Berlin, Germany. 2008. [CRSREF: 3006926]

Agmy G. The effect of CPAP and NPPV on acute pulmonary edema due to systolic diastolic or valvular heart failure. European Respiratory Journal 2007;30(Suppl 51):321. [CRSREF: 3006927]

Agmy GM. The effect of CPAP and NPPV on acute cardiogenic pulmonary edema due to systolic, diastolic or valvular heart failure. In: American Thoracic Society International Conference. 2007 May 18-23; San Francisco (CA). Vol. 1. $2007:$ A963. [CRSREF: 3006928]

NCT00912158. Non invasive mechanical ventilation in acute cardiogenic pulmonary edema. clinicaltrials.gov/ct2/show/NCT00912158 (first received 3 June 2009).

\section{Austin 2013}

\section{Published and unpublished data}

ACTRN12609000410257. A randomized clinical trial of continuous positive airway pressure (CPAP) in the treatment of acute cardiogenic pulmonary oedema (APO) patients in the pre-hospital setting (public title) [A randomized clinical trial assessing survival rates in patients with acute cardiogenic pulmonary oedema (ACPO) who are treated with continuous positive airway pressure (CPAP) in the pre-hospital setting (scientific title)]. anzctr.org.au/Trial/Registration/TrialReview.aspx?id=83909 (first received 9 May 2009).

* Austin MA, Wills KE, Kilpatrick D, Gibson M, Walters EH. Effect of continuous positive airway pressure (CPAP) on mortality in the treatment of acute cardiogenic pulmonary oedema (ACPO) in the pre-hospital setting: randomised controlled trial. Emergency Medicine Australasia 2013;25(S1):1-14.

\section{Crane 2004}

Published and unpublished data [CRSSTD: 3006937]

Crane SD, Elliott MW, Gilligan P, Richards K, Gray AJ. Randomized controlled comparison of continuous positive airway pressure, bilevel non-invasive ventilation, and standard treatment in emergency department patients with acute cardiogenic pulmonary oedema. Emergency Medicine Journal 2004;21(2):155-61. [CRSREF: 3006938]

\section{Ducros 2011}

* Ducros L, Logeart D, Vicaut E, Henry P, Plaisance P, Collet JP, et al. CPAP for acute cardiogenic pulmonary oedema from out-of-hospital to cardiac intensive care unit: a randomised multicentre study. Intensive Care Medicine 2011;37(9):1501-9. [_ PubMed: 21805159]

NCT00554580. Continuous positive airway pressure for acute pulmonary edema (CPAP). clinicaltrials.gov/ct2/show/NCT00554580 (First received 7 November 2007).

\section{El-Refay 2016}

ACTRN12614001208695. Comparison of bilevel and continuous positive airway pressure noninvasive ventilation in acute cardiogenic pulmonary edema [Efficacy of noninvasive bilevel versus continuous positive airway pressure on blood gases in acute cardiogenic pulmonary edema: a single blinded randomized trial]. www.anzctr.org.au/ACTRN12614001208695.aspx (First received 6 Oct 2014).

* El-Refay BH, Gwada RF, Ibrahim BS. Bi-level versus continuous positive airway pressure in acute cardiogenic pulmonary edema: a randomized control trial. Clinical Medicine Research 2015;4(6):221-28. [DOI: 10.11648/j.cmr.20150406.19]

\section{Frontin 2011}

[CRSSTD: 3006952]

* Frontin P, Bounes V, Houzé-Cerfon CH, Charpentier S, Houzé-Cerfon V, Ducassé JL. Continuous positive airway pressure for cardiogenic pulmonary edema: a randomized study. American Journal of Emergency Medicine 2011;29(7):775-81. [CRSREF: 3006953]

NCT00439075. Randomised controlled comparison of continuous positive airway pressure (CPAP) with standard treatment in out-of-hospital patients with acute cardiogenic pulmonary edema. clinicaltrials.gov/ct2/show/NCT00439075 First received 23 February 2007.

\section{Gray 2008}

[CRSSTD: 3006954]

* Gray A, Goodacre S, Newby DE, Masson M, Sampson F, Nicholl J. Noninvasive ventilation in acute cardiogenic pulmonary edema. New England Journal of Medicine 2008;359(2):142-51. [CRSREF: 3006955]

Gray AJ, Goodacre S, Newby DE, Masson MA, Sampson F, Dixon S, et al. A multicentre randomised controlled trial of the use of continuous positive airway pressure and non-invasive positive pressure ventilation in the early treatment of patients presenting to the emergency department with severe acute cardiogenic pulmonary oedema: the $3 \mathrm{CPO}$ trial. Health Technology Assessment 2009;13(33):1-106. [CRSREF: 3006956]

ISRCTN07448447. The effect of continuous positive airway pressure (CPAP) and non-invasive positive pressure ventilation (NIPPV) in acute cardiogenic pulmonary oedema (ACPO) [3CPO]. isrctn.com/ISRCTN07448447 (First received 25 April 
0416 Non-invasive positive pressure ventilation (CPAP or bilevel NPPV) for cardiogenic pulmonary oedema 2003).

Hao 2002

[CRSSTD: 3007072$]$

Hao CX, Luo XR, Liu YM. Treatment of severe cardiogenic pulmonary edema with continuous positive airway pressure by nasal face mask. Acta Academiae Medicinae Jiangxi 2002;42(5):48-50. [CRSREF: 3007073]

\section{Kelly 2002}

Published and unpublished data [CRSSTD: 3006957]

Kelly CA, Newby DE, McDonagh TA, MacKay TW, Barr J, Boon NA, et al. Randomised controlled trial of continuous positive airway pressure and standard oxygen therapy in acute pulmonary oedema. European Heart Journal 2002;23(17):1379-86. [CRSREF: 3006958]

\section{L'Her 2004}

[CRSSTD: 3006959]

L'Her E, Duquesne F, Girou E, Rosiere XD, Le Conte P, Renault S, et al. Noninvasive continuous positive airway pressure in elderly cardiogenic pulmonary edema patients. Intensive Care Medicine 2004;30(5):882-8. [CRSREF: 3006960]

\section{Levitt 2001}

[CRSSTD: 3006961]

Levitt MA. A prospective, randomized trial of BiPAP in severe acute congestive heart failure. Journal of Emergency Medicine 2001;21(4):363-9. [CRSREF: 3006962]

\section{Li 2005}

[CRSSTD: 3007128]

Li XK, Zhao WH. The treatment of acute cardiogenic pulmonary edema with noninvasive positive pressure ventilation. Chongqing Medical Journal 2005;34(4):575-6. [CRSREF: 3007129]

\section{Lin 1991}

[CRSSTD: 3006965]

Lin M, Chiang $\mathrm{H}$. The efficacy of early continuous positive airway pressure therapy in patients with acute cardiogenic pulmonary edema. Journal of the Formosan Medical Association 1991;90(8):736-43. [CRSREF: 3006966]

\section{Lin 1995}

[CRSSTD: 3006967]

Lin M, Yang Y, Chiang H, Chang M, Chiang BN, Cheitlin MD. Reappraisal of continuous positive airway pressure therapy in acute cardiogenic pulmonary edema. Chest 1995;107(5):1379-86. [CRSREF: 3006968]

\section{Masip 2000}

[CRSSTD: 3006971]

Masip J, Betbesé AJ, Paéz J, Vecilla F, Cañizares R, Padró J, et al. Non-invasive pressure support ventilation versus conventional oxygen therapy in acute cardiogenic pulmonary oedema: a randomized trial. Lancet 2000;356:2126-32. [CRSREF: 3006972]

\section{Moritz 2003}

[CRSSTD: 3007152]

Moritz F, Benichou J, Vanhest M, Richard JC, Line S, Hellot MF, et al. Boussignac continuous positive airway pressure device in the emergency care of acute cardiogenic pulmonary oedema: a randomized pilot study. European Journal of Emergency Medicine 2003;10(3):204-8. [CRSREF: 3007153; PubMed: 12972896]

\section{Nava 2003}

Published and unpublished data [CRSSTD: 3006977]

Carbone G, Di Battista N, Nava S. Noninvasive bilevel ventilation vs conventional therapy in the treatment of acute cardiogenic pulmonary edema: a randomized controlled study. European Respiratory Journal 2000;16:A3815. [CRSREF: 3006978]

* Nava S, Carbone G, DiBattista N, Bellone A, Baiardi P, Cosentini R, et al. Noninvasive ventilation in cardiogenic pulmonary edema. American Journal of Respiratory and Critical Care Medicine 2003;168(12):1432-7. [CRSREF: 3006979; MEDLINE: 12958051]

Nava S. Bilevel ventilation reduces the rate of endotracheal intubation in the hypercapnic, but not in the hypoxemic patients during acute respiratory failure due to cardiogenic pulmonary edema: a multicenter randomized study vs standard medical therapy. European Respiratory Journal 2001;18:A184s. [CRSREF: 3006980] 
0416 Non-invasive positive pressure ventilation (CPAP or bilevel NPPV) for cardiogenic pulmonary oedema

Published and unpublished data [CRSSTD: 3006981]

* Park M, Lorenzi-Filho G, Feltrim MI, Viecili PR, Sangean MC, Volpe M, et al. Oxygen therapy, continuous positive airway pressure, or noninvasive bilevel positive pressure ventilation in the treatment of acute cardiogenic pulmonary edema. Arquivos Brasileiros de Cardiologia 2001;76(3):226-30. [CRSREF: 3006982; PubMed: 11262572]

Park M. Randomized prospective trial of oxygen, continuous and bilevel positive airway pressure in the treatment of cardiogenic acute pulmonary edema. American Journal of Respiratory and Critical Care Medicine 2002;165(Suppl 8):A27. [CRSREF: 3006983]

\section{Park 2004}

Published and unpublished data [CRSSTD: 3006984]

Park M, Sangean MC, Volpe MS, Feltrim MIZ, Nozawa E, Leite PF, et al. Randomized, prospective trial of oxygen, continuous positive airway pressure by face mask in acute cardiogenic pulmonary edema. Critical Care Medicine 2004; 32(12):2407-15. [CRSREF: 3006985; PubMed: 15599144]

\section{Räsänen 1985}

[CRSSTD: 3006986]

Räsänen J, Heikkilä J, Downs J, Nikki P, Väisänen I, Viitanen A. Continuous positive airway pressure by face mask in acute cardiogenic pulmonary edema. American Journal of Cardiology 1985;55(4):296-300. [CRSREF: 3006987; PubMed: 3881920

\section{Takeda 1997}

Published and unpublished data [CRSSTD: 3006990]

Takeda S, Takano T, Ogawa R. The effect of nasal continuous positive airway pressure on plasma endothelin-1 concentrations in patients with severe cardiogenic pulmonary edema. Anesthesia and Analgesia 1997;84(5):1091-6. [CRSREF: 3006991; PubMed: 9141937]

\section{Takeda 1998}

Published and unpublished data [CRSSTD: 3006992]

Takeda S, Neijima J, Takano T, Nakanishi K, Takayama M, Sakamoto A, et al. Effect of nasal continuous positive airway pressure on pulmonary edema complicating acute myocardial infarction. Japanese Circulation Journal 1998;62(8):553-8. [CRSREF: 3006993; PubMed: 9741730]

\section{Thys 2002}

Published and unpublished data [CRSSTD: 3006994]

Thys F, Roeseler J, Reynaert M, Liistro G, Rodenstein DO. Noninvasive ventilation for acute respiratory failure: a prospective randomised placebo-controlled trial. European Respiratory Journal 2002;20(3):545-55. [CRSREF: 3006995; PubMed: 12358327]

\section{Zokaei 2016}

Zokaei A, Ahmadi SJ, Hemmati N. Noninvasive Pressure Control Inverse Ratio Ventilation (NIPCIRV) versus conventional oxygen therapy for treatment of acute cardiogenic pulmonary edema. Research Journal of Medical Sciences 2016; 10(5):449-52. [DOI: 10.3923/rjmsci.2016.449.452]

\section{Excluded studies}

\section{ACTRN12610000487011}

ACTRN12610000487011. Prehospital continuous positive airway pressure (CPAP) for acute cardiogenic pulmonary oedema: a randomised controlled trial [In prehospital patients with acute cardiogenic pulmonary oedema, does continuous positive airway pressure (CPAP) plus standard care, compared to standard care alone, reduce mortality?]. www.anzctr.org.au/ACTRN12610000487011.aspx (First received 9 June 2010).

\section{ACTRN12610000528055}

ACTRN12610000528055. The effects of continuous positive airway pressure on lung function in patients with acute exacerbation of heart failure [In patients with acute decompensated heart failure does continuous positive airway pressure compared to oxygen or standard medical therapy result in improved lung function?]. www.anzctr.org.au/ACTRN12610000528055.aspx (First received 25 June 2010).

\section{Baratz 1992}

[Other: PMID 1424858]

Baratz DM, Westbrook PR, Shah PK, Mohsenifar Z. Effect of nasal continuous positive airway pressure on cardiac output and oxygen delivery in patients with congestive heart failure. Chest 1992;102(5):1397-401. [PubMed: 1424858]

\section{Bautin 2005}

Published and unpublished data [CRSSTD: 3006929]

Bautin A, Khubulava G, Naumov A, Garifzjanov A, Etin V. NPPV in the treatment of the cardiogenic edema (CPE) after heart 
0416 Non-invasive positive pressure ventilation (CPAP or bilevel NPPV) for cardiogenic pulmonary oedema surgery. European Respiratory Journal 2005;26(Suppl 49):3112. [CRSREF: 3006930]

\section{Belenguer-Muncharaz 2017}

[ClinicalTrials.gov: NCT02977572]

Belenguer-Muncharaz A, Mateu-Campos L, Gonzalez-Luis R, Vidal-Tegedor B, Ferrandiz-Selles A, Arguedas-Cervera J, et al. Non-invasive mechanical ventilation versus continuous positive airway pressure relating to cardiogenic pulmonary edema in an intensive care unit. Archivos de Bronconeumologia 2017;53(10):561-7. [ PubMed: 28689679]

\section{Bellone 2002}

[CRSSTD: 3007018 ]

Bellone A, Barbieri A, Ricci C, Iori E, Donateo M, Massobrio M, et al. Acute effects of non-invasive ventilatory support on functional mitral regurgitation in patients with exacerbation of congestive heart failure. Intensive Care Medicine 2002; 28(9):1348-50. [CRSREF: 3007019; DOI: 10.1007/s00134-002-1424-1]

\section{Bellone 2004}

[CRSSTD: 3006931]

Bellone A, Monari A, Cortellaro F, Vetorello M, Arlati S, Coen D. Myocardial infarction rate in acute pulmonary edema: noninvasive support ventilation versus continuous positive airway pressure. Critical Care Medicine 2004;32(9):1860-5. [CRSREF: 3006932]

\section{Bellone 2005}

[CRSSTD: 3006933]

Bellone A, Vettorello M, Monari A, Cortellaro F, Coen D. Noninvasive pressure support ventilation vs. continuous positive airway pressure in acute hypercapnic pulmonary edema. Intensive Care Medicine 2005;31:807-11. [CRSREF: 3006934]

\section{Bendjelid 2005}

Bendjelid K, Schütz N, Suter PM, Fournier G, Jacques D, Fareh S, et al. Does continuous positive airway pressure by face mask improve patients with acute cardiogenic pulmonary edema due to left ventricular diastolic dysfunction? Chest 2005; 127(3):1053-8. [ PubMed: 15764794]

\section{Bersten 1991}

Published and unpublished data [CRSSTD: 3006935]

Bersten AD, Holt AW, Vedig AE, Skowronski GA, Bagooley CJ. Treatment of severe cardiogenic pulmonary edema with continuous positive airway pressure delivered by face mask. New England Journal of Medicine 1991;325(26):1825-30. [CRSREF: 3006936]

\section{Blanco 2015}

Blanco JB, Esquinas AM. Acute effects of continuous positive airway pressure on pulse pressure in CHF. Arquivos Brasileiros de Cardiologia 2015;104(2):175-6. [PubMed: 25830857]

\section{Chadda 2002}

[CRSSTD: 3007034; DOI: 10.1097/01.CCM.0000034691.01813.94]

Chadda K, Annane D, Hart N, Gajdos P, Raphael JC, Lofaso F. Cardiac and respiratory effects of continuous positive airway pressure and noninvasive ventilation in acute cardiac pulmonary edema. Critical Care Medicine 2002;30(11):2457-61.

[CRSREF: 3007035]

\section{Craven 2000}

Craven RA, Singletary N, Bosken L, Sewell E, Payne M, Lipsey R. Use of bilevel positive airway pressure in out-of-hospital patients. Academic Emergency Medicine 2000;7(9):1065-8. [PubMed: 11044006]

\section{Delclaux 2000}

[CRSSTD: 3006939]

Delclaux C, L'Her E, Alberti C, Mancebo J, Abroug F, Conti G, et al. Treatment of acute hypoxemic nonhypercapnic respiratory insufficiency with continuous positive airway pressure delivery by a face mask. JAMA 2000;284:2352-60. [CRSREF: 3006940]

\section{Dib 2012}

Dib JE, Matin SA, Luckert A. Prehospital use of continuous positive airway pressure for acute severe congestive heart failure. Journal of Emergency Medicine 2012;42(5):553-8. [PubMed: 21911283]

\section{Ferrari 2007}

[CRSSTD: 3006941; ClinicalTrials.gov: NCT00453947]

Ferrari G, Olliveri F, De Filippi G, Milan A, Apra F, Boccuzzi A, et al. Noninvasive positive airway pressure and risk of myocardial infarction in acute cardiogenic pulmonary edema: continuous positive airway pressure vs noninvasive positive pressure ventilation. Chest 2007;132(6):1804-9. [CRSREF: 3006942] 
0416 Non-invasive positive pressure ventilation (CPAP or bilevel NPPV) for cardiogenic pulmonary oedema

\section{Ferrari 2010}

[CRSSTD: 3006943]

Ferrari G, Groff P, De Filippi G, Giostra F, Mazzone M, Potale G, et al. Continuous positive airway pressure (CPAP) vs. noninvasive positive pressure ventilation (NIV) in acute cardiogenic pulmonary edema (ACPE): A prospective randomized multicentric study. Journal of Emergency Medicine 2006;30:246-7. [CRSREF: 3006944]

* Ferrari G, Milan A, Groff P, Pagnozzi F, Mazzone M, Molino P, et al. Continuous positive airway pressure vs. pressure support ventilation in acute cardiogenic pulmonary edema: a randomized trial. Journal of Emergency Medicine 2010; 39(5):676-84. [CRSREF: 3006945]

NCT00446498. CPAP Versus NPPV in ACPE [Continuous positive airway pressure versus non-invasive positive pressure support ventilation in acute cardiogenic pulmonary oedema: a prospective randomised multicentre trial]. clinicaltrials.gov/show/nct00446498 (first received 13 March 2007).

\section{Ferrer 2003}

Ferrer M, Esquinas A, Leon M, Gonzalez G, Alarcon A, Torres A. Noninvasive ventilation in severe hypoxemic respiratory failure: a randomized clinical trial. American Journal of Respiratory and Critical Care Medicine 2003;168(12):1438-44.

\section{Fontanella 2010}

[CRSSTD: 3006949]

Bordonali T, Fontanella B, Affatato A, Saporetti A, Carubelli V, Ciccarese C, et al. Comparison of continuous positive airway pressure (CPAP) versus bilevel non invasive pressure support ventilation (NIPSV) in acute cardiogenic pulmonary edema. European Heart Journal 2009;30:369. [CRSREF: 3006950; EMBASE: 797]

${ }^{*}$ Fontanella B, Affatato A, Ciccarese C, Sacchini M, Volpini M, Bianchetti F, et al. Prospective comparison of continuous positive airway pressure (CPAP) versus bilevel non invasive pressure support ventilation (BPAP) in acute cardiogenic pulmonary edema. European Heart Journal Supplements 2010;12 (supplement F):F37-F38. [CRSREF: 3006951]

\section{Foti 2009}

Foti G, Sangalli F, Berra L, Sironi S, Cazzaniga M, Rossi GP, et al. Is helmet CPAP first line pre-hospital treatment of presumed severe acute pulmonary edema? Intensive Care Medicine 2009;35(4):656-62. [PubMed: 19030843]

\section{Gorbunova 2007}

[CRSSTD: 3007062]

Gorbunova M, Babak S, Tatrskiy A. Effect of nasal continuous positive airway pressure on respiratory failure and left ventricular dysfunction complicating acute myocardial infarction. European Respiratory Journal 2005;26(Suppl 49):1. [CRSREF: 3007063]

* Gorbunova MV, Tatarsky AR, Babak SL, Golubev LA, Chuchalin AG. Clinical and hemodynamic effects of CPAP-therapy in patients with cardiogenic pulmonary edema [?????????? ? ??????????????? ??????? ???? ??????? ? ????????? ? ???????????? ?????? ?????? ]. General Reanimatology 2007;3(1):52-6. [DOI: 10.15360/1813-9779-2007-1-52-56]

\section{Hubble 2006}

Hubble MW, Richards ME, Jarvis R, Millikan T, Young D. Effectiveness of prehospital continuous positive airway pressure in the management of acute pulmonary edema. Prehospital Emergency Care 2006;10(4):430-9. [PubMed: 16997770]

\section{L'Her 2003}

L'Her E. Noninvasive mechanical ventilation in acute cardiogenic pulmonary edema. Current Opinion in Critical Care 2003; 9(1):67-71. [PubMed: 12548032]

\section{Leman 2005}

Leman P, Greene S, Whelan K, Legassick T. Simple lightweight disposable continuous positive airways pressure mask to effectively treat acute pulmonary oedema: Randomized controlled trial. Emergency Medicine Australasia 2015;17(3):224-30. [PubMed: 15953223]

\section{Liesching 2014}

* Liesching T, Nelson DL, Cormier KL, Sucov A, Short K, Warburton R, et al. Randomized trial of bilevel versus continuous positive airway pressure for acute pulmonary edema. Journal of Emergency Medicine 2014;46(1):130-40. [PubMed: 24071031]

Liesching TN, Cromier K, Nelson D, Short K, Sucov A, Hill NS. Bilevel noninvasive ventilation vs continuous positive airway pressure to treat acute pulmonary edema. American Journal of Respiratory and Critical Care Medicine 2003;167(Suppl 7):27. [CRSREF: 3006964]

\section{Martin-Bermudez 2002}

Published and unpublished data [CRSSTD: 3006969]

Martin-Bermudez R, Rodríguez-Portal J, García-Garmendia J. Non-invasive ventilation in cardiogenic pulmonary edema. 
0416 Non-invasive positive pressure ventilation (CPAP or bilevel NPPV) for cardiogenic pulmonary oedema

Preliminary results of a randomized trial. Intensive Care Medicine 2002;28:S68. [CRSREF: 3006970]

Mehta 1997

[CRSSTD: 3006973]

Mehta S, Jay GD, Woolard RH, Hipona RA, Connolly EM, Cimini DM, et al. Randomized, prospective trial of bilevel versus continuous positive airway pressure in acute pulmonary edema. Critical Care Medicine 1997;25(4):620-8. [CRSREF: 3006974]

\section{Minuto 2003}

Minuto A, Giacomini M, Giamundo B, Tartufari A, Denkewitz T, Marzorati S, et al. Non-invasive mechanical ventilation in patients with acute cardiogenic pulmonary edema. Minerva Anestesiologica 2003;69(11):838-40. [PubMed: 14735023]

\section{Moritz 2007}

[CRSSTD: 3006975]

Moritz F, Brousse B, Gellee B, Chajara A, L'Her E, Hellot MF, et al. Continuous positive airway pressure versus bilevel noninvasive ventilation in acute cardiogenic pulmonary edema: a randomized multicenter trial. Annals of Emergency Medicine 2007;50(6):666-75. [CRSREF: 3006976; PubMed: 17764785]

\section{NCT00375154}

NCT00375154. HERMES Study: Study on the feasibility and efficiency of noninvasive positive-pressure ventilation (NPPV) in prehospital care [Noninvasive positive-pressure ventilation (NPPV) for acute respiratory failure in out-of-hospital patients: a multicenter, prospective, randomized controlled trial (PI: Thys)]. ClinicalTrials.gov/show/NCT00375154 (first received 12 September 2006).

\section{Nouira 2011}

Nouira S, Boukef R, Bouida W, Kerkeni W, Beltaief K, Boubaker H, et al. Non-invasive pressure support ventilation and CPAP in cardiogenic pulmonary edema: a multicenter randomized study in the emergency department. Intensive Care Medicine 2011;37(2):249-56. [PubMed: 21136039]

\section{Oliver 2013}

Oliver CM, Narayanan M. Out-of-hospital CPAP in the treatment of cardiogenic pulmonary oedema. Journal of the Intensive Care Society 2013;14(2):176-7.

\section{Ozsancak 2013}

Ozsancak A, Sidhom SS, Liesching TN, Howard W, Hill NS. Evaluation of the total face mask for noninvasive ventilation to treat acute respiratory failure. Chest 2011;139(5):1034-41.

\section{Pagano 2018}

Pagano A, Numis FG, Rosato V, Russo T, Porta G, Bosso G, et al. Pressure support ventilation vs continuous positive airway pressure for treating of acute cardiogenic pulmonary edema: A pilot study. Respiratory Physiology \& Neurobiology 2018;255:7-10. [DOI: 10.1016/j.resp.2018.04.007]

\section{Philip-Joet 1999}

[CRSSTD: 3007182]

Philip-Joet FF, Paganelli FF, Dutau HL. Hemodynamic effects of bilevel nasal positive airway pressure ventilation in patients with heart failure. Respiration 1999;66(2):136-43. [CRSREF: 3007183]

\section{Plaisance 2007}

[CRSSTD: 3007184$]$

NCT00390442. Out-of-hospital CPAP for severe cardiogenic pulmonary edema [Effect of continuous positive airway pressure as a first line therapy in out-of-hospital management of severe cardiogenic pulmonary edema]. clinicaltrials.gov/show/NCT00390442 (first received 19 October 2006).

* Plaisance P, Pirracchio R, Berton C, Vicaut E, Payen D. A randomized study of out-of-hospital continuous positive airway pressure for acute cardiogenic pulmonary oedema. European Heart Journal 2007;28(23):2895-901. [CRSREF: 3007185]

\section{Popova 2010}

[CRSSTD: 3007190]

Popova X, Avdeev S, Nekludova G, Chuchalin A. Effect of noninvasive ventilation (NIV) on exercise tolerance in patients with acute decompensated heart failure. In: Europe Respiratory Society Conference; 2010 Sep 18-22; Barcelona, Spain. 2010:E3918. [CRSREF: 3007191]

\section{Rusterholtz 1999}

[CRSSTD: 3007202]

Rusterholtz T, Kempf J, Berton C, Gayol S, Tournoud C, Zaehringer M, et al. Noninvasive pressure support ventilation (NIPSV) with face mask in patients with acute cardiogenic pulmonary edema. Intensive Care Medicine 1999;25(1):21-8. 
0416 Non-invasive positive pressure ventilation (CPAP or bilevel NPPV) for cardiogenic pulmonary oedema

[CRSREF: 3007203]

Sharon 2000

[CRSSTD: 3006988]

Sharon A, Shpirer I, Kaluski E, Moshkovitz Y, Milanov O, Polak R, et al. High-dose intravenous Isosorbide-dinitrate is safer and better than Bi-PAP ventilation for severe pulmonary edema. Journal of the American College of Cardiology 2000; 36(3):832-7. [CRSREF: 3006989; PubMed: 10987607]

Somauroo 2000

[CRSSTD: 3007222]

Somauroo J, Wilkinson M, White V, Rodrigues E, Connolly D, Calverley P, et al. Acute hemodynamic changes of nasal bilevel and continuous positive airway pressure ventilation in patients with congestive heart failure. American Journal of Respiratory and Critical Care Medicine 2000;161(3):A548. [CRSREF: 3007223]

\section{Uy 2004}

Uy CA, Limpin MB, Guzman AV, De Guia TS. Continuous positive airway pressure among patients with cardiogenic pulmonary edema. American Journal of Respiratory and Critical Care Medicine 2004;169:A524.

\section{Vaisanen 1987}

[CRSSTD: 3007232]

Vaisanen IT, Rasane J. Continuous positive airway pressure and supplemental oxygen in the treatment of cardiogenic pulmonary edema. Chest 1987;92(3):481-5. [CRSREF: 3007233]

\section{Weitz 2007}

Published and unpublished data [CRSSTD: 3006996; Other:]

Weitz G, Struck J, Zonak A, Balnus S, Perras B, Dodt C. Prehospital noninvasive pressure support ventilation for acute cardiogenic pulmonary edema. European Journal of Emergency Medicine 2007;14(5):276-9. [CRSREF: 3006997; PubMed:

\section{Studies awaiting classification}

Ongoing studies

\section{Other references}

\section{Additional references}

\section{Allison 1991}

Allison RC. Initial treatment of pulmonary edema: a physiological approach. American Journal of the Medical Sciences 1991;302(6):385-91. [MEDLINE: 1772126]

\section{Alviar 2018}

Alviar CL, Miller PE, McAreavey D, Katz JN, Lee B, Moriyama B, et al; ACC Critical Care Cardiology Working Group. Positive pressure ventilation in the cardiac intensive care unit. Journal of the American College of Cardiology 2018; 72(13):1532-53. [DOI: 10.1016/j.jacc.2018.06.074]

\section{Anzueto 2004}

Anzueto A, Frutos-Vivar F, Esteban A, Alía I, Brochard L. Stewart T, et al. Incidence, risk factors and outcome of barotrauma in mechanically ventilated patients. Intensive Care Medicine 2004;30(4):612-9.

\section{Benjamin 2017}

Benjamin EJ, Blaha MJ, Chiuve SE, Cushman M, Das SR, Deo R, et al. Heart disease and stroke statistics-2017 Update: A report From the American Heart Association. Circulation 2017;135(10):e146-603. [PubMed: 28122885]

Buda 1979

Buda AJ, Pinsky MR, Ingels NB Jr, Daughters GT, Stinson EB, Alderman EL. Effect of intrathoracic pressure on left ventricular performance. New England Journal of Medicine 1979;301(9):453-9. [DOI: 10.1056/NEJM197908303010901]

\section{Collins 2006}

Collins SP, Mielniczuk LM, Whittingham HA, Boseley ME, Schramm DR, Storrow AB. The use of noninvasive ventilation in emergency department patients with acute cardiogenic pulmonary edema: a systematic review. Annals of Emergency Medicine 2006;48(3):260-9.

\section{Egger 1997}

Egger M, Smith GD, Schneider M, Minder C. Bias in meta-analysis detected by simple, graph test. BMJ 1997; 315(7109):629-34.

\section{Ezekowitz 2017}

Ezekowitz JA, O'Meara E, McDonald MA, Abrams H, Chan M, Ducharme A, et al. 2017 Comprehensive update of the 
0416 Non-invasive positive pressure ventilation (CPAP or bilevel NPPV) for cardiogenic pulmonary oedema

Canadian Cardiovascular Society guidelines for the management of heart failure. Canadian Journal of Cardiology 2017; 33(11):1342-433. [PubMed: 29111106]

Gay 2009

Gay PC. Complications of noninvasive ventilation in acute care. Respiratory Care 2009;54(2):246-57. [MEDLINE: 19173756]

\section{Guyatt 2008}

Guyatt GH, Oxman AD, Vist G, Kunz R, Falck-Ytter Y, Alonso-Coello P, et al; GRADE Working Group. GRADE: an emerging consensus on rating quality of evidence and strength of recommendations. BMJ 2008;336(7650):924-6. [DOI:

10.1136/bmj.39489.470347.AD]

\section{Hess 2004}

Hess DR. The evidence for noninvasive positive-pressure ventilation in the care of patients in acute respiratory failure: a systematic review of the literature. Respiratory Care 2004;49(7):810-29. [ PubMed: 15222912]

\section{Higgins 2011}

Higgins JP, Green S, editor(s). Cochrane Handbook for Systematic Reviews of Interventions Version 5.1.0 (updated March 2011). The Cochrane Collaboration, 2011. Available from www.handbook.cochrane.org.

\section{Higgins 2017}

Higgins JP, Churchill R, Chandler J, Cumpston MS, editor(s). Cochrane Handbook for Systematic Reviews of Interventions version 5.2.0 (updated June 2017), Cochrane, 2017. Available from training.cochrane.org/handbook 2017.

\section{Higgins 2018}

Higgins JP, Lasserson T, Chandler J, Tovey D, Churchill R. Methodological Expectations of Cochrane Intervention Reviews. community.cochrane.org/mecir-manual 2018 (accessed 25 March 2019).

\section{Ho 2006}

Ho KM, Wong K. A comparison of continuous and bi-level positive airway pressure non-invasive ventilation in patients with acute cardiogenic pulmonary oedema: a meta-analysis. Critical Care 2006;10(2):R49.

\section{Jadad 2000}

Jadad AR, Moher M, Browman GP, Booker L, Sigouin C, Fuentes M, et al. Systematic reviews and meta-analyses on treatment of asthma: critical evaluation. BMJ 2000;320(7234):537-40.

\section{Lefebvre 2011}

Lefebvre C, Manheimer E, Glanville J. Chapter 6: Searching for studies. In: Higgins JP, Green S, editor(s). Cochrane Handbook for Systematic Reviews of Interventions Version 5.1.0 (updated March 2011). The Cochrane Collaboration, 2011. Available from www.handbook.cochrane.org.

\section{Lenique 1997}

Lenique F, Habis M, Lofaso F, Dubois-Rande JL, Harf A, Brochard L. Ventilatory and haemodynamic effects of continuous positive airway pressure in left heart failure. American Journal of Respiratory and Critical Care Medicine 1997;155(2):500-5. [DOI: 10.1164/ajrccm.155.2.9032185]

\section{Levine 2008}

Levine S, Nguyen T, Taylor N, Friscia ME, Budak MT, Rothenberg P. Rapid disuse atrophy of diaphragm fibers in mechanically ventilated humans.. New England Journal of Medicine 2008;358(13):1327-35. [DOI: 10.1056/NEJMoa070447]

\section{Magder 1983}

Magder SA, Lichtenstein S, Adelman AG. Effect of negative pleural pressure on left ventricular hemodynamics. American Journal of Cardiology 1983;52(5):588-93. [MEDLINE: 6613883]

\section{Masip 2005}

Masip J, Roque M, Sanchez B, Fernandez R, Subirana M, Exposito JA. Noninvasive ventilation in acute cardiogenic pulmonary edema: systematic review and meta-analysis. JAMA 2005;294(24):3124-30.

\section{McKibbon 2004}

McKibbon KA, Wilczynski NL, Haynes RB. What do evidence-based secondary journals tell us about the publication of clinically important article in primary healthcare journals? BMC Medicine 2004;2:33.

\section{Nadar 2005}

Nadar S, Prasad N, Taylor RS, Lip GY. Positive pressure ventilation in the management of acute and chronic cardiac failure: a systematic review and meta-analysis. International Journal of Cardiology 2005;99(2):171-85. [DOI: 10.1016/j.ijcard.2004.03.047]

\section{Nava 2009}

Nava S, Hill N. Non-invasive ventilation in acute respiratory failure. Lancet 2009;374(9685):250-9. [DOI: 
0416 Non-invasive positive pressure ventilation (CPAP or bilevel NPPV) for cardiogenic pulmonary oedema

10.1016/S0140-6736(09)60496-7]

\section{Packer 1993}

Packer M. How should physicians view heart-failure - the philosophical and physiological evolution of 3 conceptual models of the disease. American Journal of Cardiology 1993;71(9):C3-C11. [DOI: 10.1016/0002-9149(93)90081-M]

\section{Pang 1998}

Pang D, Keenan SP, Cook DJ, Sibbald WJ. The effect of positive pressure airway support on mortality and the need for intubation in cardiogenic pulmonary edema: a systematic review. Chest 1998;114(4):1185-92. [MEDLINE: 9792593]

\section{Peter 2006}

Peter JV, Moran JL, Phillips-Hughes J, Graham P, Bersten AD. Effect of non-invasive positive pressure ventilation (NIPPV) on mortality in patients with acute cardiogenic pulmonary oedema: a meta-analysis. Lancet 2006;367:1155-63.

\section{Ponikowski 2016}

Ponikowski P, Voors AA, Anker SD, Bueno H, Cleland JG, Coats AJ, et al; ESC Scientific Document Group. 2016 ESC Guidelines for the diagnosis and treatment of acute and chronic heart failure: The Task Force for the diagnosis and treatment of acute and chronic heart failure of the European Society of Cardiology (ESC) Developed with the special contribution of the Heart Failure Association (HFA) of the ESC. European Heart Journal 2016;37(27):2129-200. [DOI:

10.1093/eurheartj/ehw128]

\section{Potts 2009}

Potts JM. Noninvasive positive pressure ventilation: effect on mortality in acute cardiogenic pulmonary edema: a pragmatic meta-analysis. Polskie Archiwum Medycyny Wewn?trznej 2009;119(6):349-52.

\section{Review Manager 2014}

Review Manager (RevMan) [Computer program]. Version 5.3. Copenhagen: The Nordic Cochrane Centre, The Cochrane Collaboration, 2014.

\section{Rudiger 2005}

Rudiger A, Harjola VP, Muller A, Mattila E, Saila P, Nieminen M, et al. Acute heart failure: clinical presentation, one-year mortality and prognostic factors. European Journal of Heart Failure 2005;7(4):662-70. [PubMed: 15921809]

\section{Slutsky 2013}

Slutsky AS, Ranieri VM. Ventilator-induced lung injury. New England Journal of Medicine 2013;369(22):2126-36. [MEDLINE: 24283226]

\section{Spalding 2017}

Spalding MC, Cripps MW, Minshall CT. Ventilator-associated pneumonia: new definitions. Critical Care Clinics 2017; 33(2):277-92. [DOI: 10.1016/j.ccc.2016.12.009]

\section{Sterne 2011}

Sterne JA, Sutton AJ, loannidis JP, Terrin N, Jones DR, Lau J, et al. Recommendations for examining and interpreting funnel plot asymmetry in meta-analyses of randomised controlled trials. BMJ 2011;343:d4002. [DOI: 10.1136/bmj.d4002]

\section{Tobin 1994}

Tobin MJ. Mechanical ventilation. New England Journal of Medicine 1994;330(15):1056-61. [DOI: 10.1056/NEJM199404143301507]

\section{Wang 2005}

Wang CS, FitzGerald JM, Schulzer M, Mak E, Ayas NT. Does this dyspneic patient in the emergency department have congestive heart failure? JAMA 2005;294(15):1944-56. [DOI: 10.1001/jama.294.15.1944; MEDLINE: 16234501]

\section{Weng 2010}

Weng CL, Zhao YT, Liu QH, Fu CJ, Sun F, Ma YL, et al. Meta-analysis: Noninvasive ventilation in acute cardiogenic pulmonary edema. Annals of Internal Medicine 2010;152(9):590-600.

\section{Winck 2006}

Winck JC, Azevedo LF, Costa-Pereira A, Antonelli M, Wyatt JC. Efficacy and safety of non-invasive ventilation in the treatment of acute cardiogenic pulmonary edema - a systematic review and meta-analysis. Critical Care (London, England) 2006;10(2):R69.

\section{Yancy 2013}

Yancy CW, Jessup M, Bozkurt B, Butler J, Casey DE Jr, Drazner MH, et al; American College of Cardiology Foundation/American Heart Association Task Force on Practice Guidelines. 2013 ACCF/AHA guideline for the management of heart failure: a report of the American College of Cardiology Foundation/American Heart Association Task Force on practice guidelines. Circulation 2013;128(16):e240-327. [DOI: 10.1161/CIR.0b013e31829e8776] 


\section{Zumdahl 2002}

Zumdahl, SS. Chemical Principles. 4th edition. Boston, MA: Houghton Mifflin Company, 2002.

\section{Other published versions of this review}

\section{Vital 2005}

Vital FMR, Sen A, Atallah AN, Ladeira MTT, Soares BGDO, Burns KEA, Hawkes C. Non-invasive positive pressure ventilation (CPAP or BiPAP) in cardiogenic pulmonary oedema (Protocol). Cochrane Database of Systematic Reviews 2005, Issue 3. Art. No.: CD005351 DOI: 10.1002/14651858.CD005351.

\section{Vital 2008}

Vital FMR, Saconato H, Ladeira MT, Sen A, Hawkes CA, Soares B, Burns KEA, Atallah ÁN. Non-invasive positive pressure ventilation (CPAP or bilevel NPPV) for cardiogenic pulmonary edema. Cochrane Database of Systematic Reviews 2008, Issue 3. Art. No.: CD005351 DOI: 10.1002/14651858.CD005351.pub2.

\section{Vital 2013}

Vital FMR, Ladeira MT, Atallah ÁN. Non? invasive positive pressure ventilation (CPAP or bilevel NPPV) for cardiogenic pulmonary oedema. Cochrane Database of Systematic Reviews 2013, Issue 5. Art. No.: CD005351 DOI:

10.1002/14651858.CD005351.pub3.

\section{Classification pending references}

\section{Data and analyses}

\section{NPPV vs SMC}

\begin{tabular}{|c|c|c|c|c|}
\hline Outcome or Subqroup & Studies & Partic & Statistical Method & Effect Estimate \\
\hline 1.1 HOSPITAL MORTALITY & 21 & 2484 & Risk Ratio(M-H, Random, 95\% Cl) & $0.65[0.51,0.82]$ \\
\hline 1.2 Hospital mortality - by NPPV & 21 & 2484 & Risk Ratio(M-H, Random, 95\% Cl) & $0.71[0.58,0.87]$ \\
\hline 1.2.1 CPAP vs SMC & 16 & 1454 & Risk Ratio(M-H, Random, 95\% Cl) & $0.65[0.48,0.88]$ \\
\hline 1.2.2 bilevel NPPV vs SMC & 11 & 1030 & Risk Ratio(M-H, Random, 95\% Cl) & $0.72[0.53,0.98]$ \\
\hline 1.3 Hospital mortality - by location & 21 & 2484 & Risk Ratio(M-H, Random, 95\% Cl) & $0.65[0.51,0.82]$ \\
\hline 1.3.1 ER & 10 & 1596 & Risk Ratio(M-H, Random, 95\% Cl) & $0.66[0.47,0.93]$ \\
\hline 1.3.2 ICU & 10 & 862 & Risk Ratio(M-H, Random, 95\% Cl) & $0.52[0.35,0.77]$ \\
\hline 1.3.3 unclear & 1 & 26 & Risk Ratio(M-H, Random, 95\% Cl) & $1.94[0.09,43.50]$ \\
\hline $\begin{array}{l}1.4 \mathrm{Hospital}_{\text {mortality - by baseline }} \\
\mathrm{PaCO}_{2}\end{array}$ & 21 & 2484 & Risk Ratio(M-H, Random, 95\% Cl) & $0.65[0.51,0.82]$ \\
\hline 1.4.1 $\mathrm{PaCO} 2<=45 \mathrm{mmHa}$ & 10 & 581 & Risk Ratio(M-H, Random, 95\% Cl) & $0.41[0.27,0.63]$ \\
\hline 1.4.2 $\mathrm{PaCO} 2>45 \mathrm{mmHg}$ & 11 & 1903 & Risk Ratio(M-H, Random, 95\% Cl) & $0.82[0.65,1.03]$ \\
\hline $\begin{array}{l}1.5 \text { Hospital mortality - sensitivity } \\
\text { analysis (low risk of bias) }\end{array}$ & 7 & 1505 & Risk Ratio(M-H, Random, 95\% Cl) & $0.81[0.61,1.06]$ \\
\hline $\begin{array}{l}\text { 1.6 Hospital mortality - sensitivity } \\
\text { analysis (missing data) }\end{array}$ & 18 & 2283 & Risk Ratio(M-H, Random, 95\% Cl) & $0.68[0.54,0.86]$ \\
\hline $\begin{array}{l}1.7 \text { Hospital mortality - sensitivity } \\
\text { analysis (fixed-effect) }\end{array}$ & 21 & 2484 & Risk Ratio(M-H, Fixed, 95\% Cl) & $0.67[0.55,0.81]$ \\
\hline 1.8 ETI RATE & 20 & 2449 & Risk Ratio(M-H, Random, 95\% Cl) & $0.49[0.38,0.62]$ \\
\hline $1.9 \mathrm{ETI}$ rate - by NPPV & 20 & 2449 & Risk Ratio(M-H, Random, 95\% Cl) & $0.49[0.39,0.63]$ \\
\hline 1.9.1 CPAP vs SMC & 15 & 1413 & Risk Ratio(M-H, Random, 95\% Cl) & $0.46[0.34,0.62]$ \\
\hline 1.9.2 Bilevel NPPV vs SMC & 11 & 1036 & Risk Ratio(M-H, Random, 95\% Cl) & $0.50[0.31,0.81]$ \\
\hline 1.10 ETI rate - by location & 20 & 2449 & Risk Ratio(M-H, Random, 95\% Cl) & $0.49[0.38,0.62]$ \\
\hline 1.10.1 ER & 9 & 1561 & Risk Ratio(M-H, Random, 95\% Cl) & $0.60[0.37,0.96]$ \\
\hline 1.10.2 ICU & 10 & 862 & Risk Ratio(M-H, Random, 95\% Cl) & $0.40[0.29,0.56]$ \\
\hline 1.10.3 unclear & 1 & 26 & Risk Ratio(M-H, Random, 95\% Cl) & $0.47[0.13,1.67]$ \\
\hline 1.11 ETI rate - by baseline $\mathrm{PaCO}_{2}$ & 20 & 2449 & Risk Ratio(M-H, Random, 95\% Cl) & $0.49[0.38,0.62]$ \\
\hline 1.11.1 $\mathrm{PaCO} 2<=45 \mathrm{mmHg}$ & 9 & 523 & Risk Ratio(M-H, Random, 95\% Cl) & $0.37[0.26,0.52]$ \\
\hline 1.11.2 $\mathrm{PaCO} 2>45 \mathrm{mmHa}$ & 11 & 1926 & Risk Ratio(M-H, Random, 95\% Cl) & $0.64[0.46,0.91]$ \\
\hline $\begin{array}{l}1.12 \text { ETI rate - sensitivity analysis } \\
\text { (low risk of bias) }\end{array}$ & 6 & 1491 & Risk Ratio(M-H, Random, 95\% Cl) & $0.85[0.55,1.32]$ \\
\hline $\begin{array}{l}1.13 \text { ETI rate - sensitivity analysis } \\
\text { (missing data) }\end{array}$ & 17 & 2248 & Risk Ratio(M-H, Random, 95\% Cl) & $0.52[0.40,0.69]$ \\
\hline
\end{tabular}


0416 Non-invasive positive pressure ventilation (CPAP or bilevel NPPV) for cardiogenic pulmonary oedema

\begin{tabular}{|c|c|c|c|c|}
\hline 1.14 ETI rate - by face mask type & 20 & 2449 & Risk Ratio(M-H, Random, 95\% Cl) & $0.49[0.38,0.62]$ \\
\hline $\begin{array}{l}\text { 1.14.1 Exclusive full face mask } \\
\text { use }\end{array}$ & 15 & 2213 & Risk Ratio(M-H, Random, 95\% Cl) & $0.52[0.40,0.69]$ \\
\hline $\begin{array}{l}\text { 1.14.2 Exclusive or permissive } \\
\text { nasal mask use }\end{array}$ & 5 & 236 & Risk Ratio(M-H, Random, 95\% Cl) & $0.35[0.20,0.62]$ \\
\hline 1.15 ACUTE MI INCIDENCE & 5 & 1313 & Risk Ratio(M-H, Random, 95\% Cl) & $1.03[0.91,1.16]$ \\
\hline 1.16 Acute MI incidence - by NPPV & 5 & 1313 & Risk Ratio(M-H, Random, 95\% Cl) & $1.03[0.91,1.16]$ \\
\hline 1.16.1 CPAP vs SMC & 3 & 569 & Risk Ratio(M-H, Random, 95\% Cl) & $0.96[0.80,1.14]$ \\
\hline 1.16.2 bilevel NPPV vs SMC & 5 & 744 & Risk Ratio(M-H, Random, 95\% Cl) & $1.09[0.92,1.29]$ \\
\hline $1.17 \underline{\text { HOSPITAL LENGTH OF STAY }}$ & 11 & 1714 & $\begin{array}{l}\text { Mean Difference(IV, Random, 95\% } \\
\mathrm{Cl} \text { ) }\end{array}$ & $-0.31[-1.23,0.61]$ \\
\hline $\begin{array}{l}1.18 \text { Hospital length of stay - by } \\
\text { NPPV }\end{array}$ & 11 & 1714 & $\begin{array}{l}\text { Mean Difference(IV, Random, 95\% } \\
\text { CI) }\end{array}$ & $-0.19[-1.02,0.64]$ \\
\hline 1.18.1 CPAP vs SMC & 7 & 943 & $\begin{array}{l}\text { Mean Difference(IV, Random, 95\% } \\
\text { CI) }\end{array}$ & $-0.52[-1.77,0.72]$ \\
\hline 1.18.2 bilevel NPPV vs SMC & 6 & 771 & $\begin{array}{l}\text { Mean Difference(IV, Random, 95\% } \\
\text { Cl) }\end{array}$ & $0.39[-0.35,1.13]$ \\
\hline $\begin{array}{l}1.19 \text { Hospital length of stay - by } \\
\text { location }\end{array}$ & 11 & 1714 & $\begin{array}{l}\text { Mean Difference(IV, Random, 95\% } \\
\text { Cl) }\end{array}$ & $-0.30[-1.21,0.61]$ \\
\hline 1.19.1 ER & 8 & 1455 & $\begin{array}{l}\text { Mean Difference(IV, Random, 95\% } \\
\text { Cl) }\end{array}$ & $-0.38[-1.70,0.93]$ \\
\hline 1.19.2 ICU & 3 & 259 & $\begin{array}{l}\text { Mean Difference(IV, Random, 95\% } \\
\text { CI) }\end{array}$ & $-0.21[-1.30,0.89]$ \\
\hline $\begin{array}{l}1.20 \text { Hospital length of stay - by } \\
\text { baseline } \mathrm{PaCO}_{2}\end{array}$ & 11 & 1714 & $\begin{array}{l}\text { Mean Difference(IV, Random, 95\% } \\
\text { CI) }\end{array}$ & $-0.30[-1.21,0.61]$ \\
\hline 1.20.1 $\mathrm{PaCO} 2<=45 \mathrm{mmHg}$ & 5 & 397 & $\begin{array}{l}\text { Mean Difference(IV, Random, 95\% } \\
\text { CI) }\end{array}$ & $-1.18[-2.33,-0.04]$ \\
\hline 1.20.2 $\mathrm{PaCO} 2>45 \mathrm{mmHg}$ & 6 & 1317 & $\begin{array}{l}\text { Mean Difference(IV, Random, 95\% } \\
\text { CI) }\end{array}$ & $0.60[-0.15,1.34]$ \\
\hline $1.21 \underline{\text { ICU LENGTH OF STAY }}$ & 6 & & $\begin{array}{l}\text { Mean Difference(IV, Random, 95\% } \\
\text { CI) }\end{array}$ & No totals \\
\hline $\begin{array}{l}1.22 \text { SYSTOLIC BP AFTER ONE } \\
\text { HOUR }\end{array}$ & 7 & 1408 & $\begin{array}{l}\text { Mean Difference(IV, Random, 95\% } \\
\text { CI) }\end{array}$ & $-1.72[-5.03,1.58]$ \\
\hline $\begin{array}{l}1.23 \text { Systolic BP after one hour - by } \\
\text { NPPV }\end{array}$ & 7 & 1408 & $\begin{array}{l}\text { Mean Difference(IV, Random, 95\% } \\
\text { Cl) }\end{array}$ & $-1.72[-5.03,1.59]$ \\
\hline 1.23.1 CPAP vs SMC & 7 & 866 & $\begin{array}{l}\text { Mean Difference(IV, Random, 95\% } \\
\text { CI) }\end{array}$ & $-1.65[-5.58,2.28]$ \\
\hline 1.23.2 bilevel NPPV vs SMC & 3 & 542 & $\begin{array}{l}\text { Mean Difference(IV, Random, 95\% } \\
\text { CI) }\end{array}$ & $-1.89[-8.01,4.23]$ \\
\hline $\begin{array}{l}1.24 \text { DIASTOLIC BP AFTER ONE } \\
\text { HOUR }\end{array}$ & 6 & 1361 & $\begin{array}{l}\text { Mean Difference(IV, Random, 95\% } \\
\text { CI) }\end{array}$ & $1.46[-1.86,4.78]$ \\
\hline $\begin{array}{l}1.25 \text { Diastolic BP after one hour - by } \\
\text { NPPV }\end{array}$ & 6 & 1361 & $\begin{array}{l}\text { Mean Difference(IV, Random, 95\% } \\
\text { Cl) }\end{array}$ & $1.05[-2.15,4.25]$ \\
\hline 1.25.1 CPAP vs SMC & 6 & 823 & $\begin{array}{l}\text { Mean Difference(IV, Random, 95\% } \\
\text { CI) }\end{array}$ & $0.92[-3.92,5.75]$ \\
\hline 1.25.2 bilevel NPPV vs SMC & 3 & 538 & $\begin{array}{l}\text { Mean Difference(IV, Random, 95\% } \\
\text { Cl) }\end{array}$ & $1.08[-2.88,5.04]$ \\
\hline 1.26 MEAN BP AFTER ONE HOUR & 3 & 251 & $\begin{array}{l}\text { Mean Difference(IV, Random, 95\% } \\
\text { CI) }\end{array}$ & $-2.50[-8.29,3.30]$ \\
\hline $\begin{array}{l}1.27 \text { RESPIRATORY RATE AFTER } \\
\text { ONE HOUR }\end{array}$ & 10 & 1636 & $\begin{array}{l}\text { Mean Difference(IV, Random, 95\% } \\
\mathrm{CI})\end{array}$ & $-1.87[-2.70,-1.03]$ \\
\hline $\begin{array}{l}1.28 \text { Respiratory rate after one hour } \\
\text { - by NPPV }\end{array}$ & 10 & 1636 & $\begin{array}{l}\text { Mean Difference(IV, Random, 95\% } \\
\text { Cl) }\end{array}$ & $-1.58[-2.22,-0.94]$ \\
\hline 1.28.1 CPAP vs SMC & 10 & 1107 & $\begin{array}{l}\text { Mean Difference(IV, Random, 95\% } \\
\text { Cl) }\end{array}$ & $-1.64[-2.41,-0.87]$ \\
\hline 1.28.2 bilevel NPPV vs SMC & 3 & 529 & $\begin{array}{l}\text { Mean Difference(IV, Random, 95\% } \\
\text { Cl) }\end{array}$ & $-2.17[-4.69,0.35]$ \\
\hline
\end{tabular}


0416 Non-invasive positive pressure ventilation (CPAP or bilevel NPPV) for cardiogenic pulmonary oedema

\begin{tabular}{|c|c|c|c|c|}
\hline $\begin{array}{l}1.29 \underline{\mathrm{PaO}}_{2}(\mathrm{mmHg}) \text { AFTER ONE } \\
\text { HOUR }\end{array}$ & 10 & 1428 & $\begin{array}{l}\text { Mean Difference(IV, Random, 95\% } \\
\text { CI) }\end{array}$ & $16.19[3.54,28.84]$ \\
\hline $\begin{array}{l}1.30 \mathrm{PaO}_{2}(\mathrm{mmHg}) \text { after one hour - } \\
\text { by NPPV }\end{array}$ & 10 & 1428 & $\begin{array}{l}\text { Mean Difference(IV, Random, 95\% } \\
\text { Cl) }\end{array}$ & $13.74[2.72,24.76]$ \\
\hline 1.30.1 CPAP vs SMC & 8 & 761 & $\begin{array}{l}\text { Mean Difference(IV, Random, 95\% } \\
\text { Cl) }\end{array}$ & $9.55[-9.10,28.19]$ \\
\hline 1.30.2 bilevel NPPV vs SMC & 6 & 667 & $\begin{array}{l}\text { Mean Difference(IV, Random, 95\% } \\
\text { CI) }\end{array}$ & $19.50[4.29,34.71]$ \\
\hline 1.31 ADVERSE EVENTS & 11 & 9570 & Risk Ratio(M-H, Random, 95\% Cl) & $1.04[0.73,1.50]$ \\
\hline 1.31.1 Skin damage & 2 & 190 & Risk Ratio(M-H, Random, 95\% Cl) & $9.09[0.74,111.09]$ \\
\hline 1.31.2 Pneumonia & 1 & 130 & Risk Ratio(M-H, Random, 95\% Cl) & $0.50[0.05,5.38]$ \\
\hline 1.31.3 Gastrointestinal bleeding & 2 & 170 & Risk Ratio(M-H, Random, 95\% Cl) & $2.32[0.35,15.42]$ \\
\hline 1.31.4 Gastric distention & 1 & 83 & Risk Ratio(M-H, Random, 95\% Cl) & $13.26[0.82,215.12]$ \\
\hline 1.31.5 Vomiting & 5 & 1467 & Risk Ratio(M-H, Random, 95\% Cl) & $1.03[0.49,2.17]$ \\
\hline 1.31.6 Pneumothorax & 2 & 1165 & Risk Ratio(M-H, Random, 95\% Cl) & $0.72[0.08,6.89]$ \\
\hline 1.31.7 Sinusitis & 1 & 130 & Risk Ratio(M-H, Random, 95\% Cl) & $3.00[0.12,72.31]$ \\
\hline 1.31.8 Discomfort with mask & 3 & 1100 & Risk Ratio(M-H, Random, 95\% Cl) & $12.59[2.39,66.28]$ \\
\hline 1.31.9 Hypotension & 1 & 1030 & Risk Ratio(M-H, Random, 95\% Cl) & $0.82[0.58,1.16]$ \\
\hline 1.31.10 Arrhythmia & 1 & 1027 & Risk Ratio(M-H, Random, 95\% Cl) & $0.83[0.50,1.38]$ \\
\hline 1.31.11 Cardiorespiratory arrest & 4 & 1352 & Risk Ratio(M-H, Random, 95\% Cl) & $0.60[0.34,1.05]$ \\
\hline 1.31.12 Gastric aspiration & 1 & 1037 & Risk Ratio(M-H, Random, 95\% Cl) & $1.58[0.06,38.61]$ \\
\hline 1.31.13 Stroke & 1 & 130 & Risk Ratio(M-H, Random, 95\% Cl) & $0.20[0.01,4.09]$ \\
\hline 1.31.14 Seizures & 1 & 130 & Risk Ratio(M-H, Random, 95\% Cl) & $0.33[0.01,8.03]$ \\
\hline 1.31.15 Claustrophobia & 1 & 130 & Risk Ratio(M-H, Random, 95\% Cl) & $3.00[0.12,72.31]$ \\
\hline 1.31.16 Hypercapnia & 3 & 299 & Risk Ratio(M-H, Random, 95\% Cl) & $0.76[0.16,3.62]$ \\
\hline
\end{tabular}

\section{Figures}

\section{Figure 1}


0416 Non-invasive positive pressure ventilation (CPAP or bilevel NPPV) for cardiogenic pulmonary oedema

3791 records identified through database

searching

2805 records after software de-duplication

2 records from reference lists

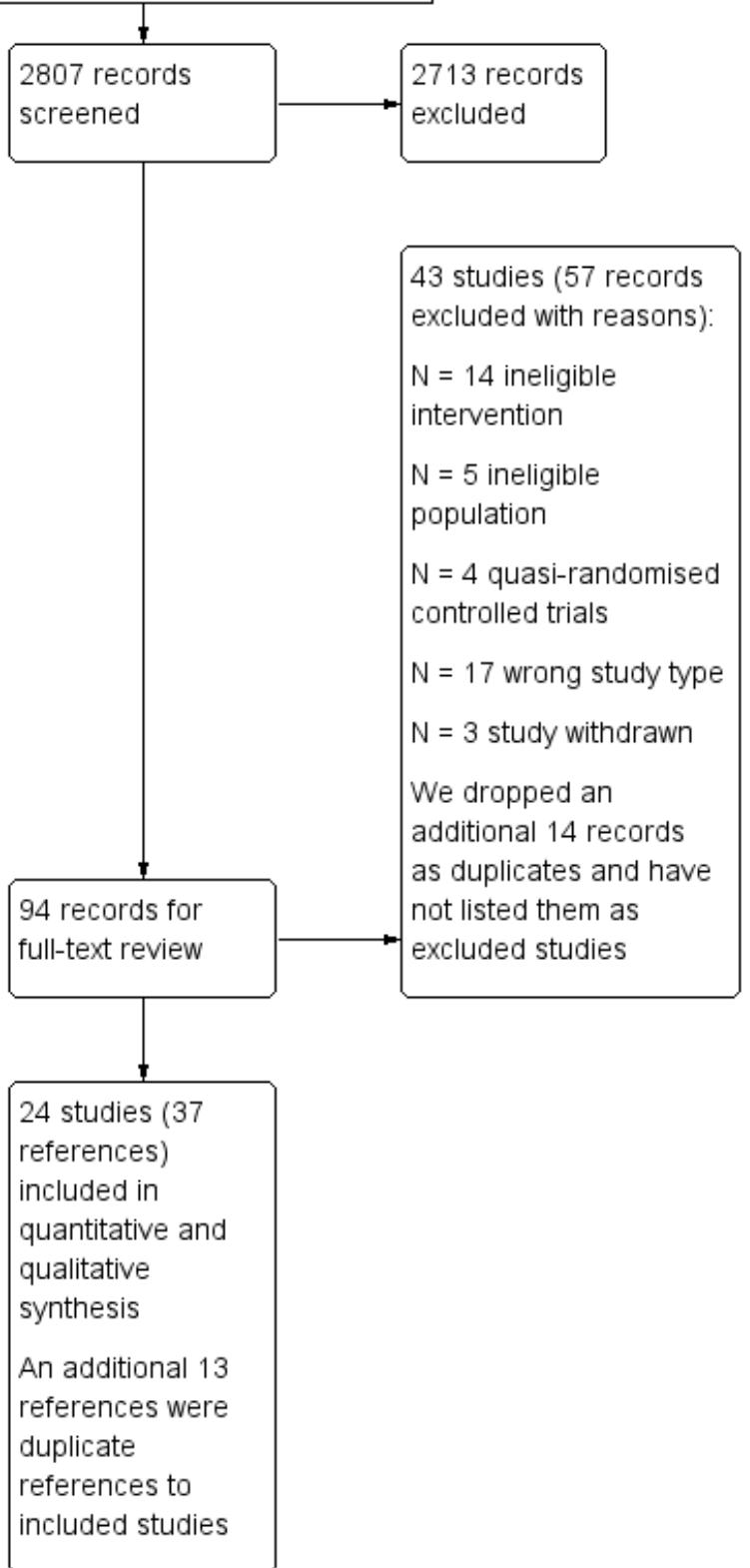

Caption

PRISMA statement flow diagram for 2019 review update.

Figure 2 
0416 Non-invasive positive pressure ventilation (CPAP or bilevel NPPV) for cardiogenic pulmonary oedema

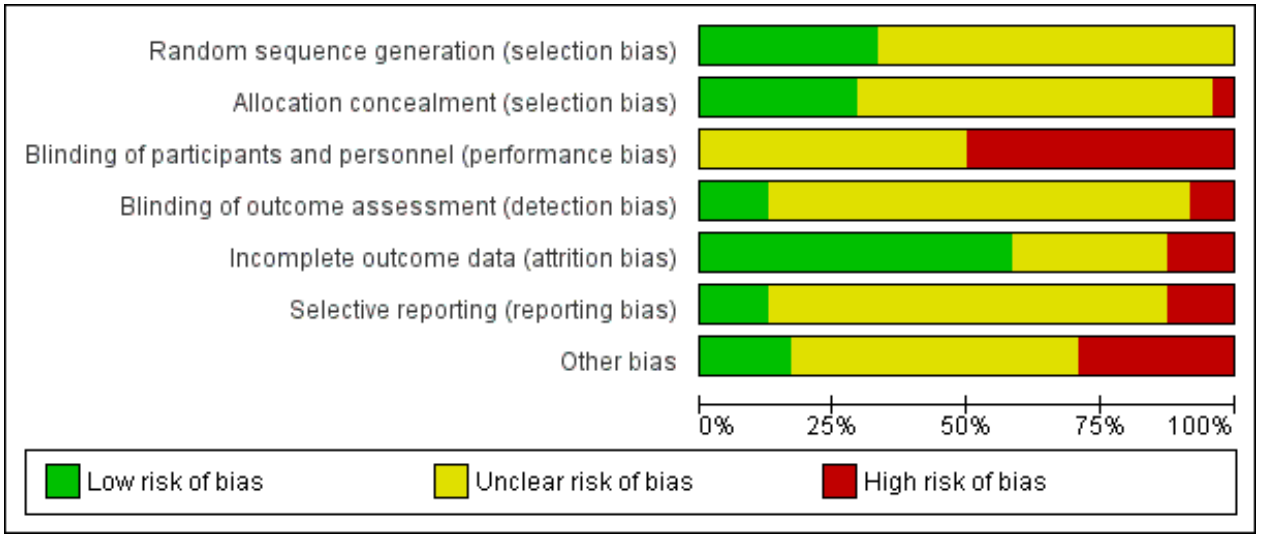

Caption

Risk of bias graph: review authors' judgements about each risk of bias item presented as percentages across all included studies.

Figure 3 


\begin{tabular}{|c|c|c|c|c|c|c|c|}
\hline & 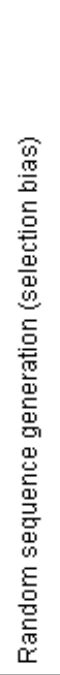 & 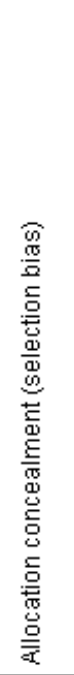 & 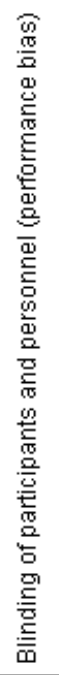 & 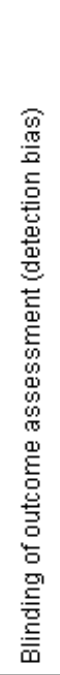 & 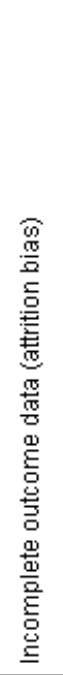 & 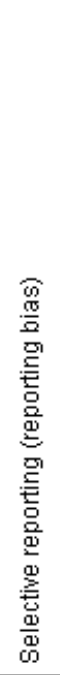 & 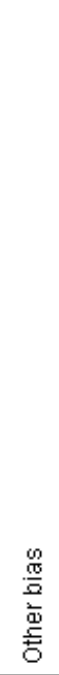 \\
\hline Agmy 2008 & $?$ & $?$ & $\Theta$ & $?$ & + & $\theta$ & $\theta$ \\
\hline Austin 2013 & $\odot$ & $\odot$ & $\Theta$ & + & + & + & + \\
\hline Crane 2004 & + & $\odot$ & $\theta$ & $?$ & + & $?$ & $?$ \\
\hline Ducros 2011 & $?$ & $?$ & $\odot$ & + & + & $\odot$ & 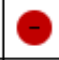 \\
\hline EI-Refay 2016 & $?$ & $?$ & $\odot$ & + & $\theta$ & $?$ & 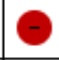 \\
\hline Frontin 2011 & + & $\odot$ & $\odot$ & $?$ & + & + & $\odot$ \\
\hline Gray 2008 & $\odot$ & $\odot$ & $\Theta$ & $\theta$ & + & + & + \\
\hline Hao 2002 & $?$ & $?$ & $?$ & $?$ & $?$ & $?$ & $\theta$ \\
\hline Kelly 2002 & $?$ & $?$ & $?$ & $?$ & $\odot$ & $?$ & $?$ \\
\hline L'Her 2004 & + & $\odot$ & $\odot$ & 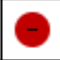 & $\odot$ & $?$ & $\theta$ \\
\hline Levitt 2001 & $\odot$ & $?$ & $?$ & $?$ & $?$ & $?$ & $\theta$ \\
\hline Li 2005 & $?$ & $?$ & $?$ & $?$ & $?$ & $?$ & $\odot$ \\
\hline Lin 1991 & $?$ & $?$ & $\Theta$ & $?$ & $\theta$ & $?$ & $?$ \\
\hline Lin 1995 & $?$ & $?$ & $\odot$ & $?$ & $\odot$ & $?$ & $?$ \\
\hline Masip 2000 & $\odot$ & $\theta$ & $\odot$ & $?$ & $\odot$ & $?$ & $?$ \\
\hline Moritz 2003 & $?$ & $?$ & $?$ & $?$ & $?$ & $?$ & $?$ \\
\hline Nava 2003 & + & - & $?$ & $?$ & + & $?$ & $\odot$ \\
\hline Park 2001 & $?$ & $?$ & $?$ & $?$ & $?$ & $?$ & $?$ \\
\hline Park 2004 & $?$ & $?$ & $?$ & $?$ & 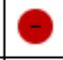 & $?$ & $?$ \\
\hline Räsänen 1985 & $?$ & $?$ & $?$ & $?$ & $\odot$ & $?$ & $?$ \\
\hline Takeda 1997 & $?$ & $?$ & $?$ & $?$ & $?$ & $?$ & $?$ \\
\hline Takeda 1998 & $?$ & $?$ & $?$ & $?$ & $\odot$ & $?$ & $?$ \\
\hline Thys 2002 & $?$ & $\odot$ & $\odot$ & $?$ & $\odot$ & $?$ & $?$ \\
\hline Zokaei 2016 & $?$ & $?$ & $?$ & $?$ & $?$ & $\odot$ & $?$ \\
\hline
\end{tabular}

Caption

Risk of bias summary: review authors' judgements about each risk of bias item for each included study.

Figure 4 (Analysis 1.1) 
0416 Non-invasive positive pressure ventilation (CPAP or bilevel NPPV) for cardiogenic pulmonary oedema

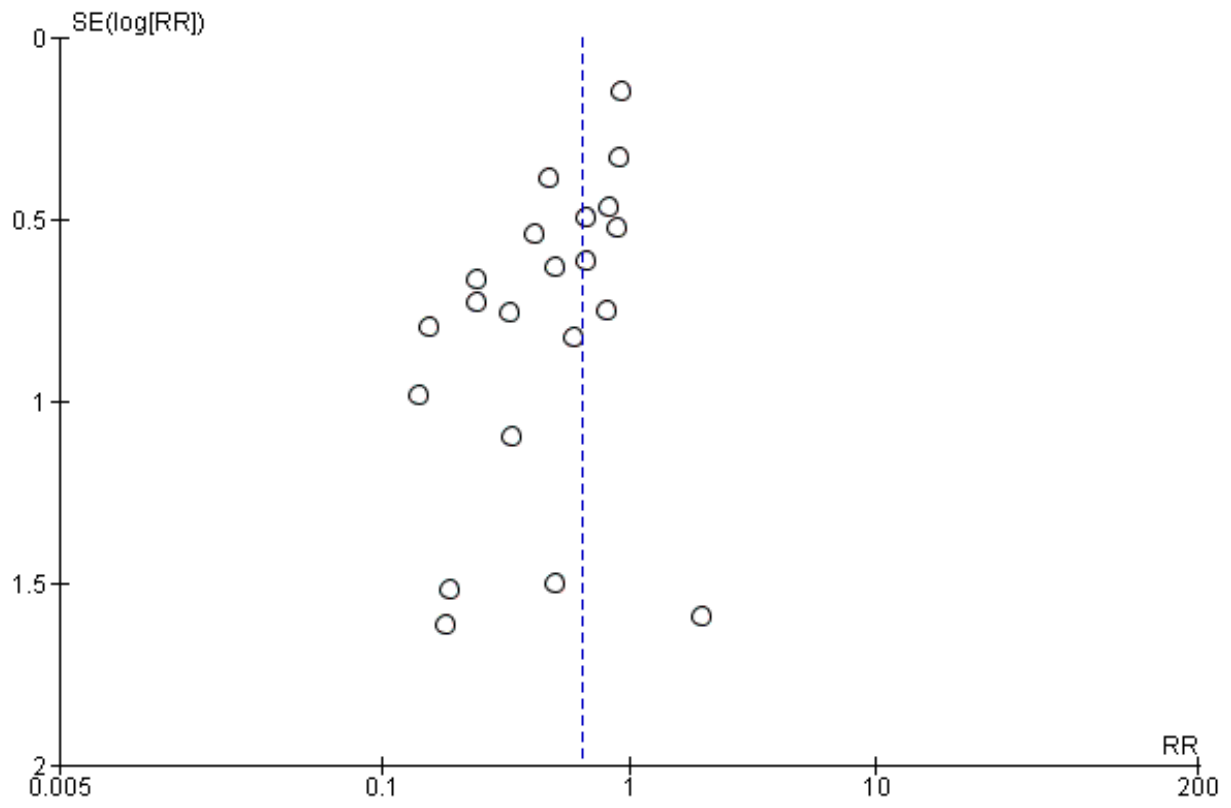

\section{Caption}

Funnel plot of comparison: 1 NPPV vs SMC, outcome: 1.1 HOSPITAL MORTALITY.

Figure 5 (Analysis 1.8)

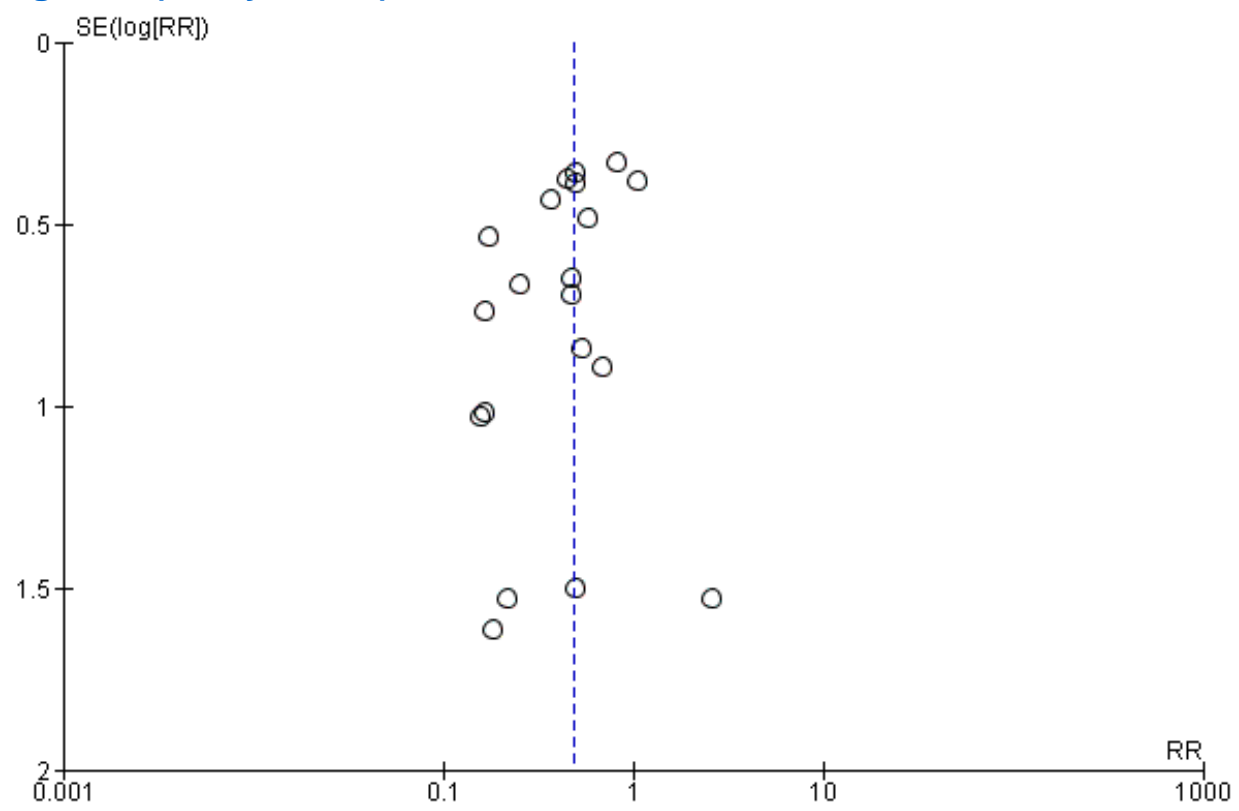

Caption

Funnel plot of comparison: 1 NPPV vs SMC, outcome: 1.8 ETI RATE.

Figure 6 (Analysis 1.17) 
0416 Non-invasive positive pressure ventilation (CPAP or bilevel NPPV) for cardiogenic pulmonary oedema

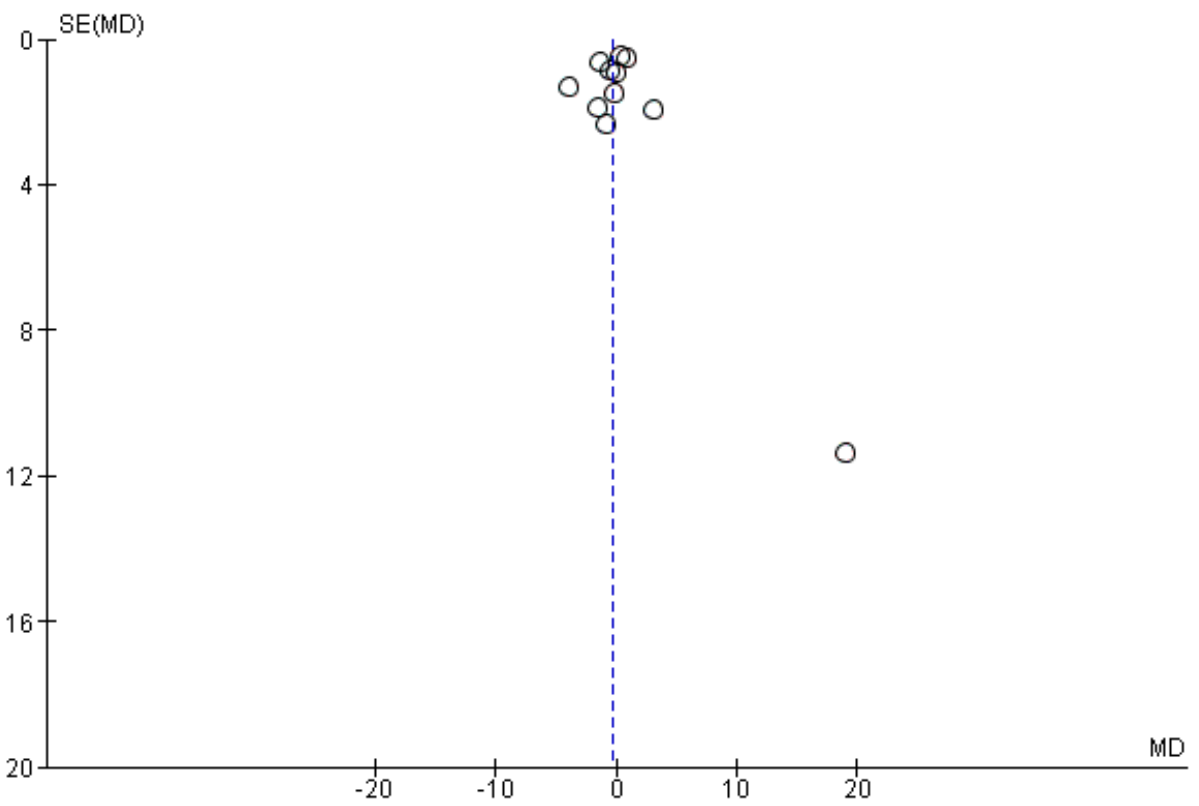

Caption

Funnel plot of comparison: 1 NPPV vs SMC, outcome: 1.17 HOSPITAL LENGTH OF STAY.

\section{Sources of support}

\section{Internal sources}

- No sources of support provided

\section{External sources}

- This project was supported by the National Institute for Health Research, via Cochrane Infrastructure funding to the Heart Group. The views and opinions expressed therein are those of the authors and do not necessarily reflect those of the Systematic Reviews Programme, NIHR, NHS or the Department of Health, UK

\section{Feedback}

\section{Appendices}

\section{Search strategy 2018}

\section{CENTRAL \& DARE}

\#1 MeSH descriptor: [Heart Failure] explode all trees

\#2 MeSH descriptor: [Myocardial Infarction] explode all trees

\#3 myocardial next infarction

\#4 (cardiogenic near/6 edema)

\#5 (cardiogenic near/6 oedema)

\#6 (pulmonary near/6 edema)

\#7 (pulmonary near/6 oedema)

\#8 heart next failure

\#9 cardiac next failure

\#10 cardiac next insufficiency

\#11 heart next insufficiency

\#12 left next ventricular next insufficiency

\#13 left next ventricular next dysfunction

\#14 wet next lung

$\# 15 \# 1$ or \#2 or \#3 or \#4 or \#5 or \#6 or \#7 or \#8 or \#9 or \#10 or \#11 or \#12 or \#13 or \#14

\#16 MeSH descriptor: [Ventilators, Mechanical] explode all trees

\#17 MeSH descriptor: [Respiration, Artificial] explode all trees

\#18 mechanical next ventilation 
0416 Non-invasive positive pressure ventilation (CPAP or bilevel NPPV) for cardiogenic pulmonary oedema \#19 artificial next ventilation

\#20 assisted next ventilation

\#21 artificial next respiration

\#22 (positive near/6 pressure near/6 ventilation)

\#23 (respirator or respirators)

\#24 pulmonary next ventilat ${ }^{*}$

\#25 non next invasive next ventilation

\#26 noninvasive next ventilation

\#27 non-invasive next ventilation

\#28 positive next airway next pressure

\#29 positive next pressure next respiration

\#30 pressure next support next ventilation

\#31 mask next ventilation

\#32 bipap

\#33 nippv

\#34 nppv

\#35 niv

\#36 cpap

\#37 niav

\#38 aprv

\#39 ippb

\#40 ippv

\#41 peep

\#42 positive next end next expiratory next pressure

$\# 43$ (\#16 or \#17 or \#18 or \#19 or \#20 or \#21 or \#22 or \#23 or \#24 or \#25 or \#26)

$\# 44$ (\#27 or \#28 or \#29 or \#30 or \#31 or \#32 or \#33 or \#34 or \#35 or \#36)

$\# 45$ (\#37 or \#38 or \#39 or \#40 or \#41 or \#42)

\#46 \#43 or \#44 or \#45

\#47 \#15 and \#46

\section{MEDLINE Ovid}

1. exp Heart Failure/

2. exp Myocardial Infarction/

3. cardiogenic edema $\$ . t w$.

4. cardiogenic oedema $\$ . t w$.

5. pulmonary oedema.tw.

6. pulmonary edema.tw.

7. cardiac failure.tw.

8. heart failure.tw.

9. cardiac insufficiency.tw.

10. Pulmonary Edema/

11. heart insufficiency.tw.

12. Ventricular Dysfunction, Left/

13. wet lung.tw.

14. or $/ 1-13$

15. exp Respiration, Artificial/

16. exp Ventilators, Mechanical/

17. mechanical ventilation.tw. 
18. artificial ventilation.tw.

19. assisted ventilation.tw.

20. artificial respiration.tw.

21. (respirator or respirators).tw.

22. bipap.tw.

23. nippv.tw.

24. nppv.tw.

25. niv.tw.

26. niav.tw.

27. cpap.tw.

28. aprv.tw.

29. ippb.tw.

30. ippv.tw.

31. peep.tw.

32. positive pressure ventilation.tw.

33. pulmonary ventilation.tw.

34. non invasive ventilation.tw.

35. noninvasive ventilation.tw.

36. pressure support ventilation.tw.

37. positive end expiratory pressure.tw.

38. bi-level positive airway pressure.tw.

39. bilevel positive airway pressure.tw.

40. or/15-39

41. 14 and 40

42. randomized controlled trial.pt.

43. controlled clinical trial.pt.

44. randomized.ab.

45. placebo.ab.

46. drug therapy.fs.

47. randomly.ab.

48. trial.ab.

49. groups.ab.

50.42 or 43 or 44 or 45 or 46 or 47 or 48 or 49

51. exp animals/ not humans.sh.

52. 50 not 51

53. 41 and 52

\section{Embase Ovid}

1. exp Congestive Heart Failure/

2. exp Heart Infarction/

3. cardiogenic oedema\$.tw.

4. cardiogenic edema $\$ . t w$.

5. pulmonary oedema.tw.

6. pulmonary edema.tw.

7. cardiac failure.tw.

8. heart failure.tw.

9. cardiac insufficiency.tw.

10. Lung Edema/ 
11. heart insufficiency.tw.

12. heart left ventricle function/

13. wet lung.tw.

14. or/1-13

15. exp Ventilator/

16. $\exp$ Artificial Ventilation/

17. mechanical ventilation.tw.

18. artificial ventilation.tw.

19. assisted ventilation.tw.

20. artificial respiration.tw.

21. (respirator or respirators).tw.

22. bipap.tw.

23. nippv.tw.

24. nppv.tw.

25. niv.tw.

26. niav.tw.

27. cpap.tw.

28. aprv.tw.

29. ippb.tw.

30. ippv.tw.

31. peep.tw.

32. positive pressure ventilation.tw.

33. pulmonary ventilation.tw.

34. non invasive ventilation.tw.

35. noninvasive ventilation.tw.

36. pressure support ventilation.tw.

37. positive end expiratory pressure.tw.

38. bi-level positive airway pressure.tw.

39. bilevel positive airway pressure.tw.

40. or/15-39

41. 14 and 40

42. random\$.tw.

43. factorial\$.tw.

44. crossover $\$$.tw.

45. cross over\$.tw.

46. cross-over\$.tw.

47. placebo\$.tw.

48. (doubl\$ adj blind\$).tw.

49. (singl\$ adj blind\$).tw.

50. assign\$.tw.

51. allocat\$.tw.

52. volunteer\$.tw.

53. crossover procedure/

54. double blind procedure/

55. randomized controlled trial/

56. single blind procedure/ 
0416 Non-invasive positive pressure ventilation (CPAP or bilevel NPPV) for cardiogenic pulmonary oedema

57.42 or 43 or 44 or 45 or 46 or 47 or 48 or 49 or 50 or 51 or 52 or 53 or 54 or 55 or 56

58. (animal/ or nonhuman/) not human/

59. 57 not 58

60.41 and 59

61. limit 60 to embase

\section{CINAHL}

S43 S14 and S39 and S42

S42 S40 or S41

$\mathrm{S} 41 \mathrm{TI}\left(\right.$ random $^{*}$ or trial or clinical study or group* or placebo*) or AB (random* or trial or clinical study or group* or placebo*) S40 (MH "Clinical Trials+")

$\mathrm{S} 39 \mathrm{~S} 15$ or $\mathrm{S} 16$ or $\mathrm{S} 17$ or $\mathrm{S} 18$ or $\mathrm{S} 19$ or $\mathrm{S} 20$ or $\mathrm{S} 21$ or $\mathrm{S} 22$ or $\mathrm{S} 23$ or $\mathrm{S} 24$ or $\mathrm{S} 25$ or S26 or S27 or S28 or S29 or S30 or $\mathrm{S} 31$ or S32 or S33 or S34 or S35 or S36 or S37 or S38

S38 TI (bi-level positive airway pressure) or AB (bi-level positive airway pressure)

S37 $\mathrm{TI}$ (positive end expiratory pressure) or $\mathrm{AB}$ (positive end expiratory pressure)

S36 $\mathrm{TI}$ (pressure support ventilation) or $\mathrm{AB}$ (pressure support ventilation)

S35 TI (noninvasive ventilation) or $A B$ (noninvasive ventilation)

S34 $\mathrm{TI}$ (non invasive ventilation) or AB (non invasive ventilation)

S33 $\mathrm{TI}$ (pulmonary ventilation) or $\mathrm{AB}$ (pulmonary ventilation)

$\mathrm{S} 32 \mathrm{TI}$ (positive pressure ventilation) or $\mathrm{AB}$ (positive pressure ventilation)

S31 TI (peep) or AB (peep)

S30 TI (ippv) or AB (ippv)

S29 TI (ippb) or AB (ippb)

S28 TI (aprv) or AB (aprv)

S27 TI (cpap) or AB (cpap)

S26 TI (niav) or $A B$ (niav)

S25 TI (niv) or AB (niv)

S24 TI (nppv) or AB (nppv)

S23 TI (nippv) or AB (nippv)

S22 TI (bipap) or AB (bipap)

$\mathrm{S} 21 \mathrm{TI}$ (respirator or respirators) or $\mathrm{AB}$ (respirator or respirators)

$\mathrm{S} 20 \mathrm{TI}$ (artificial respiration) or $\mathrm{AB}$ (artificial respiration)

$\mathrm{S} 19 \mathrm{TI}$ (assisted ventilation) or $\mathrm{AB}$ (assisted ventilation)

$\mathrm{S} 18 \mathrm{TI}$ (artificial ventilation) or $\mathrm{AB}$ (artificial ventilation)

S17 TI (mechanical ventilation) or AB (mechanical ventilation)

S16 (MH "Ventilation, Mechanical, Differentiated")

S15 (MH "Ventilators, Mechanical")

$\mathrm{S} 14 \mathrm{~S} 1$ or $\mathrm{S} 2$ or $\mathrm{S} 3$ or $\mathrm{S} 4$ or $\mathrm{S} 5$ or $\mathrm{S} 6$ or $\mathrm{S} 7$ or $\mathrm{S} 8$ or $\mathrm{S} 9$ or $\mathrm{S} 10$ or $\mathrm{S} 11$ or $\mathrm{S} 12$ or $\mathrm{S} 13$

$\mathrm{S} 13 \mathrm{TI}$ (wet lung) or $\mathrm{AB}$ (wet lung)

S12 (MH "Ventricular Dysfunction, Left")

$\mathrm{S} 11 \mathrm{TI}$ (heart insufficiency) or AB (heart insufficiency)

S10 (MH "Pulmonary Edema")

S9 $\mathrm{TI}$ (cardiac insufficiency) or AB (cardiac insufficiency)

S8 TI (heart failure) or $A B$ (heart failure)

S7 TI (cardiac failure) or AB (cardiac failure)

S6 TI (pulmonary edema*) or AB (pulmonary edema*)

S5 TI (pulmonary oedema*) or AB (pulmonary oedema*)

S4 TI (cardiogenic edema*) or AB (cardiogenic edema*) 
0416 Non-invasive positive pressure ventilation (CPAP or bilevel NPPV) for cardiogenic pulmonary oedema

S3 $\mathrm{TI}$ (cardiogenic oedema*) or AB (cardiogenic oedema*)

S2 (MH "Myocardial Infarction+")

S1 (MH "Heart Failure, Congestive+")

\section{LILACS}

("congestive heart failure" OR "cardiogenic edema" OR "cardiogenic oedema" OR "cardiac insufficiency" OR "heart insufficiency" OR "left ventricular dysfunction" OR "myocardial infarction" OR "heart failure" OR "pulmonary edema" OR "left ventricular dysfunction" OR "wet lungs") [Words] and ("artificial ventilation" OR "assisted ventilation" OR "mechanical ventilation" OR "artificial respiration" OR "positive pressure ventilation" OR "respirator or respirators" OR "pulmonary ventilator" OR "positive end expiratory pressure" OR "non invasive ventilation" OR "noninvasive ventilation" OR "bi-level positive airway pressure" OR "bilevel positive airway pressure" OR "positive airway pressure" OR "positive pressure respiration" OR "pressure support ventilation" OR "mask ventilation" OR "peep" OR "cpap" OR "nppv" OR "nippv" OR "niv" OR "niav" OR "aprv" OR "ippb" OR "ippv") [Words]

\section{WHO database}

Condition: congestive heart failure or cardiogenic oedema or cardiac insufficiency or heart insufficiency or left ventricular dysfunction or myocardial infarction or heart failure or pulmonary oedema or left ventricular dysfunction or wet lungs Intervention: artificial ventilation or assisted ventilation or mechanical ventilation or positive pressure ventilation or positive end expiratory pressure or noninvasive ventilation or cpap or nppv or bilevel or niv

\section{Clinicaltrials.gov}

Condition: congestive heart failure OR cardiogenic edema OR cardiac insufficiency OR heart insufficiency OR left ventricular dysfunction OR myocardial infarction OR heart failure OR pulmonary oedema OR wet lungs

Intervention: (artificial OR assisted OR mechanical OR positive pressure OR noninvasive) AND ventilation OR positive end expiratory pressure OR cpap OR nppv OR bilevel OR niv 